\title{
Relation of Interpersonal Conflict Behaviors to Emotion Dysregulation and PTSD in Adolescents with a History of Betrayal Trauma
}

Vanessa M. Jacoby

Follow this and additional works at: https://researchrepository.wvu.edu/etd

\section{Recommended Citation}

Jacoby, Vanessa M., "Relation of Interpersonal Conflict Behaviors to Emotion Dysregulation and PTSD in Adolescents with a History of Betrayal Trauma" (2014). Graduate Theses, Dissertations, and Problem Reports. 5872.

https://researchrepository.wvu.edu/etd/5872

This Dissertation is protected by copyright and/or related rights. It has been brought to you by the The Research Repository @ WVU with permission from the rights-holder(s). You are free to use this Dissertation in any way that is permitted by the copyright and related rights legislation that applies to your use. For other uses you must obtain permission from the rights-holder(s) directly, unless additional rights are indicated by a Creative Commons license in the record and/ or on the work itself. This Dissertation has been accepted for inclusion in WVU Graduate Theses, Dissertations, and Problem Reports collection by an authorized administrator of The Research Repository @ WVU.

For more information, please contact researchrepository@mail.wvu.edu. 
Relation of Interpersonal Conflict Behaviors to Emotion Dysregulation and PTSD

in Adolescents with a History of Betrayal Trauma

Vanessa M. Jacoby

\author{
Dissertation submitted to the \\ Eberly College of Arts and Science \\ at West Virginia University \\ in partial fulfillment of the requirements for the degree of \\ Doctorate of Philosophy in Psychology, Clinical Child Emphasis
}

Elisa M. Krackow, Ph.D., Chair

Melanie Booth-Butterfield, Ph.D.

Christina L. Duncan, Ph.D.

Amy Gentzler, Ph.D.

Joseph R. Scotti, Ph.D.

Department of Psychology

Morgantown, West Virginia

2014

Keywords: Betrayal Trauma, Emotion Regulation, Posttraumatic Stress Disorder, Conflict, Communication

Copyright 2014 Vanessa M. Jacoby 


\author{
Abstract \\ Relation of Interpersonal Conflict Behaviors to Emotion Dysregulation and PTSD \\ in Adolescents with a History of Betrayal Trauma
}

\title{
Vanessa M. Jacoby
}

Posttraumatic stress disorder (PTSD) is a disorder that develops in response to exposure to a traumatic stressor. Although this is the most well known diagnosis for individuals who have difficulties after a traumatic event, research documents numerous difficulties and psychopathology that can result from traumatic events, many of which do not fit the DSM-IV criteria of PTSD. Specifically, severe, chronic, interpersonal trauma tends to have a different pattern of effects on individuals than does acute, noninterpersonal trauma. This is particularly true for children (e.g., van der Kolk, Roth, Pelcovitz, Sunday, \& Spinazzola, 2005). Because of this, the construct of Developmental Trauma Disorder (DTD) was introduced, although it is not currently recognized in the DSM 5. Emotion regulation skills and interpersonal dysfunction are two core components of this disorder. Trauma perpetrator (i.e., betrayal trauma) has also been found to be an important trauma characteristic when determining the clinical trajectory following traumatic experiences. The current study examined whether adolescents who have experienced betrayal trauma exhibit more negative communication behavior during a stressful interpersonal task, and report more emotion regulation deficits, than adolescents with non-betrayal trauma histories. The study also examined whether emotion regulation mediates the relation between betrayal trauma and negative communication. Finally, analyses were conducted to determine if PTSD or betrayal trauma best predicts negative communication behavior. Adolescents with a history of betrayal trauma reported more emotion regulation difficulties, and exhibited significantly more aggressive, negative nonaggressive, and fewer positive behaviors when engaged in a stressful interpersonal task with their mothers. Although PTSD symptom severity was related to experiencing a betrayal trauma, neither PTSD severity nor PTSD diagnosis predicted interpersonal difficulties as well as betrayal trauma history or emotion regulation difficulties. Finally, emotion regulation difficulties were found to mediate the relation between betrayal trauma and negative communication behavior. These results lend support for adding DTD to the next version of the DSM, illustrating that clinically significant problems related to trauma may not look "PTSD-like." 
Acknowledgments

This study would not be possible without the time and support given to me by my mentors, supervisors, fellow lab members, committee members, and my family. I would like to thank Joseph Scotti, Ph.D. for his mentorship, supervision, and feedback with the initial conceptualization and design of the study, the data collection and writing process, and also throughout my career. I would also like to thank Elisa Krackow, Ph.D. for her willingness to become my mentor, and provide me with supervision and feedback throughout the data collection and writing process. I would like to thank Jodi Arnold, Ph.D. for her overwhelming support and mentorship with my dissertation process during my internship year. I would like to thank Melanie Booth-Butterfield, Ph.D., Christina Duncan, Ph.D., and Amy Gentzler, Ph.D. for their support and feedback as Dissertation Committee members. Finally, my project would not be possible without the help of my fellow lab members, especially Sarah Nunley, M.S., and Meredith Norman, M.S., who coded much of the data. 


\section{List of Tables}

Table

1. Demographics (Number and Percentage): Race/Ethnicity of Mothers and Adolescents, Marital Status of Mothers, and Annual Household Income, Overall and by Sex of Adolescent. .80

2. Number (Percentage) of Participants Reporting Each Type of Non-Interpersonal Event by Sex of Adolescent and Group.

3. Number (Percentage) of Participants Reporting Each Type of Interpersonal Event by Sex of Adolescent and Group.

4. Number (Percentage) of Participants in the Betrayal Trauma Group Reporting Each Type of Interpersonal Event Classifiable as Betrayal Trauma by Sex of Adolescent. .83

5. Means (Standard Deviations) and Ranges for Non-Interpersonal, Interpersonal, and Betrayal Traumatic Events, Overall and by Sex of Adolescent and Group.

6. Means (Standard Deviations) and Ranges for Adolescent and Parent Communication Behaviors during the Low-Stress and High-Stress Problem-Solving Tasks, Overall and by Sex of Adolescent and Group.

7. Means (Standard Deviations) and Ranges for Adolescent and Parent Versions of the PTSD Reaction Index, Overall and by Sex of Adolescent and Group.

8. Means (Standard Deviations) and Ranges for the Difficulties with Emotion Regulation Scale, Overall and by Sex of Adolescent and Group. .90

9. Means (Standard Deviations) and Ranges for Adolescent and Parent Versions of the Conflict Behavior Scale, Overall and by Sex of Adolescent and Group.

10. Means (Standard Deviations) and Ranges for Adolescent and Parent Versions of the Issues Checklist, Overall and by Sex of Adolescent and Group. 
11. Means (Standard Deviations) and Ranges for Adolescent and Parent Versions of the ProblemSolving Reaction Scales following the Low-Stress and High-Stress Problem-Solving Tasks,

Overall and by Sex of Adolescent and Group.

12. Correlations Among the Subscales of the UCLA PTSD Reaction Index for Adolescent (AR) and Parent (PR) Versions. .96

13. Correlations Among the Subscales of Difficulties in Emotion Regulation Scale.

14. Correlations of Among the Primary Measures (PTSD Reaction Index, Difficulties in Emotion Regulation Scale, Conflict Behavior Questionnaire, and Issues Checklist) for Adolescent (AR) and Parent (PR) Versions .98

15. Correlations among Adolescent and Parent Communication Behaviors during the Low-Stress and High-Stress Problem-Solving Tasks .99

16. Correlation of Trauma Characteristics, PTSD Scores, and Emotion Regulation scores with Negative Communication Behavior, Conflict Behavior Questionnaire-AR, and Conflict Behavior Questionnaire-PR 100

17. Best Predictors of Negative Communication Behavior, Conflict Behavior Questionnaire-AR, and Conflict Behavior Questionnaire -PR. .101 


\section{List of Figures}

Figure

1. Graph showing total percent of mother's communication behaviors, across groups, for the Low Stress and High Stress Problem-Solving tasks.

2. Percent of Negative Aggressive, Negative Non-Aggressive, and Positive Communication Behaviors during Low and High Stress Tasks for Adolescents in the Non-Betrayal Trauma (NBT) and Betrayal Trauma (BT) Groups

3. Percent of Negative Aggressive, Negative Non-Aggressive, and Positive Communication Behaviors for Adolescents in the Non-Betrayal Trauma (NBT) and Betrayal Trauma (BT) Groups Compared with Adolescents with Low PTSD severity status vs. High PTSD severity status.....104

4. Mediation model for overall Negative Communication behavior during a stressful interpersonal task, with Betrayal Trauma History as the predictor and Emotion Dysregulation as the mediator. 
Table of Contents

Acknowledgements . $\mathrm{i}$

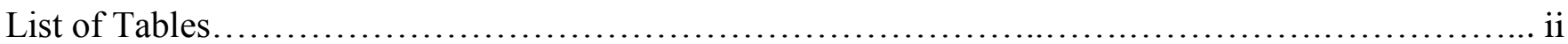

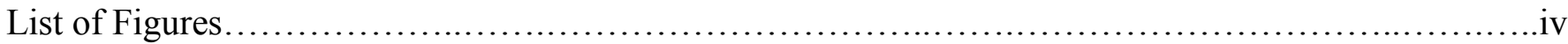

Chapter 1: Literature Review.................................................................... 1

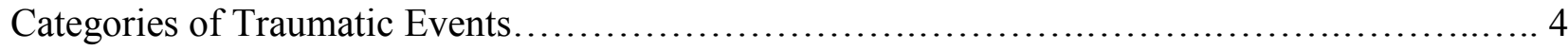

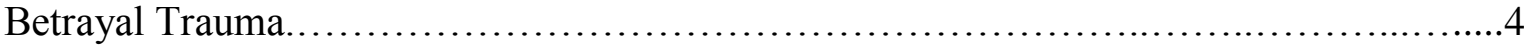

Range of Psychological Sequelae Resulting from Traumatic Exposure........................ 6

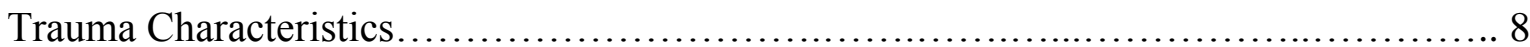

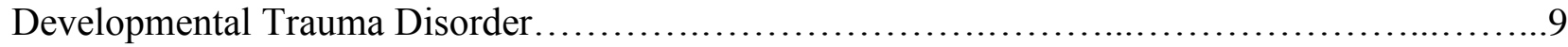

Emotion Regulation.................................................................. 11

Emotion Regulation and Interpersonal Difficulties................................ 13

Interpersonal Trauma, Emotion Regulation, and Interpersonal Difficulties............... 14

Interpersonal Difficulties in Adolescence............................................. 17

Chapter 2: Current Study............................................................... 19

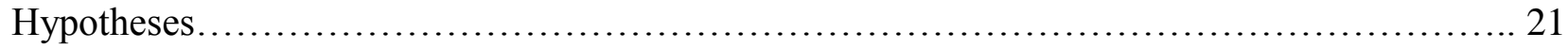

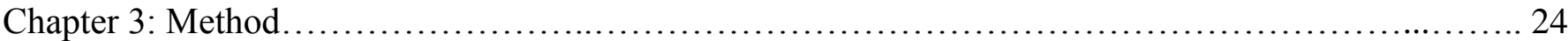

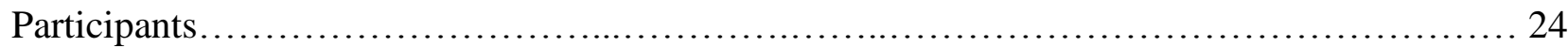

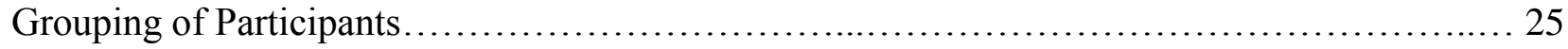

Measures................................................................................. 25

Difficulties in Emotion Regulation Scale........................................... 25

UCLA PTSD Reaction Index for DSM-IV ......................................26

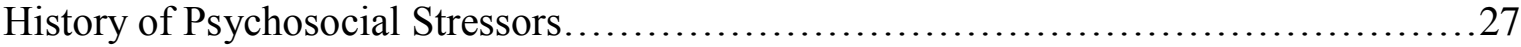

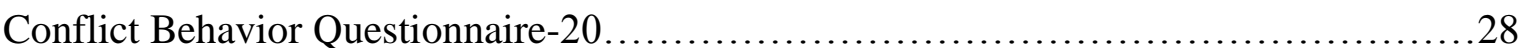

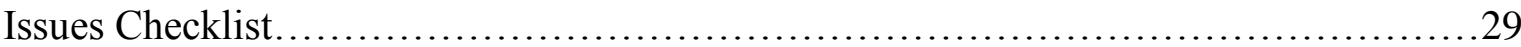


Parent-Adolescent Interpersonal Problem-Solving Behavior Coding System..... .29

Problem-Solving Reaction Scales............................................ 30

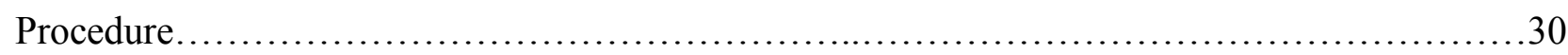

Problem-Solving Task: Low Stress......................................... 31

Problem-Solving Task: High Stress........................................... 32

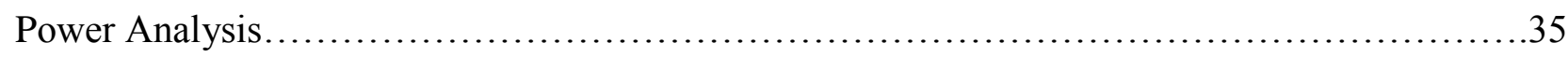

Chapter $4:$ Results................................................................... 36

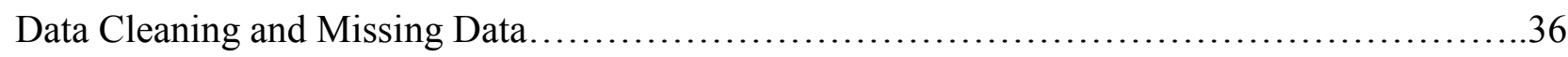

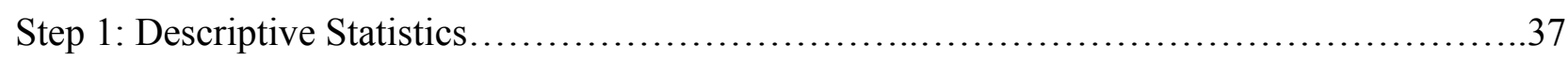

Sex, Age, Ethnicity, and Location Differences................................. 37

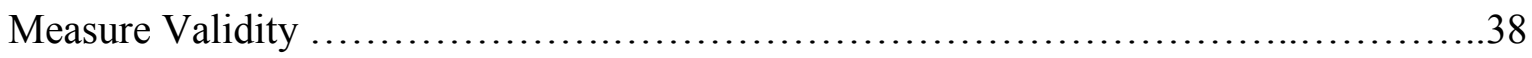

Description of the Behavioral Observations...................................... 39

Independent Variable Manipulation Check.....................................40

Step 2: Group by Task Differences in Communication Behavior...........................40

Step 3: Group Differences in Emotion Dysregulation, Perceived Conflict, and PTSD Severity...43

Step 4: PTSD Status versus Trauma Group Status...................................44

Step 5: Predictors of Negative Communication and Perceived Conflict.......................46

Best Overall Predictors.................................................48

Step 6: Identifying a Mediation Model...............................................49

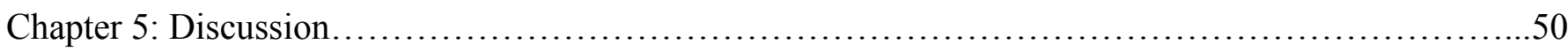

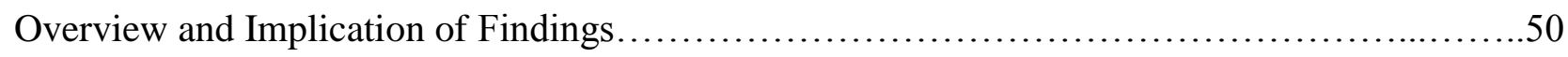

Hypothesis 1: Effect of Task.............................................. 51

Hypothesis 2: Effect of group on interpersonal difficulties.......................52

Hypothesis 3: Effect of group on emotion regulation..............................54

Hypothesis 4: Effect of group on PTSD ....................................... 55 
Hypothesis 5: Predictors of interpersonal difficulties.............................55

Hypothesis 6: Best model of trauma, emotion regulation, and interpersonal difficulties...59

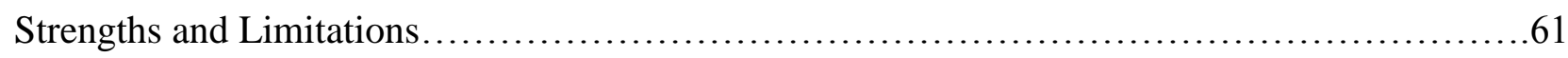

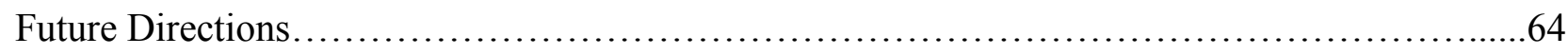

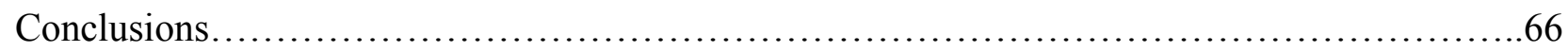

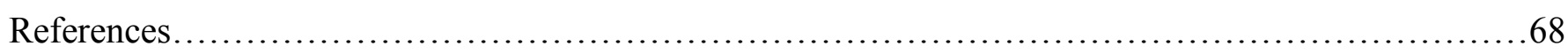

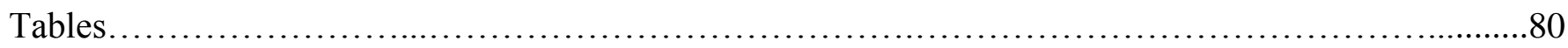

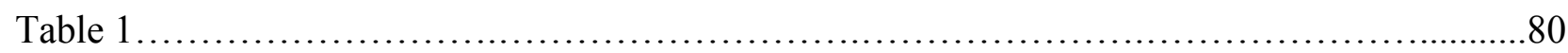

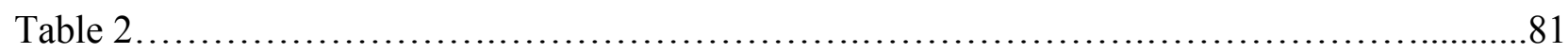

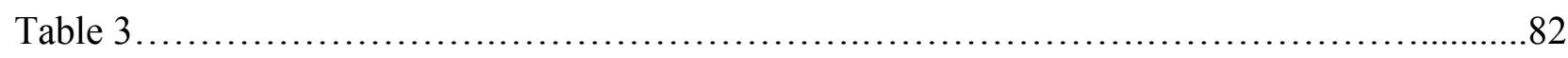

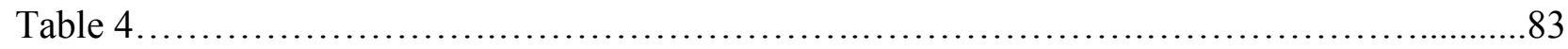

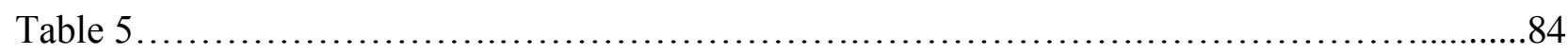

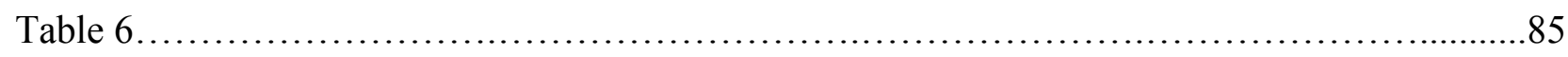

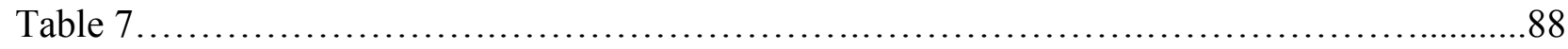

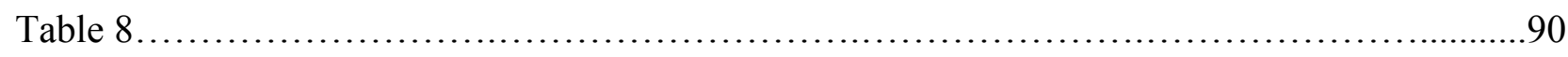

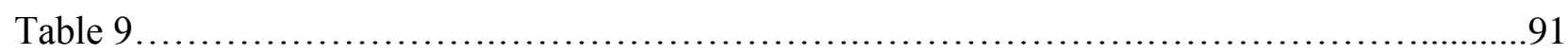

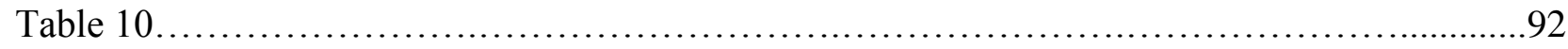

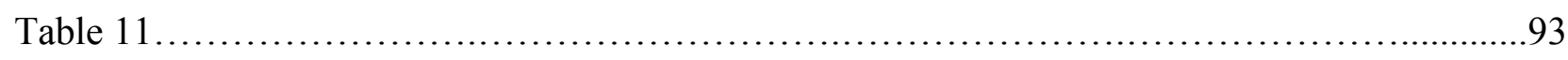

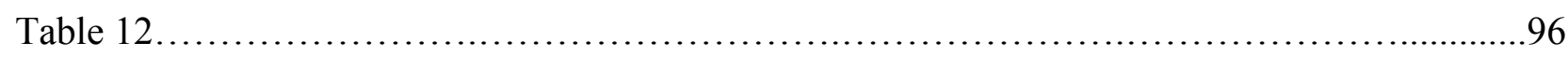

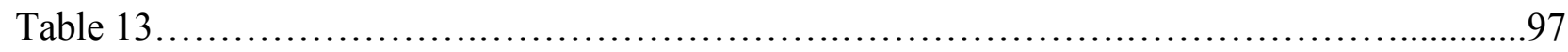

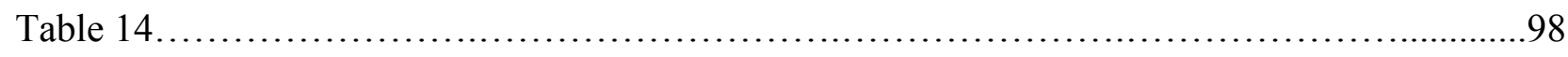

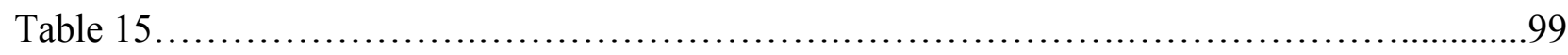

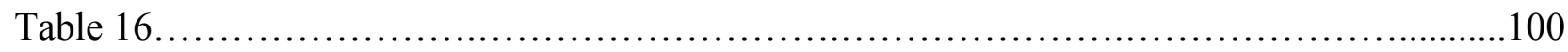

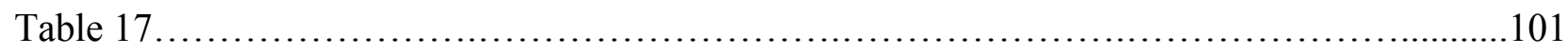

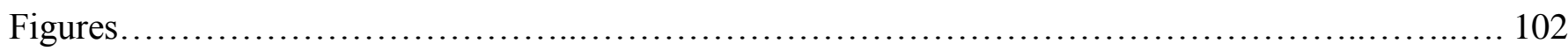


Figure 1

Figure 2 103

Figure 3 104

Figure 4 105

Appendices. 106

Appendix A: Behavior Code Descriptions, Definitions, and Examples. 106

Appendix B: Low-Stress Problem-Solving Task Worksheets. 110

Appendix C: High-Stress Problem-Solving Task Worksheet. 113

Appendix D: History of Psychosocial Stressors. 114

Appendix E: Problem-Solving Rating Scales 120 


\section{Chapter 1: Literature Review}

Posttraumatic stress disorder (PTSD) is an Axis I disorder in the Diagnostic and Statistical Manual of Mental Disorders, Fourth Edition (DSM-IV; American Psychiatric Association [APA], 2000) that develops in response to exposure to a traumatic stressor (Criterion A1), which involves the threat of death or injury to oneself or others. It is characterized by feelings of fear, helplessness, or horror at the time of the event (Criterion A2) and is followed by symptoms of reexperiencing the event (Criterion B; e.g., dreams, intrusive thoughts), avoidance (Criterion C; e.g., efforts to avoid thoughts about the event, activities, or people), and hyperarousal (Criterion D; e.g., difficulty sleeping, exaggerated startle response). In 2013, the newest version of the DSM was released. The DSM 5 (APA, 2013) made some changes to the diagnostic criterion of PTSD. The primary change was the addition of a new Criterion category: negative alterations in cognitions and mood (e.g., distorted blame of self or others regarding the traumatic event). Some changes were also made to Criterion A, which is described below. Because the current study began its protocol before the release of the DSM 5, and because assessments of PTSD using the new criteria are still being tested and validated, the current study used the DSM-IV criteria and related assessments in the protocol.

To qualify for a diagnosis of PTSD, the DSM-IV requires that the individual has experienced a "traumatic" event. It defines a traumatic event in Criterion A1 of the diagnostic criteria for PTSD as "a direct personal experience of an event that involves actual or threatened death or serious injury, or other threat to one's physical integrity; or witnessing an event that involves death, injury, or a threat to the physical integrity of another person; or learning about unexpected or violent death, serious harm, or threat of death or injury experienced by a family member or other close associate" (APA, 2000, p. 467). Additionally, to qualify as a traumatic event, the response to the event must have "involved intense fear, helplessness, or horror," or, for children, “disorganized or agitated behavior” (APA, 2000, p. 467). However, this definition is problematic. Empirical evidence is mixed; there is research that suggests that some events that do not meet this definition may be as likely to lead to later PTSD as those events that do 
meet the definition (e.g., Anders, Frazier, \& Frankfurt, 2011).

The definition of "traumatic event" in the diagnostic criteria for PTSD is not set in stone, as it has changed with each new version of the DSM. When PTSD was first introduced in the DSM-III-R (American Psychiatric Association, 1987), a traumatic event was defined as events that were "outside the range of usual human experience and that would be markedly distressing to almost anyone" (p. 250). However, this definition was modified when evidence showed that traumatic events are more common than once thought and are not necessarily out of the range of what many humans experience. In fact, 8090\% of adults (e.g., Breslau et al., 1998; Vrana \& Lauterbach, 1994; de Vries \& Olff, 2009) and 68-71\% of children and adolescents (e.g., Copeland, Keeler, Angold, \& Costello, 2007; Costello, Erkanli, Fairbank, \& Angold, 2002; Finkelhor, Ormrod, Turner, \& Hamby, 2005) report experiencing at least one potentially traumatic event in their lifetimes.

The diagnostic definition of a traumatic event is still an ongoing area of debate in the field of traumatic stress (see McNally, 2009). Some researchers argue that Criterion A should no longer be included as a necessary criterion for PTSD (e.g., Rosen \& Lilienfeld, 2008). Briere $(2004,2006)$ discusses this debate, and how categorizing events presents difficulties for multiple reasons. Briere (2004) points out that that many forms of interpersonal traumatic events, such as emotional abuse, neglect, coerced (but not physically threatening) sexual contact, or separation from caregivers do not meet Criterion A1 for PTSD, which requires an injury or threat of injury or death to the individual, or witnessing such an events. Briere also discusses how the events leading to reexperiencing, avoidance, and hyperarousal symptoms in one individual may not do so in another. For this reason, Criterion A2, the subjective response of intense fear, helplessness, and horror, were added to the PTSD criteria. However, it is difficult to determine how "intense" the subjective feelings of fear, helplessness, and horror must be to meet the qualifications of Criterion A2. Also, because emotional avoidance is a core symptom of PTSD, individuals may engage in avoidance during diagnostic assessment and inaccurately underreport their responses during the event, resulting in a decrease of PTSD diagnoses due to Criterion A2, rather than current symptoms. Finally, 
research shows that fear, helplessness, and horror do not have predictive or clinical validity in diagnosing PTSD (e.g., Adler, Wright, Bliese, Eckford, \& Hoge, 2008; Bedard-Gilligan \& Zoellner, 2008; Friedman Resick, Bryant, \& Brewin, 2011; Pereda \& Forero, 2012). To illustrate this concept, Freyd, Klest, and Allard (2005) provide an example of a sexually abused child who may not be afraid during the traumatic event because he/she is groomed by his/her perpetrator to the point that the abuse is perceived as normal behavior. However, this event may still lead to clinically significant traumatic stress symptoms following the event.

The DSM-IV requires that all of the symptoms of PTSD to be linked to one single event, rather than arising from multiple stressors, as may be the case in chronic abuse. Briere (2004) explains how this is limiting, as those who have experienced multiple, chronic events tend to have difficulty linking each of their symptoms to a single event. Altogether, Briere makes it clear that the definition of a traumatic event in the DSM-IV creates limitations that make a diagnosis unavailable to some individuals who experience significant posttraumatic stress symptoms and would benefit from a trauma-focused treatment. Without a diagnosis that clearly connects symptoms to a traumatic event, it may be harder for clinicians to match the client with the most appropriate, trauma-informed intervention. To more fully capture what may be considered traumatic, Briere uses the term "potentially traumatic event," which includes events that have been shown to be lead to posttraumatic stress, but may not meet Criterion A for PTSD, such as emotional abuse, non-violent sexual abuse, and separation from caregivers.

In 2013 (after the current study began), the APA released the DSM 5, which made some changes to Criterion A (in addition to other changes mentioned above) for PTSD. Specifically, "actual or threatened sexual violence" (but not non-violent sexual abuse) was added to the list of traumatic events. "Repeated or extreme indirect exposure to adverse details of the event" and, in children under 6-years-old, learning that a caregiver was exposed to the event, was added to the list of ways one can be exposed to the event (APA, 2013, p. 271). Lastly, Criterion A2, requiring a peritraumatic response of fear, helplessness, or horror, was removed, as a response to the evidence in the literature that these reactions are not 
necessarily predictive of later PTSD. Although these changes address some of the main concerns with the definition of a traumatic event (i.e., the problems with Criterion A2), it does not address the majority of the problems with the definitions of "trauma" that still exist.

\section{Categories of Traumatic Events}

Potentially traumatic events can be broken down into multiple categories. First, they can be categorized by indicating whether the event was caused by non-human influences or accidental doings (e.g., natural disasters, house fires, and motor vehicle accidents), or caused by intentional human acts (e.g., physical or sexual abuse or assault). These categorizations have empirical support (e.g., Briere \& Elliott, 2000; Green, Grace, Lindy, Gleser, \& Leonard, 1990). For example, Briere and Elliott (2000) found that interpersonal victimization was associated with greater number of symptoms on the Trauma Symptom Inventory than was non-human disasters. In the current study, non-human or accidental acts will be referred to as Non-Interpersonal potentially traumatic events, while those events caused by humans intentionally will be referred to as Interpersonal potentially traumatic events.

It is possible to further break down Interpersonal trauma into Relational and Non-relational trauma. Relational trauma refers to an interpersonal loss within a relationship with a caretaker of some sort. Relational trauma has also been studied and compared to non-relational potentially traumatic events. Anders, Shallcross, and Frazier (2012) examined the effects of both Criterion A1 and non-Criterion A1 relational potentially traumatic events and found that relational events (regardless of meeting the Criterion A1 definition) were more likely to lead to PTSD symptoms than non-relational events. The loss involved in relational events may be physical, such as death or separation from a loved one, or an emotional loss of trust through neglect or abuse (known as Betrayal Trauma).

\section{Betrayal Trauma}

The term betrayal trauma was introduced by Jennifer Freyd (1994, 1996, 2001). A betrayal trauma is a subgroup of relational trauma in which one is violated by a person or group of people that he or she trusts or depends on for emotional attachment and/or physical survival. Examples of betrayal trauma 
perpetrators may include caregivers, siblings, teachers, group leaders, or medical/mental health professionals. Betrayal Trauma Theory was developed to guide research in understanding the effects of betrayal events on survivors and how those effects overlap and also differ from PTSD. According to the theory, potentially traumatic events can be evaluated on two dimensions of harm: life threat/fear versus violation/betrayal of trust (Freyd, 1999, 2001). Freyd (1999) argues that although problematic responses to events considered high on life threat or fear and low on betrayal typically fit within the construct of PTSD, the response trajectory for events low on life threat or fear but high on social betrayal are different. Instead, prominent symptoms of betrayal trauma include dissociation, numbing, and more memory impairment for the event than non-betrayal traumas (Freyd, 1996; Herman, 1992). Interestingly, all of these symptoms can be conceptualized as avoidance symptoms, either to memories of the event or their related distressing emotions. To explain these unique avoidance symptoms, Freyd (1996) argues that these symptoms are adaptive in an environment in which the person that is causing you harm is also someone you depend on for survival, or if survival may be threatened by disclosing such harm. For example, a child may fear that s/he may have no caregiver if s/he discloses that a parent is being physically, sexually, or emotionally abusive. Similarly, if a sibling is the perpetrator of the event, the child may fear that the disclosure of the event may separate him/her from his/her caregivers. The child may also fear the loss of an emotional bond with the sibling that the child considers an important support system, despite the abuse. Therefore, a type of "adaptive forgetting" occurs to protect the child from his/her perceived dilemma. Because relationships with others are central to betrayal trauma, understandably, experiencing betrayal trauma may also lead to problematic patterns of relationships. Owen, Quirk, and Manthos (2012) found that individuals with a history of betrayal trauma perceived their romantic partners as having less respect for them. However, the majority of research on betrayal trauma has focused on avoidance behaviors, such as amnesia for the event and dissociation in an adult population. More research is needed to examine betrayal trauma in childhood and/or adolescence, and more research is needed to understand the effects of betrayal trauma on relationship functioning. 


\section{Range of Psychological Sequelae Resulting from Traumatic Exposure}

PTSD is one of very few mental health disorders that require experiencing a specific type of external event in order to be diagnosed, rather than only the presentation of certain thoughts, feelings, or behaviors. PTSD is also the most well known mental health disorder diagnosed for individuals who have survived potentially traumatic events. These factors, understandably, may prime clinicians to focus on PTSD-like symptoms that the patient presents with following the disclosure of a traumatic event, and overlook how other types of symptoms may be importantly related to the event. However, research illustrates that the majority of patients with PTSD have other comorbid Axis I DSM-IV disorders (Roth, Newman, Pelcovitz, van der Kolk, \& Mandel, 1997) and there are numerous difficulties and psychopathology beyond PTSD for both children and adults that can result from a traumatic experience. For example, a study of the relations between traumatic events, PTSD, and other psychiatric disorders in adults (Dorrington et al., 2014) showed that individuals with a history of at least one traumatic event were more likely to meet criteria for depressive disorders, other anxiety disorders, alcohol dependence, and somatization disorder. Further, similar to the relation between trauma exposure and PTSD (e.g., Brewin, Andrews, \& Valentine, 2000; Ogle, Rubin, \& Siegler, 2014), experiencing more traumatic events is related to a higher prevalence of those disorders (Dorrington et al., 2014).

Similar outcomes have been established in children and adolescents. Copeland, Keeler, Angold, and Costello (2007) found that children and adolescents who experienced a traumatic event had almost double the rates of DSM-IV (APA, 2000) anxiety disorders (other than PTSD), depression, or behavioral disorders compared with children and adolescents without a history of trauma exposure. Again, similar to research in adults, accumulation of traumatic events was related to higher rates of those psychiatric disorders. Finkelhor, Ormrod, Turner, and Hamby (2005) also found that children and adolescents who experienced poly-victimization had higher parent-reported (for younger children) or self-reported (for older children) general anxiety, depression and anger/aggression than children and adolescents with a single victimization. Also, similar to adult studies, the number of traumatic events experienced in 
childhood predicts the number of types of clinically significant difficulties, or "symptom complexity," in children (Cloitre et al., 2009).

Evidently, experiencing a traumatic event may lead to a range of clinically significant problems, only some of which meet criteria for PTSD, and experiencing multiple traumatic events increases the risk, severity, and complexity of these problems. This may be particularly relevant for children, as the majority of children experiencing mental health symptoms following a potentially traumatic event actually do not meet diagnostic criteria for PTSD (Kiser, Heston, Millsap, \& Pruitt, 1991). For children who have undergone chronic interpersonal or betrayal potentially traumatic events, such as physical, sexual, or emotional abuse and neglect, this may be even more important, as research has shown this population is exhibits a particularly broad range of difficulties (Ackerman, Newton, McPherson, Jones, \& Dykman, 1998; van der Kolk, 2003; van der Kolk, Roth, Pelcovitz, Sunday, \& Spinazzola, 2005). For example, Ackerman, Newton, McPherson, Jones, and Dykman (1998) found that the most common diagnoses given to abused children were separation anxiety disorder, oppositional defiant disorder, attention deficit hyperactivity disorder, and phobias, as well as PTSD. Clearly, PTSD does not capture fully the complex symptomology resulting from trauma exposures, particularly in children who have undergone chronic, interpersonal traumatic events (van der Kolk, 2005).

Clinicians and researchers have observed the evidence, described above, that a diagnosis of PTSD does not fully capture the broad range of distress and dysfunction that may be experienced by individuals who have experienced traumatic events (e.g., Briere, 2004; Cook et al., 2005; March, 1993). An important empirical question, then, is: What factors predict differential reactions and trajectories following traumatic experiences? Although this is a complex and multifaceted question, traumatic stress researchers are building a body of literature to help better understand this question, examining multiple individual, social, and environmental factors. For example, biological sex is considered an important individual risk factor, with women having a higher risk for developing PTSD (e.g., Breslau et al., 1998). Having inadequate social support both during and after a traumatic event is also associated with multiple physical and mental 
health difficulties, including but not limited to PTSD, after an event (see review by Charuvastra \& Cloitre, 2008). Culture also plays a role in how individuals are affected by potentially traumatic events. Kira, Fawzi, and Fawzi (2012) examined the mental and physical health effects of a range of potentially traumatic events two different Muslim populations living in the United States and Egypt. The authors discovered that the same events predicted different outcomes in the two groups, illustrating how cultural aspects of the environment can play a role in how individuals react to potentially traumatic events.

\section{Trauma Characteristics}

Trauma characteristics are factors that have been widely studied as potential predictors of later dysfunction in the area of traumatic stress. Overarching evidence from multiple research groups have found that cumulative traumatic events, the chronicity of a traumatic experience, the timing of a traumatic experience, and trauma type (i.e., interpersonal vs. non-interpersonal, relational versus non-relational, betrayal versus. non-betrayal), predict differential outcomes following an event. These particular trauma characteristics have been found to be predict to a wide range of difficulties including but not limited to affect dysregulation, difficult interpersonal relationships, dissociation, impulsivity, identity disturbances, suicidality, substance abuse, physical health problems, self-injury, and problematic sexual behavior (e.g., Briere, Hodges, \& Godbout, 2010; Briere, Kaltman, \& Green, 2008; Cloitre et al., 2009; Roth et al., 1997; van der Kolk, 2005; van der Kolk et al., 1996).

The majority of studies that have focused on type of trauma examined the effects of interpersonal trauma, and how clinically significant reactions to those events may differ from classic DSM-IV (APA, 2000) PTSD symptoms. Other research has focused on differences between the effects of Betrayal versus Non-Betrayal Trauma. For example, as noted above, research examining Betrayal Trauma and Betrayal Trauma Theory has found consistently higher levels of dissociation and memory impairment for the traumatic event (Crowley, 2007; Freyd, DePrince, \& Zurbbrigen, 2001) and a higher severity of depression, anxiety, PTSD (Freyd et al., 2005; Shin, Tang \& Freyd, 2012), and physical illness, (Freyd et al., 2005) following betrayal trauma versus other types of trauma. This research is vital to better 
understanding how to predict the differential trajectories of post-trauma reactions. However, further research needed that examines trauma characteristics in more detail. This would allow researchers and clinicians to understand the differences in trajectories between betrayal trauma events versus interpersonal but non-betrayal trauma events and thereby create better assessments and appropriate trauma-informed treatments for children, adolescents, and adults in need of such mental health support.

Although age of onset of the trauma may technically be considered an individual characteristic rather than trauma characteristic, it has often been included in this line of research. Age of onset is important because the effects of interpersonal traumatic events experienced at a young age may be best conceptualized as a disruption in development (Roth et al., 1997; van der Kolk, 2007; van der Kolk et al., 1996; 2005).

\section{Developmental Trauma Disorder}

The research findings suggesting that there are important differences the trajectories of mental health symptoms based on trauma type and age of onset of the trauma led to the development of new mental health constructs. First, the construct of complex PTSD was developed (Herman, 1992) to describe a cluster of symptoms experienced by adults survivors of chronic interpersonal childhood trauma. These symptoms include affect dysregulation, impulsive behaviors, alterations in consciousness (e.g., dissociation), alterations in self-perception, and alterations in relationships (e.g., interpersonal conflict, difficulty trusting others). The name of this construct shifted to Disorders of Extreme Stress Not Otherwise Specified (DESNOS) when adding it to the DSM-IV was proposed (Pelcovitz et al., 1997). In 2005, Bessel van der Kolk introduced a new term, Developmental Trauma Disorder (DTD), which is now used to describe Complex PTSD when it is seen in children and adolescents, while Complex PTSD or DESNOS is typically used in research to describe the disorder in the adult population (van der Kolk, 2005). However, these terms are relatively young and are sometimes used interchangeably, which can cause confusion when attempting to define and research these constructs. The current study will use the term Developmental Trauma Disorder, which is conceptualized as the clinical result of trauma that is 
chronic, interpersonal, and experienced at a younger age (van der Kolk et al., 1996; van der Kolk, 2005, 2007). Cook et al. (2005) explain the seven main areas of dysfunction in children and adolescents with Developmental Trauma Disorder: Attachment (e.g., interpersonal difficulties, problems with boundaries, social isolation), Biology (e.g., sensory-motor impairment, somatization), Emotion Regulation (e.g., labeling and expressing feelings, difficulty communicating wishes and needs), Dissociation (e.g., depersonalization, amnesia), Behavioral Control (e.g., aggression, eating disorders), Cognition (e.g., difficulty with attention and concentration), and Self-Concept (e.g., feelings of worthlessness, shame).

The construct of DTD is empirically supported. For example, in a sample of college women, Briere, Kaltman, and Green (2008) found that accumulated trauma during childhood, but not adulthood, predicted symptom complexity on the Traumatic Stress Index, which assesses for PTSD and DTD symptoms. Specific types of severe interpersonal trauma, including child rape, sexual abuse, physical abuse, and threats of violence were even stronger predictors of symptom complexity. A similar but much larger series of studies, the field trials for PTSD, are described by Kolk et al. (2005). One goal of the field trials was to investigate potential changes to PTSD symptom clusters, and to explore whether the symptoms experienced by survivors of chronic interpersonal trauma are best described under the criteria of PTSD, or if they are more accurately captured by the DTD constellation of symptoms. This field trial, based on adult participants, found that the majority of individuals who met criteria for DTD also met criteria for PTSD, and the younger the age of onset of trauma and the longer the individual was exposed to the trauma, the more likely an individual was to exhibit DTD in addition to PTSD. van der Kolk and colleagues (2005) concluded that as individuals with complex traumatic stress age, their symptoms tend to look more "PTSD-like." However, other studies (e.g., Ford, 1999; McDonagh-Coyle et al., 1999; Vielhauer, 1996) have found that $25-45 \%$ of individuals with a history of trauma who failed to meet criteria for PTSD met criteria for DTD.

Another study conducted by Spinazzola, Blaustein, and van der Kolk (2002) examined the prevalence of DTD in a sample of individuals diagnosed with PTSD. These authors found that $13 \%$ of 
these individuals met full criteria for DTD, greater than $30 \%$ met five of six criteria, and greater than $50 \%$ met four of six criteria for DTD. This suggests that individuals who have experienced traumatic events, even if they meet PTSD criteria, may have additional significant difficulties that do not fit within the criteria of PTSD. More knowledge about traumatic stress responses is necessary so that individuals who are encountering significant difficulties can be identified and treated if their symptoms do not correspond to classic PTSD symptoms. More large-scale research, similar to the PTSD field trials, is necessary in this area with a focus on children and adolescents, as the PTSD field trials illustrated that symptoms change with age. Specifically, further research is needed to examine whether betrayal trauma plays an important role in the development of DTD symptoms, as opposed to any interpersonal trauma.

\section{Emotion Regulation}

Thompson (1994) defines emotion regulation as "the extrinsic and intrinsic processes responsible for monitoring, evaluating, and modifying emotional reactions, especially their intensive and temporal features, to accomplish one's goals" (p. 27-28). One major component of DTD is clinically significant difficulties in regulating emotions. Cook et al. (2005) describe how survivors of traumatic events, especially events that are chronic, interpersonal traumatic stressors, often experience difficulties with emotion regulation. The development of emotion regulation skills are often explained using Bowlby's Attachment Theory (Bowlby, 1969). This is a well-known evolutionary theory that explains behavior in terms of what would be of evolutionary benefit to the survival of the individual, and thus the species. Bowlby's Attachment Theory places emphases on the fact that infants are completely dependent on their caregiver for survival, comfort, safety, and reassurance. Therefore, infant behavior focuses on keeping the caregiver close by. These behaviors may include smiling or crying (to bring the caregiver closer to them), or crawling (to bring the child to the caregiver). When the infant becomes distressed, an "attachment control system" is activated (Liotti, Cortina, \& Farina, 2008), which causes the infant to engage in careseeking behaviors. If the caregiver responds to the infant by providing comfort and care, that infant then learns the caregiver will respond to his/her behaviors and distressed emotional expressions, thereby 
effectively providing him/her with the caregiving and comfort needed. Over time, the result of this pattern of interactions with the caregiver is a secure attachment. Secure attachments can be observed by the minimal distress exhibited when the caregiver is separated from the child for a short time, and the positive affect observed when the caregiver returns (Ainsworth, Blehar, Waters, \& Wall, 1978). However, if the caregiver fails to respond appropriately and instead exhibits behaviors of overt neglect, failure to mirror the emotions of the child, or lack of positive affect and playfulness, the results of this pattern is an insecure attachment, and a disruption in cognitive and emotional development occurs (Fonagy, Target, Gergely, Allen, \& Bateman, 2003). The child fails to learn important emotion regulation skills, such as the ability to cope with stress and failure to understand their inner states (i.e., cognitions and emotions) as separate from the inner states of others and physical reality. In these cases, a child will appear anxious about separation from the caregiver, avoidant of the caregiver and ambivalent on return from separation, or a disorganized combination of these extremes (Ainsworth et al., 1978; Main \& Solomon, 1990). Without the adequate development of these emotion regulation skills, the child tends to express their emotions through intense physical means (e.g., aggression, self-injury), or numbing and dissociation. These relationship styles are carried over into relationships with others, including peers, and later, intimate relationships (Bowlby, 1973).

Briere's Self-Trauma Model $(1997,2002)$ proposes that a child's ability to cope with stressful and potentially traumatic events is dependent on the development of healthy emotion regulation skills. Yet, when trauma occurs as these self-capacities are still developing, the trauma interferes with the development of these skills, placing them at a higher risk of being emotionally overwhelmed by reminders of the trauma, as well as future stressful events and experiences. If the perpetrator of the trauma is a caregiver or someone that the child trusts and depends on for physical or emotional support (i.e., a betrayal trauma), the perpetrator becomes a conditioned stimulus for overwhelming negative affect. Additionally, stimulus generalization may occur, resulting in overwhelming conditioned emotional distress in a variety of interpersonal interactions (Foa \& Kozak, 1986). This theory is supported by a study 
of adults with childhood betrayal trauma, mentioned above, that found that childhood betrayal trauma predicted lack of perceived respect from a romantic partner (Owen et al., 2012).

\section{Emotion Regulation and Interpersonal Difficulties}

Empirical evidence from developmental psychology literature has found that deficits in emotion regulation strategies lead to difficulties in interpersonal functioning and more interpersonal conflict throughout childhood and adolescence (e.g., Adrian, Zeman, Erdley, Lisa, \& Sim, 2011; Calkins, Gill, Johnson, \& Smith, 1999; Kim, Pears, Capaldi, \& Owen, 2009, Lopes et al., 2011). Indeed, interpersonal difficulties are another core component of DTD (Cook et al., 2005).

Research examining emotion regulation difficulties and interpersonal conflict begins in toddlerhood. Calkins et al. (1999) studied the relation between emotion regulation and social behavior in toddlers, using same-age peers in the laboratory. Results showed that emotion regulation during a frustrating situation (e.g., no access to a toy) predicted cooperation versus conflict with a peer during play tasks. This suggests that emotion regulation deficits may lead to interpersonal conflict early in life.

Research in later childhood, adolescence, and emerging adulthood show results similar to that in young children, both within the context of parent-child relationships and peer relationships. However, this research is limited and the majority of studies rely on all self-report or other- report measures, as opposed to laboratory tasks, possibly limiting internal validity. For example, Lopes et al. (2011) assessed selfreported emotion regulation and its relation to self and friends' ratings of social relationship quality in college students from Germany, Spain, and the United States. These authors found that skill deficits in strategic emotion regulation were significantly related to more social conflict. Adrian et al. (2011) examined emotion dysregulation and family interpersonal difficulties in a clinical sample of adolescent girls. The authors found that emotion dysregulation mediated the relation between family interpersonal difficulties and non-suicidal self-injury in these at-risk adolescents. This suggests emotion dysregulation may be a mechanism for significant distress, interpersonally, for adolescents. Further evidence to support this relation is a 21-year longitudinal study conducted by Kim et al. (2009), in which emotion regulation 
and marital conflict were examined across generations in 190 sons and parents. Results indicated that during childhood and adolescence, parental emotion dysregulation predicted their son's emotion dysregulation. This, in turn, was directly related to the sons having conflict in their adult romantic relationship, as well as exhibiting deficits in parenting skills.

Taken together, these studies suggest that deficits in emotion regulation skills may be a key factor in predicting interpersonal problems in the context of multiple relationships from toddlerhood to early adulthood, including parents, peers, romantic partners, and later parenting skills. Children and adolescents with interpersonal trauma histories have been shown to exhibit skill deficits in emotion regulation as well as experience significant struggles in interpersonal relationships. Indeed, another domain of concern for those with DTD is disruptions in attachment, which includes difficulties in interpersonal relationships (Cook et al., 2005).

\section{Interpersonal Trauma, Emotion Regulation, and Interpersonal Difficulties}

The body of research described above studying DTD has shown that adults and children with interpersonal, cumulative trauma histories beginning at a younger age exhibit a unique pattern of symptoms, separate from PTSD, that include symptoms of emotion dysregulation and interpersonal problems. In addition to examining the diagnosis of DTD as a whole, research has also focused solely on the relation between interpersonal trauma and emotion regulation difficulties, the relation between interpersonal trauma and interpersonal difficulties, and the link between all three constructs. Emotion dysregulation and interpersonal difficulties have been shown to be related in studies of children and young adults who have experienced chronic interpersonal trauma, such as sexual and physical abuse, and neglect (Adrian et al., 2011; Calkins et al., 1999; Kim et al., 2009, Lopes et al., 2011). However, very little research has examined the potential effects of betrayal trauma on emotion regulation and interpersonal difficulties, and how that might differ from the effects of interpersonal, but non-betrayal trauma. This is especially true for research in children and adolescents, as the majority of research on betrayal trauma has focused on the adult population. 
In both adult males (Allen, Rhoades, Stanley, \& Markman, 2010; DiLillo et al., 2009) and females (Anders et al., 2012) interpersonal trauma is related to romantic relationship functioning. Anders et al. (2012) found that women who had experienced more cumulative relational traumas (both events that met Criterion for A1 and events that did not meet criterion for A1) reported less trust in their current romantic partner, less current relationship satisfaction, perceived their partner as less responsive, and felt less relationship security. DiLlillo et al. (2009) examined newlywed couples across two separate time-points. The authors found that childhood physical abuse, psychological abuse, and neglect predicted decreased marital satisfaction in husbands, while neglect predicted lower satisfaction for wives. Cumulative childhood maltreatment was also related to more marital mistrust and partner aggression. The authors found that these patterns remained at the time of follow-up, 1-2 years later. Similarly, in men who experienced combat trauma, their symptoms of PTSD were related to poorer post-deployment relationship satisfaction, confidence in the relationship, and parenting alliance for the both the men and their partners (Allen et al., 2010). Interpersonal trauma is also related to interpersonal relationship problems in children. For example, peer rejection in elementary and junior high students predicted a child's aggressive behavior 1 to 2 years later (Kupersmidt, Burchinal, \& Patterson, 1995). Only one study, which examined the adult population, has been published examining the relation between betrayal trauma and interpersonal problems, finding that those with a history of betrayal trauma perceived their romantic partners as having less respect for them (Owen et al., 2012).

Research has also found associations between interpersonal trauma and emotion dysregulation in children with interpersonal trauma histories. For example, Plattner et al. (2007) examined state and trait emotional behavior and trauma histories in a sample of youth in juvenile detention centers. The authors found that greater number of traumatic events experienced was positively correlated with higher trait emotionality. Further, the severity of trauma experienced, specifically emotional abuse and witnessing violence, was positively associated with higher levels of negative state emotions, particularly anger, during a stressing task. In conducting this literature review, no published research was found that has 
examined emotion regulation skills in individuals with betrayal trauma histories, as compared with individuals with non-betrayal trauma histories.

Not only is interpersonal trauma related to both emotion dysregulation and interpersonal difficulties, but these constructs are connected in important ways. Shields and Cicchetti (1998, 2001) examined the relation between maltreatment, reactive aggression, and emotion regulation in children involved in a day camp for inner-city youth. Using camp counselor ratings of children's behavior, maltreatment was related to more aggressive behavior towards others, bullying, as well as being a victim of bullying. Difficulties in emotion regulation mediated all of these relations. These results suggest that emotion regulation is a significant problem for children with histories of interpersonal trauma, and these difficulties strengthen the relations between interpersonal traumatic events and interpersonal conflict (i.e., bullying and victimization). However, the perpetrator of the child maltreatment was not specified in these studies, and the relations between betrayal trauma and emotion regulation have not been specifically examined in children, adolescents, or adults.

Although the findings from this body of research are important, the studies rely on self-reported or other-reported retrospective recall of relationship problems, aggression, and interpersonal conflict. Retrospective recall of perceived aggression and interpersonal conflict by an individual, their partner, or their caregiver may be a different construct than actual aggressive behavior measured in the moment by an unbiased observer. An observational, behavioral measure could tease apart whether individuals with specific types of trauma histories actually do engage in more aggressive and problematic interpersonal behavior, or if they are only perceived by others as doing so. Therefore, further research is needed with behavioral measures of interpersonal conflict.

Additionally, the studies mentioned above do not compare specific types of traumatic events. Instead, individuals with interpersonal trauma histories are compared with a heterogeneous group of participants who may have experienced a non-interpersonal trauma, or may not have experienced any potentially traumatic events. Further, very little research has been done in this area regarding betrayal 
trauma, with the exception of the study by Owen et al. (2012), which focused on perceived respect in adult romantic relationships. Research is needed that compares emotion regulation and interpersonal difficulties in those with betrayal trauma history to those with other potentially traumatic events, especially in children and adolescents.

Finally, the majority of these studies did not assess for symptoms of PTSD in their samples. Supplementary research is needed in children and adolescents, similar to the PTSD field trial, in which emotion dysregulation and problematic interpersonal behaviors are compared to PTSD diagnoses to examine whether or not a PTSD diagnosis sufficiently captures the population of youth experiencing these emotion regulation and interpersonal difficulties. If PTSD is not a sufficient diagnosis, this knowledge is needed to help researchers and clinicians understand the factors (i.e., trauma characteristics) that lead to clinically significant emotional difficulties, conflictual, and aggressive behavior in these children as opposed to only PTSD. This knowledge could then be used to develop and engage traumaexposed children in appropriate and sufficient trauma-informed treatments to fit their individual needs.

\section{Interpersonal Difficulties in Adolescence}

Clearly, undergoing chronic, interpersonal trauma has been shown to lead to difficulties in regulating emotions, which may lead to problems with interpersonal relationships, particularly in children or when the onset of a traumatic event begins in childhood. These difficulties may be even more problematic when children reach adolescence, a time when individuals are expected to gain autonomy, and therefore expected to have more control of their behavior. Further, along with this autonomy often come disagreements with parents about the adolescent's choices in friends, dress, dating, substance use, and other issues.

Typical adolescent development has been associated with increased conflict and emotion regulation problems. Multiple theories about parent-adolescent conflict have been developed to understand parent-child relationships during adolescence, including developmental, sociobiological, and psychoanalytic theories. For example, Spear (2000) discusses how behavior changes during this time, 
such as increased parent-adolescent conflict, risk-taking, and aggression, occur not only in the human species, but also in many other mammalian species. Spear argues that, in the developing brain of an adolescent, structural and functional changes in stressor-sensitive brain regions, such as the prefrontal cortex and limbic system, likely contribute to these behavioral changes. Further, the onset of many mental disorders increases during the transition from childhood to adolescence (Compas, Orosan, \& Grant, 1993; Kessler et al., 2005), anxiety reaches its lifetime peak in adolescence (Abe \& Suzuki, 1986), and suicide is the fourth leading cause of death during this developmental period (Eaton et al., 2008). Therefore, it may be that emotion dysregulation and interpersonal difficulties are typical during this period, and not only seen in adolescents with a history of experiencing interpersonal traumatic events.

In general, these theories are based on the assumption that, as children become adolescents, parent-child conflict arises and connectedness between them decreases. However, evidence from developmental literature shows that, overall, increases in parent-child conflict are minimal in adolescence, and, instead, that major parent-child conflict during this time is abnormal and clinically relevant. Smetana (1988) suggests the decrease in connectedness may be based on adolescent cognitive development that enables them to recognize inconsistencies in parent behavior and question the legitimacy of their parents' knowledge. Sociobiological theories (e.g., Steinberg, 1990) and psychoanalytic theories (Blos, 1979) argue that a decrease in connectedness is a necessary condition for the normative detachment from the primary caregiver, as an adolescent approaches independence associated with adulthood. Yet, although parent-child conflict increases in adolescence, negative changes in the parent-child relationship are minimal in typical families. For example, Collins and Laursen (2004) state that although conflict exists, frequent, high intensity fighting filled with angry emotions is not normative. Individuation theory (Youniss \& Smollar, 1985) suggests that autonomy increases when children reach adolescence, which may lead to disagreements; however, the theory posits that despite these disagreements, children maintain close relationships with their parents.

Several studies test these theories of parent-adolescent relationships. For example, Pinquart and 
Silbereisen (2002) examined patterns of change in autonomy and connectedness by observing changes in behavior during a conflict task conducted several times over a two-year period in early and middle adolescents and their mothers. They found that, although autonomy increased throughout adolescence, connectedness decreased for early adolescents (11-13 years) and increased for middle adolescents (14-16 years). However, the authors note that although the changes in connectedness were statistically significant, the size of the effects were small. A meta-analysis conducted by Laursen, Coy, and Collins (1998) revealed that parent-child conflict frequency actually decreased from early- to mid-adolescence and decreased further in late adolescence. In the same study, negative affect during conflict increased slightly from early- to mid-adolescence, and then decreased again, although it did not return to its original level. Together, this research shows that, although negative affect during arguments with parents does increase during adolescence, the increase is likely minor. Further, there is evidence to support that conflict actually decreases throughout adolescence. Finally, those relationships that are characterized by frequent, intense arguments are not normative.

Families with significant increases in the frequency and intensity of arguments when their child reaches adolescence have been shown to have difficulties prior to the child reaching adolescence (Montemayor, 1983; Offer, Ostrov, \& Howard, 1981). In conducting a meta-analysis using 30 observational studies of abused and neglected, and non-maltreated children (mean ages 1.3 - 11.5 years) Wilson, Norris, Shi, and Rack (2010) found that abused and neglected children were less likely to express positive communication (e.g., approval) and involvement behavior (e.g., eye contact, greetings), and were more likely to exhibit negative/aversive communication (e.g., disapproval, resistance) with their parents, than were non-maltreated children. Together, this suggests that one risk factor for conflict between parents and pre-adolescent children is a history of experiencing interpersonal trauma, which may lead to the significant increases of parent-child conflict when the child reaches adolescence.

\section{Chapter 2: Current Study}

The current study examined the potential difficulties, beyond PTSD, that may be exhibited by 
adolescents who have been exposed to betrayal trauma, in contrast to those who have experienced only non-betrayal potentially traumatic events. This study focused on two specific areas, emotion regulation and interpersonal difficulties, as they are two core components of DTD and have been recognized as problematic for children and adolescents who have experienced interpersonal traumatic events (e.g., Cook et al., 2005; Plattner et al., 2007, Shields \& Cicchetti, 1998, 2001; Wilson et al., 2010). Further, emotion regulation difficulties are thought to be related to interpersonal dysfunction in important ways, with early interpersonal trauma leading to a lack of the development of emotion regulation skills, which then leads to problem in interpersonal relationships (Briere, 1997, 2002; Fonagy et al., 2003). Specifically, interpersonal difficulties in the context of the parent-adolescent relationship were targeted, as this is a central relationship for adolescents, and this relationship may be challenged during this developmental period (Blos, 1979; Smetana, 1988; Steinberg, 1990).

Past research has found that individuals who have undergone interpersonal traumatic events beginning at a younger age, who experienced more chronic and severe trauma, and who experienced interpersonal traumatic events perpetrated by caregivers are more likely to exhibit problematic behavior above and beyond the symptoms of PTSD (e.g., Briere \& Elliott, 2000; Cook et al., 2005; Green et al., 1990; van der Kolk, 2003, 2007; van der Kolk et al., 2005; van der Kolk et al., 1996). Emotion dysregulation has been found to mediate the relation between interpersonal trauma and interpersonal difficulties (Shields \& Cicchetti, 1998, 2001). However, there have been several limitations to this research. Prior research has tended to rely on report or retrospective recall of interpersonal conflict behavior, rather than behavioral observations of actual interactions. Also, prior studies have not compared problematic interpersonal behavior in those who have experienced betrayal trauma events against those who have experienced acute interpersonal but non-betrayal trauma (e.g., stranger assault) or noninterpersonal traumatic events (e.g., motor vehicle crash, natural disaster). Understanding the differential risk factors (i.e., betrayal $v s$. non-betrayal perpetrators) may assist clinicians to more accurately diagnose and treat individuals with unique trauma histories. Additionally, excluding the DSM-IV field trials that 
examined only an adult population, these prior studies failed to include a measure of PTSD. A comparison of PTSD in children and adolescents would assist in determining whether or not PTSD is the best construct to capture features of this clinical population. Consequently, the current study expanded on the existing research in several ways. First, it directly compared adolescents who have experienced a betrayal trauma with adolescents without a betrayal trauma history who have experienced at least one other type of potentially traumatic event. Second, it used a behavioral measure of interpersonal conflict by observing the communication behavior of mothers and adolescents engaged in problem-solving tasks.

This study was also able to compare this behavioral measure to adolescent- and parent-reported perceived interpersonal conflict to understand if these measures are interchangeable (as is sometimes assumed in research studies), or if they represent separate constructs and should therefore both be assessed in future research. Third, this study utilized a within-subjects manipulation of an independent variable, as it varied the stressfulness of problem-solving tasks. This experimental control of an independent variable increases internal validity and therefore allows for certain causal interpretations. Lastly, adolescent participants were assessed for PTSD to determine whether significant problematic interpersonal behavior and emotion regulation difficulties occur separately from covered by a PTSD diagnosis.

\section{Hypotheses}

The proposed study consisted of six main hypotheses:

1. Effect of Task: It was hypothesized that across groups, adolescents would exhibit more negative interpersonal behavior during a high-stress interpersonal problem-solving task (discussing real-life disagreements) than a low-stress interpersonal problem-solving task (discussing hypothetical problems regarding positive events). This hypothesis reflects Individuation Theory (Youniss \& Smollar, 1985). A low-stress hypothetical task was conceptualized as eliciting minimal need for displaying autonomy, while actual disagreements within the adolescent's life were thought to elicit that need, leading to an overall increase in parent-adolescent conflict.

2. Effect of Group on Interpersonal Difficulties: Previous research has shown that interpersonal (e.g., 
Allen et al., 2010; Anders et al., 2012; DiLillo et al., 2009) and betrayal (Owen et al., 2012) trauma is related to interpersonal problems. It was hypothesized that adolescents with a betrayal trauma history would:

a. exhibit more negative communication behavior during the high-stress problem-solving task than those who have experienced only other types of traumatic events, and

b. report more perceived mother-adolescent conflict than those who have experienced only other types of traumatic events.

c. Mothers of adolescents with betrayal trauma would also report more perceived mother-adolescent conflict than mothers of adolescents without betrayal trauma.

3. Effect of Group on Emotion Regulation: Interpersonal trauma has been shown to be related to emotion regulation difficulties (e.g., Plattner et al., 2007). It was thus hypothesized that adolescents with a history of betrayal trauma would report more emotion regulation difficulties than adolescents with a history of other types of trauma, similar to previous research.

4. Effect of Group on PTSD: Prior research has shown a relation between betrayal trauma and PTSD severity (Freyd et al., 2005; Shin Tang \& Freyd, 2012) As such, it was hypothesized that adolescents with a history of betrayal trauma would have higher self-reported PTSD severity scores than adolescents with a history of other types of trauma, similar to previous research.

5. Predictors of Interpersonal Difficulties: Although interpersonal trauma is related to PTSD severity, the majority of mental health problems that children exhibit following a traumatic experience do not meet criteria for PTSD (Kiser et al., 1991), and 25-45\% of individuals meet criteria for DTD without meeting criteria for PTSD (Ford, 1999; McDonagh-Coyle et al., 1999; Vielhauer, 1996). It was therefore hypothesized that (a) history of betrayal trauma and (b) greater emotion regulation difficulties would predict more negative communication behavior above and beyond PTSD diagnosis. Also, (c) history of betrayal trauma and (d) greater emotion regulation difficulties would predict more adolescent-reported mother-adolescent conflict above and beyond PTSD diagnosis. Lastly, (e) history 
of betrayal trauma and (f) greater emotion regulation difficulties would predict more adolescentreported mother-adolescent conflict above and beyond PTSD diagnosis. Similar to previous research (e.g., Briere et al., 2008; Cloitre et al., 2009; Roth et al., 1997; van der Kolk, 1996; 2005), it was hypothesized that experiencing more chronic trauma (e.g., long standing sexual abuse) would predict (g) more negative communication behavior, (h) more adolescent reported interpersonal conflict, and (i) more parent-reported interpersonal conflict.

6. Best Model of Trauma, Emotion Regulation, and Interpersonal Difficulties: It was hypothesized that emotion regulation deficits would mediate the relation between betrayal trauma and negative communication behavior, similar to the findings of Shields \& Cicchetti (1998, 2001). Specifically, a history of betrayal trauma would predict more emotion regulation difficulties, which would thereby predict more negative communication behavior.

Failure to reject these hypotheses would show evidence that a survivor of betrayal trauma experiencing significant emotional distress and exhibiting problematic communication behavior may be appropriately classified under a DTD diagnosis, giving further support for this diagnosis to be included in the next version of the DSM. Also, it would add evidence that betrayal trauma survivors may be missed as targets for trauma-focused intervention. If researchers and clinicians focus only on the assessment of PTSD symptoms following traumatic events, those with posttraumatic stress symptoms who do not appear to meet PTSD criteria could be given inappropriate options for treatment. Alternatively, if a patient does not disclose a traumatic event during an initial assessment, clinicians may fail to recognize their symptoms as possibly related to a traumatic event. Both scenarios are likely to lead to a misdiagnosis and therefore inappropriate, or at least under-informed, treatment.

Because the purposes of this study were to evaluate difficulties that may be resulting from trauma that do not necessarily fit into the construct of PTSD, neither the DSM-IV (APA, 2000) nor the DSM 5 (APA, 2013) definition of a traumatic event was used. Instead, the term "potentially traumatic event" was used to allow inclusion of events that have been shown to be lead to posttraumatic stress (Briere, 2004), 
but may not meet Criterion A for PTSD, such as emotional abuse, non-violent sexual abuse, and separation from caregivers. See the History of Psychosocial Stressors (Appendix D) for a full list of potentially traumatic events specifically asked about in the current study.

\section{Chapter 3: Method}

\section{Participants}

A total of 58 pairs of adolescents between the ages of 12-18 and their stable legal maternal guardians participated in the study. "Stable" was defined as living with the caregiver for at least $50 \%$ of the time for at least 6 months. Participants were recruited at two university locations: West Virginia University (WVU) and the University of Texas Health Science Center, San Antonio (UTHSCSA). At the WVU locations, participants were recruited through local private and non-profit mental health clinics, community advertisements, and local high schools. At the UTHSCSA site, participants were recruited through flyers placed around the UTHSCSA Medical School and affiliated clinics, as well as a non-profit mental health clinic affiliated with the UTSHCSA Department of Psychiatry. Chi-square $\left(X^{2}\right)$ analyses found that participants recruited from UTHSCSA were more likely to be Hispanic, while participants recruited from WVU were more likely to be Caucasian. No other demographic differences were found between the two research sites.

The dyads consisted of 24 males and 29 females along with their stable maternal guardians. Most of the maternal guardians $(91 \%, n=48)$ were the biological mother of the adolescent, with $8 \%(n=4)$ adoptive mothers and one maternal grandmother. For simplicity, maternal guardians will be referred to as “mothers" from this point forward. Average age was 43 years for mothers (range $=30$-68-years, $S D=7.7$ years) and 14.5 years for adolescents (range $=12-18$ years, $S D=1.7$ years. Older age of mothers was associated with being a non-biological mother, $r(53)=.48, p<.01$, and having a higher annual family income, $r(53)=.48, p<.01$. Table 1 provides the demographic information for the participants.

Almost all of the adolescents in the sample $(96 \%, n=51)$ reported experiencing at least one noninterpersonal potentially traumatic event. A total of $81 \%(n=43)$ of the adolescents reported experiencing 
at least one interpersonal potentially traumatic events, with $58 \%(n=25)$ of those 43 adolescents $(47 \%$ of total sample) reporting a family member staying in their home as the perpetrator (i.e., betrayal trauma). About three quarters of the adolescents $(77 \%, n=41)$ reported experiencing both an interpersonal and non-interpersonal event, with $61 \%(n=25)$ of those 41 adolescents $(47 \%$ of total sample) reporting a family member staying in the home as the perpetrator of that interpersonal event. The groups did not differ in total number of non-betrayal interpersonal potentially traumatic events $F(1,51)=1.5, p=.23$, or non-interpersonal potentially traumatic events, $F(1,51)=.20, p=.66$. Tables 2,3 and 4 provide a listing of all potentially traumatic events, with frequencies of those events reported by sex and group.

Five participants reported no potentially traumatic events and were removed from the analyses (even though they participated in the full study), leaving a final sample of 53 pairs of adolescents with a trauma history and their maternal guardians. Chi-square $\left(X^{2)}\right.$ and Mann-Whitney $U$ tests revealed no significant differences among the parents or the adolescents in terms of age, ethnicity, or annual income between these five "no trauma" dyads and the final sample of 53 dyads.

\section{Grouping of Participants}

Participants were grouped according to their reported trauma histories. The Betrayal Trauma Group consisted of 27 adolescents (59\% female) who reported experiencing at least one betrayal trauma event. In the current study, a betrayal trauma was defined as experiencing an interpersonal potentially traumatic event that was perpetrated by a family member staying in their home at the time of the event. Typical perpetrators in this sample included biological fathers or step-fathers, and older siblings. The comparison group, or Non-Betrayal Trauma Group ( $n=26,50 \%$ female) reported experiencing at least one non-interpersonal event and/or at least one interpersonal event that was not perpetrated by a family member. Males and females did not differ in likelihood of group status, $X^{2}(1)=0.5, p=.50$.

\section{Measures}

Difficulties in Emotion Regulation Scale. The Difficulties in Emotion Regulation Scale (Gratz \& Roemer, 2004) is a 36-item self-report measure that assesses clinically relevant difficulties in emotion 
regulation. Items are rated on a 1 (almost never) to 5 (almost always) Likert scale. The Difficulties in Emotion Regulation Scale consists of six statistically derived domains of emotion regulation: (a) lack of awareness of emotional responses, (b) lack of clarity of emotional responses, (c) non-acceptance of emotional responses, (d) limited access to emotion regulation strategies perceived as effective, (e) difficulties controlling impulses when experiencing negative emotions, and (f) difficulties engaging in goal-directed behaviors when experiencing negative emotions; as well as a full scale total score. Original psychometrics, in a study with college students, found that the Difficulties in Emotion Regulation Scale had high internal consistency, with a Cronbach's alpha of .93 and an average Cronbach's alpha for the subscales of .85 . Evidence for construct validity was supported with correlations with the General Expectancy for Negative Mood Regulation Scale (Catanzaro \& Mearns, 1990; $r=-.69, p<.01$ ), and predictive validity was shown by positive correlations with self-harm for women, $r=.20, p<.01$, and men, $r=.26, p<.05$, and with intimate partner abuse for men, $r=.34, p<.01$. Finally, intra-class correlation coefficients have good test-retest reliability, $P=.88, p<01$. Neumann, van Lier, Gratz, and Koot (2010) found similar psychometric properties and the same factor structure in adolescents 11-17 years of age. For example, the average Cronbach's alpha for the subscales in that sample was .81. Effect sizes for gender differences were also similar between the two studies (Cohen's $d=.42$, Gratz \& Roemer, 2004; Cohen's $d=.49$, Neumann et al., 2010). Only the total score was used in the present analyses.

\section{UCLA PTSD Reaction Index for DSM-IV. The UCLA PTSD Reaction Index-Adolescent} Version (Pynoos et al., 1998; Rodriguez, Steinberg, \& Pynoos, 1999) is a self-report instrument designed to assess for a history of potentially traumatic events and the frequency of DSM-IV PTSD symptoms in adolescents 12 years of age or older. A parent version of this assessment is also available and was used in this study. Because a separate measure assessed for a history of events, only the PTSD Reaction Index items assessing for PTSD symptoms were used for this study. The 20 items ( 21 items for Parent Version) assessing for Criterion $\mathrm{B}, \mathrm{C}$, and D PTSD symptoms are rated on a 0 (none of the time) to 4 (most of the time) Likert scale. Reliability of this measure has been established by multiple studies (Cronbach's alpha 
of .85, Ellis, Lhewa, Charney, \& Cabral, 2006; Cronbach's alpha of .88, Roussos et al., 2005). Ellis and colleagues also established convergent validity with the Depression Rating Scale, $r=.72, p<.001$, and the War Trauma Screening Scale, $r=.59, p<.001$. Rodriguez, Steinberg, Saltzman and Pynoos (2001) also found good convergent validity, $r=.82, p<.001$, with the Clinician-Administered PTSD ScaleChildren and Adolescent version. Finally, Roussos and colleagues found high test-retest reliability, $r=$ $.84, p<.001$.

Using this measure, PTSD may be assessed in two ways (Steinberg, Brymer, Decker \& Pynoos, 2004). Either a total severity score can be calculated or a likely PTSD diagnosis can be considered. Rodriguez et al. (2001) suggest two methods of assessing for PTSD diagnosis. One suggestion is counting the number of symptoms endorsed as much of the time or most of the time and matching those symptoms with the symptoms required to meet a PTSD diagnosis: at least one Reexperiencing (Criterion B) symptom, three Avoidance (Criterion C) symptoms, and two Hyperarousal (Criterion D) symptoms. Secondly, a severity cutoff score can be used; Rodriguez et al. found that a cut-off of 38 has the greatest sensitivity and specificity for detecting a PTSD diagnosis. The current study utilized and compared both methods of assessing for the presence of a PTSD Diagnosis. A counting of symptoms was chosen for the analyses as it was found to be a more liberal diagnostic criterion within this sample.

History of Psychosocial Stressors. The History of Psychosocial Stressors (Scotti et al., 2000) was developed to evaluate the number and characteristics of potentially traumatic events that participants have experienced in their lives. There are two versions of the scale: a detailed version and a brief version. The brief version asks only if the respondent has experienced or witnessed certain types of potentially traumatic events (lists types of traumas) and how distressing the event is for the respondent currently; it does not ask for details about each specific trauma. The detailed version of this scale includes items asking what the specific trauma was, age it occurred, how long it lasted, respondent's relationship to the offender, etc. (Jacoby, 2011). The detailed version of the scale yields a score for total number of incidents (e.g., two car accidents), total number of types of events (e.g., two car accidents, and one natural disaster), 
and chronicity of events (using number of times and ages the events occurred). The detailed version was used in this study for two purposes: to place participants into the two trauma groups, and to predict negative communication and perceived conflict, using scores for types of incidents, number of incidents, chronicity, and relation to the offender.

Ruggiero, Del Ben, Scotti, and Rabalais (2003) found a 1-week test-retest reliability for the History of Psychosocial Stressors of $r(90)=.82, p<.001$. The History of Psychosocial Stressors has been found to differentially predict self-reported PTSD or borderline personality disorder (BPD) symptom severity in a sample of college students. Jacoby and Scotti (2012) found that endorsing more noninterpersonal events at a young age (0-4 years old) predicted higher BPD symptoms, $6=6.7, t(1)=2.13$, $p<.05$, while endorsing them at an older age (17-20 years old) predicted higher severity of PTSD symptoms, $B=.51, t(1)=2.07, p<.05$. When the chronicity score was used, only report of interpersonal events, $B=1.3, t(1)=6.39, p<.01$, predicted both higher reported BPD symptoms, $F(2,602)=29.9, p<$ $.01, R^{2}=.09$, and PTSD symptoms, $B=.29, t(1)=6.56, p<.01, F(2,602)=39.2, p<.01, R^{2}=.12$ (Jacoby \& Scotti, 2012).

Conflict Behavior Questionnaire-20. The Conflict Behavior Questionnaire (Prinz, 1977; Prinz, Foster, Kent, \& O’Leary, 1979) is a measure of perceived conflict behavior at home within the past three weeks between parents and adolescents, and includes a parent (75 items) and an adolescent version (73 items). The measure can be completed by mothers or fathers, and the adolescent version has two subversions directed at either their mother or their father. Items are rated as either true or false. A shorter, 20item version was developed, and correlates well $(r=.96)$ with the longer form. The Conflict Behavior Questionnaire yields one total score, with higher scores meaning more perceived parent-child conflict behavior in the home. This form also has been shown to discriminate between distressed and nondistressed teens when rated by both mothers and fathers (Robin \& Foster, 1989). Both the parent and adolescent (directed at mother) versions of this measure were used in this study. Total scores were used and compared to the behavioral observation of communication during problem-solving tasks. 
Issues Checklist. The Issues Checklist, from Robin and Foster's (1989) book on negotiating parent-adolescent conflict, assesses conflictual issues and the perceived anger intensity of disputes over these issues. In the current study, parents and adolescents completed identical versions, indicating whether each issue on the list had been discussed and how many times it had been discussed during the past four weeks; the anger intensity of the discussion was then rated on a 1 (calm) to 5 (angry) Likert scale. This checklist yields two scores: Number of Issues and Total Anger Intensity of endorsed items. The Betrayal Trauma and Non-Betrayal Trauma Groups were compared on these scores. This measure was also used to determine the conflictual issues that the dyad discussed during the problem-solving tasks (see Procedures below).

Parent-Adolescent Interpersonal Problem-Solving Behavior Coding System. The behavioral coding system created for this study was heavily based on Robin and Foster's (1989) behavioral coding of positive and negative parent-adolescent communication, as well a review by Markman and Notarius (1987) of behavioral coding systems for family interactions. Changes to Robin and Foster's code were minimal, and included combining codes with similar functions (e.g., combining Criticism and Negative Exaggeration), and excluding codes that infer internal behaviors (e.g., Anger) and intentions (e.g., Willingness to Listen) to maximize coding reliability.

In the present study, coders watched digital video recordings of the parent-adolescent interactions, and coded communication behavior based on an exchange coding procedure. An exchange was defined as ending when (1) a statement/question is completed and either (a) the other person speaks, (b) there are 5 seconds of silence, or (2) another person interrupts the speaker in the middle of a sentence and the other person does not finish their sentence within 5 seconds. Coding dimensions were divided into Negative Aggressive Communication, Negative Non-Aggressive Communication, and Positive Communication. All communication behaviors that did not fit into those categories were coded as Neutral Talk. Appendix A provides the complete coding system, definitions, and examples. Communication behaviors were measured using a total percentage of that behavior for that participant during a problem-solving task. For 
example, the formula to calculate total Positive Communication Behaviors during one task would be: total seconds of Positive Communication/(total seconds of Total Communication Behavior). Communication behaviors were compared for mother and adolescents across groups, as well as used in mediation and regression analyses.

Coders for this portion of the study were two graduate student researchers masked to group status, as well as the author. The graduate researchers coded a total of $49 \%(n=26)$ of the dyads and the author of the study coded the remaining dyads. Throughout data collection, $25 \%$ of interactions (15 dyads) were randomly selected to be double coded by the author to examine coder agreement. Inter-rater reliability was monitored using Cohen's Kappa coefficient $(K=.64-.79)$. If agreement fell below $K=.60$ throughout the coding process, additional training was conducted with the author of the study until agreement met the required values. This occurred one time with one graduate student coder after initial training, and it was resolved after one addition training meeting.

Problem-Solving Reaction Scales. Following the problem-solving tasks, the mother and adolescent each completed Problem-Solving Reaction Scales, a brief measure created for this study. The Problem-Solving Reaction Scales consisted of six questions regarding each participant's perception of their interaction with their partner during the problem-solving task, rated on 1-7 point bipolar scales. The questions inquire about their perception of task difficulty, their emotional state during the task, their perception of how cooperative each participant was (themselves and their partners), whether they were successful at completing the task, and whether their interaction with their partner was typical or atypical of most interactions with that person. The Problem-Solving Reaction Scales provided a short break between the two tasks and was used as a manipulation check to compare the stress associated with the Low- and High-Stress Tasks.

\section{Procedure}

Before coding began, the graduate student coders were trained during a pilot study using volunteer parent and adolescent dyads and graduate student actors. These volunteer dyads completed only the two 
problem-solving tasks, without completing the paper-and-pencil measures, and their data were not used in any analyses. Checking of reliablity was completed regularly throughout training until Cohen's Kappa coefficient reached at least .60 for all behavioral codes.

This study was conducted in two main locations. The first 21 dyads participated in the Department of Psychology at West Virginia University, using the Traumatic Stress Research Group Lab, the Memory and Law Research Lab, or the Quinn Curtis Center. To accommodate transportation difficulties of participants, two sessions were conducted in the participants' homes, per their requests. The final 32 participants participated at the University of Texas Health Science Center in the Conference Room of the University Plaza Building, which is a facility dedicated to clinical research and community clinical services. After completing the consent and assent process, adolescents and their mothers completed a packet of adolescent-report (i.e., PTSD Reaction Index, Difficulties in Emotion Regulation Scale, and Conflict Behavior Questionnaire) and parent-report (Demographics, PTSD Reaction Index, Difficulties in Emotion Regulation Scale, and Conflict Behavior Questionnaire) questionnaires in two separate rooms. The adolescents were then interviewed alone using the History of Psychosocial Stressors. After the interview was complete, the mother and adolescent returned to the same room and began the first of two problem-solving tasks.

Problem-Solving Task: Low Stress. To complete Low-Stress Task, mothers and adolescents sat together at a table in a room where a digital video camera recorded their interactions. Once seated at the table, the participants were given three topics to discuss that involved planning and organizing joint activities that the dyad might enjoy, along with worksheets that were created for the study to help guide them in their problem solving (see Appendix B). The dyad jointly chose which topic they would discuss first, second, and third. The three topics were: planning your next family vacation (55\% of the sample chose to complete first), planning a party for a loved one (30\% chose to complete first), and planning a garden ( $15 \%$ chose to complete first). After the dyad chose the order of their topics, they listened to verbal directions regarding their first topic, received the corresponding worksheet, and were informed that the 
investigator would leave the room during all of their problem-solving tasks to allow them to discuss the topics privately (although they were aware they were being video recorded). The dyad was asked to knock loudly on the table when they had completed the first topic. When the first topic was completed, the investigator entered the room, read the directions for the second topic, handed out the corresponding worksheet, and asked the dyad to knock loudly when this second topic was completed. The third topic was conducted in the same manner. The dyads were given a total of ten minutes to discuss all three topics and attempt to find solutions to the problems, which included reading the directions for the second and third topics (to reduce time burden of the session for the participants). When the 10 minutes elapsed, the Low-Stress Task was stopped, regardless of how many topics were completed. One dyad in the NonBetrayal Trauma Group completed all three topics before the 10 minutes elapsed and were asked to complete a fourth topic: planning a party for a second loved one. Both mother and adolescent behavior were later coded via the digital video recordings. Following the Low-Stress Task, the mother and adolescent each completed the Problem-Solving Reaction Scales.

Problem-Solving Task: High Stress. The second problem-solving task (High-Stress Task) used in this study was modeled after the conflict task paradigm used by multiple researchers examining both parent-adolescent conflict and emotion regulation (e.g., Kobak, Cole, Ferenz-Gillies, Fleming, \& Gamble, 1993). Mothers and their adolescent children completed identical versions of the Issues Checklist (Robin \& Foster, 1989), which lists topics that parents and adolescents typically argue about, including money, dating, friends, alcohol or drugs, household rules, and siblings. The checklist instructed the participants to place a checkmark next to each topic that had been discussed together at home in the past four weeks, and to rate how angry they felt during the last discussion of that topic. The dyad was encouraged to not discuss the checklist with each other as they were completing it, even though they would see each other's checklists later, as the investigator was interested in each of the participants' own perceptions. After the participants completed the checklist, the issues that the mothers and adolescents endorsed and their corresponding emotion ratings were compared to identify their three most prominent areas of 
disagreement; these were then used as the three topics of discussion for this problem-solving task. Although the mother and adolescent were asked to choose, together, their "three biggest issues at home" using the Issues Checklist as a guide, the researcher directed the dyad in this process to ensure the issues they discussed matched the issues endorsed on the checklist. To order the discussion, the first topic discussed was their identified "biggest issue at home," their second was their "second biggest issue at home," and their third topic was their "third biggest issue at home." One dyad in the Non-Betrayal Trauma Group endorsed less than three issues discussed within the last four weeks; as such, their second and third topics were chosen as topics they had discussed within the last six months. The most common issues chosen for this task were: cleaning room or doing household chores (chosen by $40 \%$ of sample), school/grades (chosen by $36 \%$ of sample), and cursing/talking back to parents (chosen by $30 \%$ of the sample).

After the three issues were chosen, the participants were directed to think of a "position statement" for each topic. A position statement was defined as one short sentence that begins with "If it were my way: ." The dyad was given approximately 30 seconds tol minute to think of their position statements. Then, the dyad was instructed to attempt to come to a solution to their first problem, and they were given a corresponding worksheet (see Appendix C) to help guide them in their problem solving. In order to facilitate the discussion, dyads were asked to begin the task by making their position statement regarding their first topic to each other. As soon as the position statements were made, the investigator left the room and the participants were instructed to knock loudly on the table when the first topic was completed. The investigator entered the room when the participants completed the first topic and asked the participants to make their position statements regarding their second topic. After these position statements were made, the investigator gave the participants their second corresponding worksheet and left the room. The third topic was completed in the same way. The dyads were given a total of 10 minutes to discuss all three topics and attempt to find solutions to the problems, which included making their position statements for the second and third topics. When the 10 minutes elapsed, the High-Stress Task 
was stopped, regardless of how many topics were completed. Twelve dyads (6 dyads in each of the two groups) completed all three topics before the 10 minutes had elapsed, and were asked to quickly choose and complete a fourth task ("fourth biggest issue at home"), chosen together with the assistance of the investigator. Both mother and adolescent behavior were later coded via the digital video recordings.

Following the High-Stress Task, the participants completed the Problem-Solving Reaction Scales regarding their perceptions of the High-Stress Task, and were then debriefed. Following debriefing, mothers and adolescents each received a \$20 honorarium for their participation. Participants recruited at West Virginia University had the opportunity to schedule a no-cost 50-minute parent-adolescent communication training session based on their interactions, conducted by a master's-level graduate student therapist. This communication training session was based on an empirically supported treatment by Robin and Foster (1989) for decreasing parent-adolescent conflict. In this session, the therapist used examples, based on the problem-solving tasks, to teach both the parent and adolescent effective communication skills. Following the free session, the families were provided referral sources for further treatment if the family desired. Ultimately, only one family chose to participate in this treatment. The free communication training session could not be offered to participants recruited at UTHSCSA due to IRB regulations regarding the requirement of offering any and all research benefits in both Spanish and English, which was not possible to provide.

There were several reasons that the High Stress Task was always completed after the Low Stress task, rather than counterbalancing the order of the two tasks. Primarily, it was possible that emotional activation following the High-Stress Task could "spill" over into the Low-Stress Task if the order of the tasks were switched. This would essentially make the Low Stress Task no longer "low stress." Secondly, it was assumed that participants would be more fatigued during the last task, which could add to the stress level of the task. This again, would make it less likely that the Low Stress Task would be truly "low stress." Because the purpose of the task manipulation was to provide participants with a task that was "low stress" counterbalancing the tasks may then defeat the purpose of providing two tasks. Therefore, for 
all participants, the order of the tasks was the same: Low Stress Task followed by High Stress Task.

\section{Power Analysis}

A power analysis calculated the necessary power needed for the planned between group analyses of variance (ANOVA) and multivariate analyses of variance (MANOVA). These power analyses were completed using $\mathrm{G}^{*}$ Power (ver 3.0.10) to determine the number of participants per group that would result in an $80 \%$ chance (power of .80 ) of correctly rejecting the null hypothesis. This is the value for power that has been recommended by Cohen (1988) and is commonly accepted in the social sciences. The calculation of power requires a determination of the effect sizes for the primary measures being utilized. Effect sizes for measures are, by necessity, estimations made from published research or preliminary studies, or the researcher may use "default" estimate equivalent to small, medium, and large effects (see Cohen, 1988).

Several sources were utilized to estimate effect sizes of key measures based on published research. Neumann and colleagues (2010), in a study employing the DERS with an adolescent sample (ages 11-17 years), found effect sizes (Cohen's $d$ ) ranging from .22 to .49 (averaging .36) on 5 of the 6 DERS subscales. These values are considered to be medium to large effect sizes. Available research on coding behaviors during interaction tasks suggest medium to large effect sizes. For example, Kobak et al. (1993), in a study of problem-solving behavior in a mother-child interaction task (children aged 14-18 years), found correlations between their behavioral measures and measures of attachment and anxiety in the range of .30 to .50 ; these are considered to represent medium to large effect sizes. Additionally, Beijersbergen, Bakermans-Kranenburg, van Ijzendoorn, and Juffer (2008) had a medium effect size (Cohen's $d=.25$ ) in their analysis of parent-child interactions during a family interaction task (all children were 14 years old).

Given the above, it was assumed that large effect sizes were attainable for the key measures utilized in this study. As such, the following values were entered into the G*Power program: (a) alpha= $.05,(\mathrm{~b})$ power $=.80$, and $(\mathrm{c})$ number of groups $=2$. Calculations were run for each type of analysis that 
was planned. The following calculations were run: a priori one-way ANOVA for a large (value of $f=.40$ ) effect size, a repeated measures MANOVA for within-between interactions with six measurements for a large (value of $f=.40$ ) effect size, a MANOVA for special effects and interactions with two predictors and three response variables for a large (value of $f^{2}=16$ ) effect size, a two-tailed point biserial correlation with a large (value of $\rho=.50$ ), and a linear multiple regression for $R^{2}$ deviation from zero with a large (value of $f^{2}=.35$ ). For all but one analysis (repeated measures MANOVA), the maximum total sample size that the program estimated was 52 (26 per group) for large effect sizes. A minimum of 26 participants (parent-child dyads) per group were recruited. The sample size needed for the repeated measures MANOVAs was estimated to be 86 (43 per group) for large effect sizes. Therefore, the repeated measures MANOVAS were considered to be exploratory in nature.

\section{Chapter 4: Results}

When reporting results of measures with reports from both the parent and adolescent (i.e., PTSD Reaction Index, Conflict Behavior Questionnaire, Issues Checklist, Problem-Solving Reaction Scales), AR and PR are used after the measure name to differentiate between the Adolescent Report (AR) and Parent Report (PR) of the measure.

\section{Data Cleaning and Missing Data}

Missing data were minimal for the majority of the measures in the study, with the Difficulties in Emotion Regulation Scale-PR having no missing data. Four percent of the data on the PTSD Reaction Index-AR, $0.4 \%$ on the Conflict Behavior Questionnaire-AR, less than $0.01 \%$ on the Conflict Behavior Questionnaire-PR, and less than $0.01 \%$ on the Difficulties in Emotion Regulation Scale-AR were missing. These data were replaced with the mean score across participants for that item on each measure. One dyad failed to complete the Problem-Solving Reaction Scales due to time constraints and therefore was not used in the analyses for that measure. Although, technically, the PTSD Reaction Index-PR had no missing data, the measure allows parents to answer I don't know regarding any of their child's PTSD symptoms. Twenty-one out of the 53 mothers (40\%) answered I don't know to at least $20 \%$ of the Criterion B, C, and 
D PTSD items. The total number of items answered I don't know were not significantly related to group status, $F(1,51)=1.6, p=.21$. Therefore, due to the questionable validity of the data for this measure, it was not used in the main analyses.

\section{Step 1: Descriptive Statistics}

Descriptive statistics (i.e., mean, median, mode, standard deviation, range) were calculated to describe the sample and the key variables (e.g., Communication Behaviors, PTSD Reaction Index, Difficulties in Emotion Regulation Scale, Conflict Behavior Questionnaire, and Issues Checklist). Effect sizes were calculated using partial eta squared $\left[\eta_{p}^{2}=\mathrm{SSeffect} /(\mathrm{SSeffect}+\mathrm{SSerror})\right.$; with effect sizes labeled as: "small" $\geq .01$, "medium" $\geq .06$, "large" $\geq .14$ ] for MANOVAs and $R^{2}$ for regression analyses. Correlations were calculated among all variables for an initial determination of their interrelations and internal consistency.

Sex, age, ethnicity, and location recruitment differences. No sex differences were found for total number of non-interpersonal, interpersonal, or betrayal trauma events reported. Mean scores for all measures and subscales, by Sex of Adolescent and Group, are reported in Tables 5 through 11. ANOVAs were conducted on each measure to determine if there was sex. An effect for Sex was found for the Total PTSD severity score of the PTSD Reaction Index-AR, $F(1,51)=6.8, p<.05$. There were no Sex differences for the total scores on the PTSD Reaction Index-PR, Problem-Solving Reaction Scales (AR and PR), Issues Checklist (AR and PR), Conflict Behavior Questionnaire (AR and PR), or the Difficulties in Emotion Regulation Scale.

Pearson correlations were used to determine potential relations between the age of the adolescents and mothers and the key variables. Older adolescents, $r(53)=.29, p<.05$, were more likely to report experiencing or witnessing non-interpersonal events (e.g., car accident, illness, injury). No age differences were found on the total number of overall interpersonal events experienced or witnessed, or on total number of betrayal events experienced or witnessed.

One-way ANOVAs compared Caucasian (vs. Non-Caucasian), as well as Hispanic (vs. Non- 
Hispanic), mothers and adolescents on key variables. On the Issues Checklist, Hispanic adolescents scored higher than Non-Hispanic adolescents on Issues, $F(1,51)=9.1, p<.01(M=10.7$ for Hispanic adolescents, $M=6.6$ for Non-Hispanic adolescents $)$ and Anger, $F(1,51)=7.1, p<.05(M=24.2$ for Hispanic adolescents, $M=14.2$ for Non-Hispanic adolescents). Non-Caucasian adolescents $(M=94.9)$ reported significantly higher scores on the Difficulties in Emotion Regulation Scale, $F(1,51)=5.9, p<$ .05 , than Caucasian adolescents $(M=78.1)$ and were more likely to report an interpersonal (but not necessarily betrayal) potentially traumatic event, $X^{2}=5.6, p<.05$, than were Caucasian adolescents.

Separate one-way ANOVAS compared participants recruited from West Virginia University (WVU) vs. the University of Texas Health Science Center (UTHSCSA) on the total scores of key measures (i.e., Difficulties in Regulating Emotions Scale, UCLA PTSD Reaction Index, Issues Checklist, Conflict Behavior Questionnaire). A repeated measures MANOVA compares these two recruitment groups on the 3 Communication Behaviors (Negative Aggressive, Negative Non-Aggressive, Positive) during the 2 Tasks (Low Stress Task and High Stress Task). The ANOVAS revealed that adolescents recruited from UTHSCSA reported more Non-Interpersonal potentially traumatic events, $F(1,51)=9.2, p$ $<.01(M=3.5, S D=1.8$ vs. $M=2.0, S D=1.5)$, reported having more issues discussed in the past month on the Issues Checklist, $F(1,51)=10.3, p<.01(M=10.0, S D=4.8$ vs. $M=5.5, S D=4.8)$, and more anger associated with discussing those issues $F(1,51)=8.7, p<.01(M=22.7, S D=14.5$ vs. $M=11.2$, $S D=10.9$ ), than adolescents recruited from WVU. Mothers of adolescents recruited from UTHSCSA also reported having more issues discussed in the past month than mothers of adolescents recruited from WVU, $F(1,51)=10.6, p<.01(M=11.9, S D=5.6$ vs. $M=6.7, S D=5.3)$, but no differences were found on reported anger associated with issues for the mothers. No other differences on any measures were found between the two recruitment sites. The distribution of these participants across the Betrayal and Non-Betrayal Trauma Groups was similar, $X^{2}=1.1, p=.29$.

Measure validity. To ensure internal consistency of central measures used, Cronbach's alpha $(\alpha)$ was calculated, and all subscales of a measure were correlated with each other. All adolescent and parent 
report measures exhibited good to excellent internal consistency $(\alpha=.86-.95)$. Overall, measures and their subscales correlated as expected. All three PTSD Reaction Index subscales were significantly correlated for both AR, $r(53)=.63-.76, p<.01$, and PR, $r(53)=.57-.66, p<.01$. Table 12 presents the PTSD Reaction Index inter-subscale correlations. Table 13 provides subscale correlations for the Difficulties in Emotion Regulation Scale. Some subscales of the Difficulties in Emotion Regulation Scale had weaker inter-correlations than expected, based on previous psychometric research from Neumann et al. (2010). For example, Awareness was unrelated to Strategies, $r(53)=.06, p=.70$. The scores for Total Issues and Total Anger on the Issues Checklist were correlated for both PR, $r(52)=.73, p<.001$, and AR, $r(53)=$ $.83, p<.001$.

Correlation analyses of the total scores on the key measures were conducted for a preliminary examination of the relations among these variables. The measures correlated as expected. The PR and AR versions of the PTSD Reaction Index, with higher scores indicating greater severity of PTSD symptoms, agreed moderately with each other, $r(53)=.63, p<.01$, as did the AR and PR versions of the Conflict Behavior Questionnaire, $r(53)=.62, p<.01$, and the report of Total Issues, $r(53)=.58, p<.01$, and Total Anger, $r(53)=.61, p<.01$, on the Issues Checklist. Tables 14 and 15 present the correlations among these key measures.

Description of the behavioral observations. Adolescents engaged in Communication Behaviors (either verbal or non-verbal), on average, for 3.2 minutes $(S D=1.2$ minutes, range $=0.8-6.6$ minutes $)$ during the Low-Stress Task and 2.9 minutes $(S D=1.4$ minutes, range $=$ 0.5-7.6 minutes $)$ during the HighStress Task. For the mothers, Communication Behaviors accounted for an average of 5.8 minutes $(S D=$ 1.2 minutes, range $=1.5-8.6$ minutes $)$ during the Low-Stress Task and 4.5 minutes $(S D=1.6$ minutes, range $=$ 0.9-7.7 minutes $)$ during the High-Stress Task. Overall, the Non-Betrayal Trauma Group $(M=3.6$ minutes) engaged in more communication behavior during the Low-Stress Task, $F(1,51)=6.2, p<.05$, than did the Betrayal Trauma Group ( $M=2.8$ minutes). There were no other significant differences found in the total time engaged in communication by either the adolescents or the mothers by either sex of the 
adolescent or group membership during either problem-solving task. On average, 0.8 minutes $(S D=0.5$ minutes, range $=0-2.2$ minutes $)$ of the 10 -minute Low-Stress Task and 1.7 minutes $(S D=1.2$ minutes, range $=4.4$ ) of the 10-minute High-Stress Task were used to explain directions, make position statements, and answer questions between completing the sub-tasks. For both the Low- and High-Stress Tasks, there were no differences by group or sex of adolescent in the amount of time interacting with the investigator.

Independent variable manipulation check. To ensure that the Low- and High-Stress Tasks successfully manipulated the level of participant stress, a repeated measures MANOVA was conducted using the Problem-Solving Reaction Scales. It should be noted that this analysis is estimated to be underpowered, and is therefore exploratory in nature. For the adolescents (Problem-Solving Reaction Scales-AR), $F(1,50)=19.6, p<.001, \eta_{p}^{2}=.28$, and mothers (Problem-Solving Reaction Scales-PR), $F(1$, $49)=54.6, p<.001, \eta_{p}^{2} .53$, a main effect of Task was revealed. This suggests that the problem-solving tasks were successful in manipulating the level of stress for both the adolescents and mothers, regardless of trauma group status. This ensures that significant differences between groups during these tasks were not a result of differential stress reactions to the problem-solving tasks.

For adolescents, a Group x Question interaction was also revealed, $F(5,50)=3.4, p<.05, \eta_{p}^{2}=$ .06. Post hoc LSD (least significant difference) tests revealed that the Betrayal Trauma Group reported significantly higher Upset scores, higher Uncooperative-Self scores, and lower Atypical scores than the Non-Betrayal Trauma Group, across tasks, $p<.05$. Table 11 provides a list of means by group and sex on the Problem-Solving Reaction Scales-AR and Problem-Solving Reaction Scales-PR.

\section{Step 2: Group by Task Differences in Communication Behavior}

This step is exploratory in nature, as a power analyses estimated it to be underpowered. Therefore, non-significant effects should be interpreted with caution. Step 2 examined Hypothesis 1, that adolescents would exhibit more negative interpersonal behavior during a high-stress interpersonal problem-solving task than a low-stress interpersonal problem-solving task. It also examined Hypothesis 2a, that adolescents with a betrayal trauma history would exhibit more negative communication behavior during 
the high-stress problem-solving task than those who have experienced only other types of traumatic events. A 2 Groups (Betrayal Trauma, Non-Betrayal Trauma) x 2 Tasks (Low-Stress, High-Stress) x 3 Type of Communication Behavior (Negative Aggressive, Negative Non-Aggressive, Positive) repeated measures MANOVA was conducted to determine whether experiencing a betrayal trauma was related to differences in: (a) Positive Communication, (b) Negative Non-Aggressive Communication, and (c) Negative Aggressive Communication. The initial plan of analysis was to enter the communication behavior of the mothers as a covariate to control for effects of the behavior of the mothers on the communication behavior of the adolescents, as opposed to a history of betrayal trauma. It was found that the communication behavior of the mothers did significantly correlate with the communication behaviors of the adolescents during the tasks (see Table 15). However, only those forms of communication behavior in which mothers differed by group is appropriate to enter into the analysis as a covariate. Therefore, a preliminary repeated-measures MANOVA 2 Groups (Betrayal Trauma, Non-Betrayal Trauma) x 2 Tasks (Low-Stress, High-Stress) x 3 Type of Communication Behavior (Negative Aggressive, Negative NonAggressive, Positive) was conducted on the behaviors of the mothers first. The analysis found a main effect of Task $F(1,51)=31.4, p<.001, \eta_{p}^{2}=.38$, and Communication Behavior, $F(2,102)=196.9, p<$ $.001, \eta_{p}^{2}=.79$, with no main effect of Group and no significant interactions. Post hoc LSD tests showed that, across groups, mothers increased their non-neutral (Negative Aggressive + Negative Non-Aggressive + Positive) communication behavior from the Low-Stress Task to the High-Stress Task $(p<.05)$. Also, across groups and tasks, mothers engaged in more Positive communication than Negative NonAggressive communication, and engaged in more Negative Non-Aggressive Communication than Aggressive Communication ( $p<.05$, see Figure 1 and Table 6). The lack of group differences for the communication behavior of mothers indicates that any group differences found in the communication behavior of the adolescents would likely not be a function of the behavior of the mothers. However, the main effect for Task suggests that mother's overall communication behavior (across behavior type), may affect changes in communication behavior from the Low- to High-Stress Task for the adolescents. 
Therefore, two separate scores of mothers' overall behavior (Positive + Negative Non-Aggressive +Negative Aggressive) were analyzed as covariates in the subsequent analysis: Total Communication during the High-Stress Task and Total Communication during the Low-Stress Task.

When examining the communication behavior of the adolescents, a 2 Groups (Betrayal Trauma, Non-Betrayal Trauma) x 2 Tasks (Low-Stress, High-Stress) x 3 Type of Communication Behavior (Negative Aggressive, Negative Non-Aggressive, Positive) MANOVA revealed a significant 3-way Task x Behavior x Group interaction, $F(2,102)=5.5, p<.05, \eta_{p}^{2}=.10$. Post hoc LSD tests $(p<.05)$ showed that, during the Low-Stress Task, there were no significant differences between the groups for Negative Aggressive, Negative Non-Aggressive, or Positive Communication Behavior. Although both the Betrayal Trauma and the Non-Betrayal Trauma Groups displayed an increase in Negative Non-Aggressive Communication Behavior from the Low-Stress to the High-Stress Task, the Betrayal Trauma Group displayed a significantly larger increase in this behavior than did the Non-Betrayal Trauma Group. The Betrayal Trauma Group also significantly increased their Negative Aggressive Communication Behavior, unlike the Non-Betrayal Trauma Group, which showed no change $(p<.05)$. Contrariwise, the NonBetrayal Trauma Group demonstrated a significant increase in Positive Communication Behavior from the Low-Stress to High-Stress Task $(p<.05)$, and engaged in significantly more Positive Communication behavior during the High-Task than the Betrayal Trauma Group. There was no significant change in Positive Communication Behavior for the Betrayal Trauma Group from Low-Stress to High-Stress Task. When the total communication behavior of the mothers during the Low- and High-Stress Tasks were entered as covariates, there were no changes in the pattern or significance levels of the results of the MANOVA. Therefore, only the non-covaried MANOVA results are reported here and the non-covaried means are reported in Table 6 and Figure 2.

In sum, for all adolescents, increasing the stress of the interpersonal problem-solving task led to an increase in Negative Communication (both Aggressive and Non-Aggressive), failing to reject Hypothesis 1. Only the Non-Betrayal Trauma Group simultaneously increased Positive Communication Behavior, 
and the Betrayal Trauma Group engaged in significantly more Negative Aggressive and Negative NonAggressive Communication than did the Non-Betrayal Trauma Group, failing to reject Hypothesis $2 \mathrm{a}$. Step 3: Group Differences in Emotion Dysregulation, Perceived Conflict, and PTSD Severity

Step 3 was conducted with two goals in mind:

1) to evaluate group differences in reported emotion regulation (Difficulties in Emotion Regulation Scale), perceived parent-adolescent conflict (Conflict Behavior Questionnaire), total issues reported, and reported anger within the past month (Issues Checklist) and

2) to evaluate group differences on reported PTSD severity.

The first goal of Step 3 corresponds with Hypotheses 2b, 2c, and 3. Hypothesis $2 b$ and 2c state that the Betrayal Trauma Group would have more parent-reported and more adolescent reported parentadolescent conflict. Hypothesis 3 states that the Betrayal Trauma Group would report more difficulties in regulating their emotions than the Non-Betrayal Trauma Group. The second goal of Step 3 corresponds with the Hypothesis 4, that the Betrayal Trauma Group would report higher total PTSD severity. To complete this step, a series of ANOVAs were conducted to determine if there was an effect for Group. See Tables 5-11 for a list of means by group and sex for these variables.

A 2 Group (Betrayal Trauma Group and Non-Betrayal Trauma Group) ANOVA revealed that the Betrayal Trauma Group reported higher scores than the Non-Betrayal Trauma Group on the Difficulties in Emotion Regulation Scale Total Score, $F(1,51)=11.4, p<.01, \eta_{p}^{2}=.18$. A 2 Group (Betrayal Trauma and Non-Betrayal Trauma) ANOVA was conducted on the Conflict Behavior Questionnaire-AR. A second 2 Group (Betrayal Trauma and Non-Betrayal Trauma) was conducted on the Conflict Behavior Questionnaire-PR. Only the Conflict Behavior Questionnaire-PR showed significantly higher scores for the Betrayal Trauma Group, $F(1,51)=5.7, p<.05, \eta_{p}^{2}=.10$. Two separate 2 Group (Betrayal Trauma and Non-Betrayal Trauma) ANOVAs were conducted on the Issues Checklist-AR for Total Issues and Total Anger. Identical ANOVAs were also conducted on the Issues Checklist-PR. On the Issues Checklist-AR, only the Total Issues showed significantly higher scores for the Betrayal Trauma Group, 
$F(1,51)=4.6, p<.05, \eta_{p}^{2}=.08$, with no significant differences between groups on the Total Issues on the Issues Checklist-PR or the Total Anger (Issues Checklist-AR and Issues Checklist-PR) scales of the Issues Checklist. These findings present evidence that adolescents with a history of betrayal trauma have more difficulty regulating their emotions than those who have experienced other types of potentially traumatic events. These individuals also report having more interpersonal issues, as measured by the Issues Checklist, and are perceived by others close to them (i.e., their mothers) as engaging in more interpersonal conflict, as measured by the Conflict Behavior Questionnaire-PR. On the other hand, the adolescents in the Betrayal Trauma Group did not report more perceived mother-child conflict than did the Non-Betrayal Trauma Group.

Lastly, a 2 Group (Betrayal Trauma and Non-Betrayal Trauma) ANOVA revealed that the Betrayal Trauma Group reported higher Total PTSD Severity scores than the Non-Betrayal Trauma Group, $F(1,51)=6.0, p<.05, \eta_{p}^{2}=.11$. Because there were significant sex differences found on the PTSD Reaction Index-AR (see Step 1), the above ANOVA was re-run using Sex as a covariate. This did not change the significance level for the analysis and the effect size remained large. Therefore, the noncovaried results are reported. Although Total Score differences were found on the Difficulties in Regulating Emotions Scale and the UCLA PTSD Reaction Index, analyses of the subscales of these measures were not conducted because they were estimated to be underpowered. However, no subscale analyses were needed to test the Hypotheses in this study.

\section{Step 4: PTSD Status vs. Trauma Group Status}

Step 4 of the analyses was conducted to test Hypothesis 5a, that a history of betrayal trauma would be a better predictor of negative communication than PTSD diagnosis. According to the scoring criteria of the PTSD Reaction Index, $17 \%$ of sample of adolescents (by parent-report) and $9.4 \%$ of the sample of adolescents (by adolescent-report) met criteria for a DSM-IV diagnosis of PTSD. Because this resulted in an insufficient number of participants meeting DSM-IV PTSD criteria to conduct a MANOVA, the sample was divided by a median split on the PTSD Reaction Index-AR Total Score (median = 19). In addition to 
making statistical sense, using a median split is a more conservative analysis than using the scale derived PTSD diagnosis. Hypothesis 5a proposed PTSD diagnosis would not be related to negative communication behavior or betrayal trauma history; as such, lowering the threshold for PTSD status would make it more likely that the hypothesis would be rejected. The Adolescent Report was used due to the problematic amount of missing data on the PTSD Reaction Index-PR. Two separate 2 Groups (Betrayal Trauma, Non-Betrayal Trauma) x 2 Level ( Low PTSD, High PTSD) MANOVAs were conducted to examine whether a history of betrayal trauma is related to problematic communication behaviors or perceived interpersonal conflict, regardless of the level of PTSD.

The first MANOVA used Group (Betrayal Trauma, Non-Betrayal Trauma) and PTSD Level (Low PTSD, High PTSD) as the independent variables, and total percent of Negative Aggressive, Negative Non-Aggressive, and Positive Communication Behavior exhibited during the High-Stress Task as the dependent variables. The MANOVA revealed a main effect of Group, $F(3,47)=3.0, p<.05, \eta_{p}^{2}=.16$, on overall Communication Behavior, specifically Negative Aggressive Communication Behavior, $F(1,49)=$ $4.0, p<.05, \eta_{p}^{2}=.08$, and Positive Communication Behavior, $F(1,49)=4.9, p<.05, \eta_{p}^{2}=.09$. The Betrayal Trauma Group exhibited a higher level of Negative Aggressive Communication Behavior and a lower level of Positive Communication Behavior, regardless of level of PTSD (Low/High). No main effect for PTSD Level was found, nor was there an interaction between Group and PTSD Level. Figure 3 provides a display of these results.

Separate ANOVAS were used for the Conflict Behavior Questionnaire-AR and Conflict Behavior Questionnaire-PR as the dependent variables. The same independent variables entered in the above analysis were entered for both ANOVA analyses: Group (Betrayal Trauma, Non-Betrayal Trauma) and PTSD Level (Low PTSD, High PTSD). Similar to the results of the behavioral measures, and corroborating Step 3, a Group effect was found for the Conflict Behavior Questionnaire-PR, $F(1,49)=$ $4.2, \mathrm{p}<.05, \eta_{p}^{2}=.08$, but not for the AR. No differences were found for PTSD Level and no interaction was found for either the AR or PR versions of the Conflict Behavior Questionnaire. 
Differences in betrayal trauma history were related to differences in communication behavior exhibited during a stressful interpersonal problem-solving task; however, level of PTSD status was not significantly related to this outcome. Corresponding with Step 2, betrayal trauma history did not lead to significantly more adolescent-reported perceived interpersonal conflict (Conflict Behavior Questionnaire). Importantly, no effects were found for level of PTSD; that is, experiencing a betrayal trauma, not higher level of PTSD symptoms, was related to problematic communication.

\section{Step 5: Predictors of Negative Communication and Perceived Conflict}

Step 5 of the analyses determined the best predictors of Negative Communication Behavior and perceived interpersonal conflict. These analyses test each component of Hypothesis 5, providing additional evidence for 5a (which was also tested in Step 4). Previous steps in the analyses established that experiencing a betrayal trauma, and not a higher level of PTSD symptoms, was significantly related to more problematic communication overall.Specifically, less Positive Communication Behavior and more Negative Communication Behavior, during a stressful interpersonal problem-solving task. Step 5 presents a series of analyses to determine which characteristics of trauma history best predict Negative Communication Behavior and perceived interpersonal conflict. This step is also designed to determine whether other variables, such as PTSD severity, PTSD diagnosis, or emotion regulation are better predictors of Negative Communication Behavior and perceived interpersonal conflict than trauma characteristics.

First, three separate series of Pearson (for continuous variables) and Spearman (for dichotomous variables) correlation analyses were conducted. The purpose of the first set of correlations was to determine the strength of the relation between seven trauma characteristics and three unique measures of interpersonal difficulties (Overall Negative Communication Behavior, Conflict Behavior QuestionnaireAR, and Conflict Behavior Questionnaire-PR). These analyses were needed to determine which trauma characteristics were appropriate to use as predictor variables in the subsequent regression analyses. The seven trauma characteristics were: Event Type (Interpersonal vs. only Non-Interpersonal events), Total 
Interpersonal Events, Event Perpetrator (Betrayal vs. Non-Betrayal), Total Betrayal Events, Total Incidents (regardless of event type), Total Interpersonal Incidents, Total Chronicity (regardless of event type), and Total Interpersonal Chronicity. The trauma characteristics were derived from the HPS (Jacoby \& Scotti, 2011). Total Incidents differs from Total Events in that Total Events accounts for only one incident of each kind of potentially traumatic event (e.g., car accident), whereas Total Incidents accounts for experiencing the same event multiple times (e.g., two car accidents). For example, an adolescent experiencing three physical assaults and two sexual assaults would get a Total Interpersonal Events score of 2, but would get a Total Interpersonal Incidents score of 5. Chronicity scores were calculated by multiplying the number of times an event occurred by the number of different age ranges (i.e., developmental periods) within which that event occurred. The age groups used to calculate chronicity were 0-4 years, 5-8 years, 9-12 years, 13-16 years, and 17-18 years. Chronicity scores can be calculated for total number of potentially traumatic events, non-interpersonal events only, interpersonal events only, and betrayal traumatic events only. Therefore, chronicity scores are not linked to one event, but across events. The detailed questions in the History of Psychosocial Stressors allows for examination of many trauma characteristics, both dichotomous and continuous. Only trauma characteristics that predicted at least one interpersonal difficulties outcome variable are reported here. The total percentage of Negative Communication Behavior (Negative Non-Aggressive plus Negative Aggressive) during the High-Stress task was used as the behavioral measure of interpersonal difficulties, as Step 2 of the analyses found a significant increase in both types of Negative Communication Behavior from the Low-Stress Task condition to the High-Stress Task condition for at least one group. Table 16 provides the correlations that were conducted.

The second series of correlations determined the relation between the PTSD Reaction Index-AR Total Score and diagnostic status with the same measures of interpersonal difficulties (see Table 16). The third series of correlations determined the strength of the relations of the same measures of interpersonal difficulties outcomes with a measure of emotion regulation. Only one measure of emotion regulation, the 
Difficulties in Emotion Regulation Scale-AR, was used (also shown in Table 16).

Next, those variables that significantly correlated with the interpersonal difficulties variables were entered into separate stepwise multiple regression analyses to determine the best predictors of each predictor type (i.e., Trauma Characteristic, PTSD Score, Emotion Regulation). All predictors that remained in the regression equation were considered as the "best" predictors. However, only one predictor variable type (i.e., one trauma characteristic, one PTSD score, one emotion regulation score) remained in each stepwise multiple regression that was conducted (see Table 17). By default, the Difficulties in Emotion Regulation Scale-AR Total Score was the best Emotion Regulation predictor, as it was the only emotion regulation measure used. Table 16 provides a listing of the best predictor for each predictor type for all three interpersonal difficulty outcome variables.

Best overall predictors. Finally, the best predictors of Overall Negative Communication Behavior (Betrayal Perpetrator, PTSD Total Score, and Difficulties in Emotion Regulation-AR), Conflict Behavior Questionnaire-AR (Total Incidents, PTSD Total Score, and Difficulties in Emotion Regulation Scale-AR), and Conflict Behavior Questionnaire-PR (Betrayal Perpetrator, PTSD Total Score, Difficulties in Emotion Regulation Scale-AR) were entered into three separate hierarchical regression analyses for the purpose of determining the best overall predictors of interpersonal difficulties. Again, all predictors that were not removed from the equation were considered the "best" predictors. PTSD Severity was entered first. Betrayal Perpetrator was entered second as it directly addresses the question of whether Betrayal Trauma History can predict Negative Communication Behavior during stressful interpersonal interactions, above and beyond having more severe PTSD symptoms (Hypothesis 3b). In other words, does PTSD effectively capture Overall Negative Communication Behavior on its own? The Difficulties in Emotion Regulation Scale Total Score was entered last to examine whether self-reported emotion regulation added to the prediction of Negative Communication Behavior, above and beyond that of PTSD severity and a history of betrayal trauma. 
The first of these regression analyses showed that: Betrayal Perpetrator, $\beta=.11, t(1)=1.99, p<$ .05 , and Difficulties in Emotion Regulation Scale-AR, $\beta=.11, t(1)=.003, p<.05$, significantly predicted Overall Negative Communication Behavior, $F(2,50)=9.0, p<.001, R^{2}=.27$. Total Incidents, $\beta=.12$, $t(1)=2.4, p<.05$, and Difficulties in Emotion Regulation Scale-AR Total Score, $\beta=.08, t(1)=3.1, p<$ .01 , significantly predicted the Conflict Behavior Questionnaire-AR, $F(2,50)=8.2, p=.001, R^{2}=.25$. Only the Difficulties in Emotion Regulation Scale-AR Total Score, $\beta=0.1, t(1)=4.1, p<.001$, significantly predicted the Conflict Behavior Questionnaire-PR, $F(1,51)=16.4, p<.001, R^{2}=.24$. Tables 15,16 , and 17 present the results of these analyses.

The results of the regression analyses suggest that experiencing a betrayal trauma event predicts Negative Communication Behavior, while PTSD severity and diagnosis (both via AR and PR) are not the best predictors of this outcome. Emotion regulation also remained a significant predictor of these outcomes, accounting for additional variance, above and beyond trauma history.

\section{Step 6: Identifying a Mediation Model}

The outcomes of the prior steps steered the course of the analyses conducted in Step 6. Having identified which aspects of trauma best predict Negative Communication Behavior, a series of mediation analyses were conducted to test the mediation role of emotion dysregulation (i.e., Difficulties in Emotion Regulation Scale) between trauma exposure and Negative Communication Behavior or perceived interpersonal conflict (Conflict Behavior Questionnaire). These analyses were conducted to examine Hypothesis 5 and to corroborate previous findings that emotion dysregulation strengthens the relation between trauma and negative interpersonal communication (Shields \& Cicchetti, 1998, 2001).

Bias-corrected bootstrapping conducted with INDIRECT (Preacher \& Hayes, 2008) was used to conduct the mediation analyses, as is recommended by Preacher and Hayes (2008) for small sample sizes (acceptable samples sizes as low as $n=20$ ). When trauma characteristics were examined in Step 5, only Betrayal Trauma History remained a significant predictor of Negative Communication Behavior. Therefore, this variable was used as the independent variable for the mediation analyses. The mediation 
analysis found the Difficulties in Emotion Regulation Scale total score to be a significant mediator in the relation between Betrayal Trauma History and Negative Communication Behavior, $F(2,50)=9.02, p<$ $.001, R^{2}=.27$ (see Figure 4).

A second set of analyses was planned to examine the moderation role of PTSD level (low vs. high) based on the PTSD Reaction Index-AR between Betrayal Trauma History and Negative Communication Behavior. This analysis was planned to further examine Hypothesis 3b. For this analysis, PTSD diagnosis was chosen to be analyzed as a moderator because the empirical question to be answered in this case was whether adolescents with interpersonal trauma histories have interpersonal conflict difficulties only in the context of diagnosable PTSD symptoms. However, Step 4 indicated that PTSD level was not significantly related to differences in Negative Communication Behavior, either on its own (i.e., main effects) or when accounting for Betrayal Trauma History (i.e., interaction effects). Therefore, it was decided that it was not appropriate to run this planned moderation analysis due to lack of statistical evidence to support the model.

\section{Chapter 5: Discussion}

\section{Overview and Implications of Findings}

The current study examined the relations between history of betrayal trauma, problematic interpersonal communication behavior, PTSD, and emotion regulation in adolescents. Although PTSD is the most well-known diagnosis for individuals who have difficulties after experiencing a traumatic event, research illustrates numerous difficulties and psychopathology that can result from trauma, many of which do not fit the DSM-IV (APA, 2000) criteria of PTSD. Specifically, severe, chronic, interpersonal, and betrayal trauma tends to have different pattern of effects on individuals (e.g., Briere \& Elliott, 2000; Cook et al., 2005; Freyd, 1996; Green et al, 1990; Herman, 1992; van der Kolk, 2003, 2007; van der Kolk et al., 1996; van der Kolk et al., 2005). Research has examined this unique pattern of responses and researchers have developed the construct of Developmental Trauma Disorder (also known as Complex PTSD) to explain this trajectory, although, this diagnosis is not yet recognized in the DSM 5. Two core components 
of Developmental Trauma Disorder include difficulty regulating one's emotions and problems with interpersonal functioning. Previous research has shown that children with interpersonal trauma histories experience problems with emotion regulation and interpersonal difficulties, and that these problems are related to each other (Shields \& Cicchetti, 1998, 2001). Self-Trauma Theory (Briere, 1997, 2002) makes sense of this relation, asserting that experiencing interpersonal trauma in childhood disrupts the development of emotion regulation skills, leaving one vulnerable to extreme emotional distress in response to future stressful events, especially in the context of interpersonal relationships. Consistent with prior research, the results of the current study support the conceptualization of emotion regulation problems and interpersonal dysfunction as stemming from early interpersonal trauma, perpetrated by a caregiver or close other. Consequently, the current study makes a novel contribution to the existing research by examining the relation between the betrayal traumatic events and interpersonal communication, the mediation role of emotion regulation, and the relation between this psychopathology and PTSD.

Hypothesis 1: Effect of Task. The current study tested six hypotheses. First, interpersonal communication was examined across the Betrayal Trauma and Non-Betrayal Trauma Groups. It was hypothesized that, on average, adolescents would exhibit more negative communication during a highstress interpersonal problem-solving task than a low-stress interpersonal problem-solving task (Hypothesis 1). Based on Individuation Theory (Youniss \& Smollar, 1985), discussing hypothetical positive events was thought to elicit low need for autonomy. Contrariwise, discussing past issues and disagreements at home likely would lead to high need for autonomy. This increase in need for autonomy was thought to increase the stressfulness of the task, which would then lead to more negative communication. It is also possible that the adolescent would have simply had less motivation to complete the hypothetical problem-solving task, and reduced interactions with their mother during the task overall, and engage in less communication behavior. However, this was not shown by the results of the analyses, as the adolescents actually interacted with their partner slightly more during the Low-Stress task than the 
High-Stress Task (3.2 minutes vs. 2.9 minutes). Regarding Hypothesis 1, the null hypothesis was rejected. Both groups of adolescents exhibited significantly more negative non-aggressive behavior during the High-Stress Task, engaging in behaviors such as defensiveness, quick rejection of their partner's solutions, and withdrawal from the task (See Appendix A for the full list of behaviors).

Hypothesis 2 examined the relation between experiencing betrayal trauma history and interpersonal difficulties. It was hypothesized that adolescents with a history of betrayal trauma would exhibit more negative communication than adolescents with no betrayal trauma history when activated by the high-stress interpersonal problem-solving task. It was also hypothesized that these adolescents would report having more interpersonal conflict with their mothers than adolescents without a betrayal trauma history, and that their mothers would similarly report more conflict with their child. Regarding Hypothesis 2, the null hypothesis was rejected. Adolescents with a betrayal trauma history increased both types of negative communication (aggressive and non-aggressive) from the low stress task to the highstress task. Although the adolescents without a history of betrayal trauma increased non-aggressive negative communication behaviors (e.g., eye rolling, defensiveness, negative self-talk), they did not exhibit an increase in aggressive communication behaviors (e.g., criticism, mocking/ridicule). Further, the adolescents without a betrayal trauma history exhibited an increase in positive communication behavior from the Low-Stress to High-Stress Task, while those with a betrayal trauma history had no change in positive communication behavior across the tasks. When engaged in stressful interpersonal experiences, adolescents with a trauma history, overall, may struggle to refrain from engaging in negative behaviors. However, adolescents without a betrayal trauma history "make up for" that behavior by also increasing positive behavior towards their partner, such as praise, active listening, use of I-statements, and compromise. Adolescents with a betrayal trauma history, however, may be unable to increase their positive communication behavior to make up for negative behavior when activated by an interpersonal interaction that is stressful. Instead, they tended to engage in more aggressive communication behaviors. This may be due to increased negative emotions, such as anger, easily triggered by stressful interactions 
(as indicated by the question on the Problem-Solving Reaction Scale about how upset they felt) paired with a struggle to regulate these strong emotions. It should be noted that the analysis that tested Hypothesis 2 was estimated to be underpowered. Therefore, the non-significant results may be due to small sample size, rather than true null results. For example, the Betrayal and Non-Betrayal Trauma groups may actually exhibit differences in communication behavior during the Low Stress Task, as well and not only the High Stress Task. However, the significant results that were found in this analysis despite the small sample size illustrate the large effects of these differences.

It is important to consider the behavior of the mothers during the problem-solving interactions, as the mother's behavior could have influenced the behavior of the adolescents. If mothers of adolescents with a betrayal trauma history communicated differently than mothers of adolescents without a betrayal trauma, group differences in the adolescents' behavior could have been a function of their reaction to their mothers, rather than a function of their trauma history. However, this was not the case in this sample, as mother's communication behavior was not related to their child's trauma history. Therefore, group differences in communication behavior were likely not a function of the way in which their mothers communicated with them. Instead, mothers' overall communication behavior, across group and behavior type, increased from the Low-Stress to the High-Stress Task. It was therefore only mother's overall communication behavior during each task that was controlled for, as the increase in mother's behavior may have affected the change in the communication behavior of the adolescent, across groups, from the Low- to High-Stress Tasks. However, even after controlling for the communication behavior of the mothers, the pattern of the adolescents' behavior remained the same. It is therefore likely that adolescent behavior was not simply a function of the behavior of the mothers. It is important to note that, as the same analysis was conducted as with the adolescent's behavior, this analysis was underpowered. Therefore, there may truly be Trauma Group differences in mother's behavior during these tasks.

Betrayal trauma history was also found to be related to the parent-report of mother-adolescent conflict, which matches with the behavioral observation of communication. However, contrary to the 
results of the behavioral observation of interpersonal conflict (i.e., communication behavior), there were no group differences found on the self-report of the adolescents about their perception of conflict between themselves and their mothers. Similar results emerged for the parent-report of mother-adolescent conflict. These results suggest that, for adolescents, self-report of conflict and a behavioral measure of conflict in a lab may represent different constructs. For example, although the behavioral task may represent conflict in the moment, the self-report may reflect the general, overall relationship between the mother and adolescent. Therefore, even though a mother and adolescent with a history of betrayal trauma may engage in more conflict when discussing stressful issues, they may not perceive that they have an overly conflictual relationship with their mothers. Another possibility is that while a lab observation may be a more internally valid measure of conflict in a particular situation, the self-report of adolescents may be a more externally valid measure of overall conflict over the course of a week. It is also possible that adolescents may have been biased by social desirability or may have been concerned that their mothers (who were in the next room) would see the answers to their questions, despite being assured that this would not happen. Finally, the discrepancy could be a product of the problems associated with retrospective recall or the recency effect. Adolescents completed the Conflict Behavior Questionnaire before engaging in the problem-solving task, soon after they arrived for the study. The fact that the adolescent and mother were currently in the process of doing something cooperative and charitable together at that moment (i.e., participating in the research study) may have influenced their recall regarding conflict between them during the past two weeks. This could reveal a potential selection bias, in that adolescents in those dyads who chose to participate in the study may perceive their relationship with their mothers as less conflictual than those who chose not to participate. Nevertheless, a significant level of perceived conflict was found in the current study.

Hypothesis 3: Effect of group on emotion regulation. Hypothesis 3 proposed that adolescents with a history of betrayal trauma would report more difficulty regulating their emotions than adolescents with other types of trauma. This hypothesis was based on previous research which established that 
children with a history of interpersonal traumatic events experience problems with emotion regulation (e.g., Plattner et al., 2007; Shields \& Cicchetti, 1998, 2001). This hypothesis also coincides with research regarding the validation of Developmental Trauma Disorder, which recognizes emotion regulation problems as a core component of this disorder. Regarding Hypothesis 3, the null hypothesis was rejected. Adolescents with a history of betrayal trauma reported more difficulties in regulating their emotions than did their peers without a betrayal trauma history. The large effect sizes of these findings illustrate the clear and clinically significant differences between these groups.

Hypothesis 4: Effect of group on PTSD. PTSD severity in relation to betrayal trauma history was examined in Hypothesis 4. This hypothesis asserted that adolescents with a history of betrayal trauma would have higher reported PTSD severity than adolescents with history of only non-betrayal traumatic events. Previous research has illustrated that individuals with betrayal trauma histories tend to report more severe PTSD symptoms than those with non-betrayal trauma histories (Freyd et al., 2005; Shin Tang \& Freyd, 2012). Regarding this hypothesis, the null hypothesis was rejected. Adolescents with a history of betrayal trauma reported having more severe PTSD symptoms than those with non-betrayal trauma histories, which replicates previous findings.

Hypothesis 5: Predictors of interpersonal difficulties. Hypothesis 5 sought to understand the predictors of problematic interpersonal conflict outcomes. This examination was based on previous research that has established that specific aspects of one's trauma history can predict the nature and severity of one's reaction to their traumatic experiences, including aspects of interpersonal dysfunction (e.g., Briere et al., 2008; Cloitre et al., 2009; Roth et al., 1997; van der Kolk, 2005; van der Kolk et al., 1996), and that emotion regulation mediates this relation (Shields \& Cicchetti, 1998, 2001). PTSD has also been shown to be related to problematic relationship functioning (Allen et al., 2010). Based on knowledge gained from the PTSD field trial studies (van der Kolk et al., 2005), it was hypothesized that experiencing a betrayal trauma and emotion regulation difficulties would be better predictors of interpersonal difficulties than PTSD status. It was also hypothesized that the chronicity of an adolescent's 
traumatic experiences would predict problematic interpersonal functioning outcomes. Three separate outcomes (one behavioral measure and two self-/parent-report measures) were examined: overall negative communication behavior, adolescent's perception of parent-adolescent conflict, and mother's perception of parent-adolescent conflict. These outcomes reflected three aspects of possible problems with interpersonal functioning. Separating these outcomes was exploratory; it was unknown whether these variables would represent similar constructs and would be predicted by the same predictor variables, or if they represented different constructs and would be differentially predicted by different aspects of traumatic experiences or psychopathology (i.e., problems regulating emotions, PTSD symptoms). For most of the components of Hypothesis 5, the null hypothesis was rejected (i.e., components 5a through $5 \mathrm{e})$.

Only the perpetrator of a trauma (i.e., experiencing at least one betrayal trauma) predicted overall negative communication (combining both the aggressive and non-aggressive types). Contrary to previous research, the number of betrayal trauma events was not related to overall negative communication nor was the number of interpersonal trauma (regardless of perpetrator), or having experienced more chronic trauma (e.g., Briere et al., 2008; Cloitre et al., 2009; Roth et al., 1997).

Similar to overall negative communication behavior, only the perpetrator of the trauma (betrayal trauma) predicted parent-reported mother-adolescent conflict. This outcome coincides with the findings of Hypothesis 2, which indicated that mothers of adolescents with betrayal trauma histories tended to report having more conflict with their adolescent. Again, similar to overall negative communication behavior, trauma type (i.e., Non-Interpersonal vs. Interpersonal, regardless of perpetrator), accumulation of interpersonal trauma, accumulation of betrayal trauma, and trauma chronicity were not related to mother's report of conflict. These findings provide preliminary evidence that mother's perception of conflict with her adolescent and an actual observation of that adolescent's behavior could represent similar constructs.

The trauma characteristic predictors of adolescent-report of mother-adolescent conflict did not match the other outcome variables. Instead, the total incidents of traumatic events, regardless of trauma 
type or perpetrator, was the best trauma characteristic in predicting adolescent-reported conflict. This mismatch of adolescent report makes sense conceptually. Mothers may focus their report of conflict on their adolescent's behavior (which is what is being measured, behaviorally, in this study). In the same way, adolescents may be focusing on their retrospective recall of their mother's behavior, which may not necessarily match their behavior during interpersonal interactions. Data from this study support this, as the behavior of the mothers was shown not to difference between the two groups. Therefore, an adolescent's perception of conflict with their interaction partner, at least as measured by the Conflict Behavior Questionnaire, may not be an accurate representation of their behavior nor of their contribution to interpersonal conflict.

Adolescents' report of the severity of their PTSD symptoms successfully predicted all outcomes of interpersonal difficulties. This indicates that as adolescents experience more frequent reexperiencing of their trauma and become more hyperaroused as a response to stimuli, they may have more difficulty communicating with others in an effective way. Additionally, they may avoid interacting with people they are close to and situations that would allow them to connect with those close to them (in this case, their mothers). However, PTSD diagnosis failed to predict behavioral outcomes of interpersonal difficulties, and failed to predict participant-reported outcomes above and beyond PTSD severity when both variables were examined together. This implies that, while more severe PTSD symptoms may predict problems with interpersonal functioning, one likely does not need to meet DSM-IV PTSD criteria to experience clinically significant interpersonal dysfunction, necessitating treatment. Like PTSD severity, adolescents' report of difficulty regulating their emotions successfully predicted each outcome of interpersonal difficulties. This suggests that as adolescents struggle to control and make sense of, and limit the intensity of their emotional states, it becomes more difficult to productively communicate and mitigate conflict with others. These findings are consistent with previous research regarding the relation between interpersonal functioning and PTSD (e.g., MacDonald, Chamberlain, Long, \& Flett, 1999), as well as interpersonal functioning and emotion regulation (e.g., Plattner et al. 2007). 
Importantly, when PTSD severity, the most predictive trauma characteristic, and emotion regulation were examined together, PTSD failed to predict interpersonal difficulties above and beyond trauma characteristics and emotion regulation. For almost all of the interpersonal difficulty outcomes, excluding parent-reported conflict, emotional regulation coupled with the most predictive trauma characteristic for that outcome best predicted that outcome. This finding is made stronger by the fact that PTSD severity was entered into the prediction equation first, before the appropriate trauma characteristic. For PTSD severity to be removed from the equation, the trauma characteristic (or the trauma characteristic plus emotion regulation) must predict the interpersonal difficulties outcome better than if the PTSD severity variable were a part of the equation. Therefore, while one may be able to predict an adolescent's negative communication behavior or reported conflict with their mothers using only information about their PTSD symptoms, it is likely more important to understand the adolescent's trauma history as well as how well they believe they can regulate their emotions. This finding highlights the importance of using a trauma-informed assessment, with the knowledge that the effects of trauma are not limited to PTSD symptoms, and the response to trauma may or may not "look like" PTSD. It also suggests that trauma-focused treatments may be appropriate for children and adolescents with a trauma history who are experiencing interpersonal difficulties or emotion regulation difficulties, regardless of the presence or severity of PTSD symptoms.

Unlike the other outcome variables, the most predictive trauma characteristic of parent-reported mother-adolescent conflict (i.e., Perpetrator) failed to remain a successful predictor after accounting for emotion regulation difficulties. Instead, adolescents' self-report of their difficulties in regulating emotions was the only remaining significant predictor of their parents' reported mother-adolescent conflict. Preliminary evidence (discussed previously) suggested that parent-reported mother-adolescent conflict may be an acceptable proxy for a behavioral measure of an adolescent's overall negative communication, yet may lack specificity in differentiating between and adolescent's tendency to engage in aggressive versus only non-aggressive behaviors. However, the findings from the analyses of the combined 
predictors do not support that interpretation. The fact that betrayal trauma remained a successful predictor of overall negative communication yet failed to do so for parent-reported conflict, suggests that these variables may represent distinct constructs and cannot be used interchangeably. Indeed, these results may further reveal the lack of specificity of this measure. Results from the examination of Hypothesis 3 determined that adolescents with a betrayal trauma history reported significantly more emotion regulation difficulties, with large effect sizes showing the magnitude of these differences. Yet, to speculate, there may be a subgroup of adolescents in the non-betrayal trauma group who report somewhat higher emotion regulation difficulties than their same trauma-group peers, yet less than the betrayal trauma group. This hypothetical "subgroup" that experiences somewhat more emotion regulation difficulties may be able to be differentiated from the betrayal trauma group with a behavioral measure of interpersonal conflict. However, parents of this "sub-group" may describe their adolescents the same as the parents of the betrayal trauma group due to a ceiling effect. In other words, at a certain level of emotion dysregulation, the relation between emotion regulation and interpersonal conflict may taper off, at least as measured by the Conflict Behavior Questionnaire.

The final component of Hypothesis 5 proposed that adolescents' report of chronic trauma exposure would predict problematic interpersonal functioning. For this component of Hypothesis 5, the results failed to reject the null hypothesis. It is possible that the measure of chronicity used in this study was not sensitive enough to capture any effect of chronicity in this sample. The sample in the study that found predictive validity of the chronicity scale in this measure (Jacoby \& Scotti, 2011) consisted of over 600 young adult college student participants. The power in that previous study allowed for the detection of smaller effects, and because the participants were adults, chronicity scores tended to be of a broader range.

\section{Hypothesis 6: Best model of trauma, emotion regulation, and interpersonal difficulties.}

Lastly, Hypothesis 6 tested a mediation model of the relations between Betrayal Trauma, Emotion Regulation, and Negative Communication Behavior. These variables were chosen a priori, as previous 
research has established this relation (Shields \& Ciccetti, 2001). Yet, the tested variables were also chosen statistically, as the results of analyses from Hypothesis 5 indicated that both trauma perpetrator and emotion regulation difficulties were the best predictors of negative communication behavior. Hypothesis 6 was supported. Emotion regulation mediated the relation between betrayal trauma and negative communication. This study supports the previous finding by Shields and Cicchetti $(1998,2001)$ and adds additional knowledge to this research area by using a behavioral measure of interpersonal conflict.

Theoretically, the findings from this study are consistent with developmental psychopathology theories of emotion regulation. In line with Self Trauma Theory (Breire, 1997, 2002), adolescents who experienced a childhood trauma perpetrated by someone they relied on for physical or emotional support are likely to struggle with these self-capacities. This then leads them to struggle in their relationships with others (Foa \& Kozak, 1986). The results of this study also add additional support to the increasing empirical evidence for the addition of Developmental Trauma Disorder in the next version of the DSM. The clear differences in emotion regulation difficulties and interpersonal communication behaviors revealed in this study illuminate the differences between adolescents who have been betrayed by a loved one or caregiver as compared to adolescents without such a history. The fact that these problems did not clearly relate to PTSD diagnoses support the notion that these difficulties cannot be explained by, and may look quite different from PTSD. Indeed, the experience of trauma that results in failure to appropriately develop emotion regulation skills, as theorized by Briere $(1997,2002)$ and Fonagy et al. (2003), can be expected to lead to different clinical outcomes than the experience of a trauma by an adolescent who has already established a secure attachment to a caregiver and has previously developed adequate emotion regulation skills. Clearly then, trauma-informed assessment must include not only items related to the symptoms of PTSD, but also items related to emotion regulation skills and interpersonal difficulties, as well as the other symptoms of Developmental Trauma Disorder and Complex PTSD. When children and adolescents present with these mental health problems, clinicians should assess whether these difficulties may be related to their potential interpersonal or betrayal trauma history. The 
results of this study also provide implications for the treatment of children and adolescents with emotion regulation deficits and interpersonal problems. These individuals would likely benefit from treatment that focuses on reducing these symptoms, but are trauma focused. Such treatments include TARGET for adolescents (Frisman, Ford, Lin, Mallon, \& Chang, 2008), and Dialectical Behavior Therapy (Linehan, 1993). The effectiveness of these evidence-based treatments suggest that, although early learning of these skills is important, these are skills that can be successfully taught overtly through therapy, even when the learning of these skills was disrupted by traumatic experiences.

\section{Strengths and Limitations}

The current study has several strengths. In terms of methodology, it utilized a behavioral measure of interpersonal conflict and compared it with self- and parent-report measures of interpersonal conflict. These multimodal assessments allowed the execution of analyses to tease apart whether betrayal trauma is actually related to more aggressive and problematic interpersonal behavior, or if they are only perceived do to so by themselves or others. In other words, it was possible to examine concurrent validity. The methodology was also enhanced by using a within-subjects manipulation of the stressfulness of the interpersonal problem-solving task. With this manipulation, one can be more confident that changes in communication behavior were due to differences in the independent variables.

The current study adds to the conceptual understand of the findings in this literature. Although prior research has examined interpersonal conflict and emotion regulation in individuals with interpersonal as compared to non-interpersonal events, the current study parsed out possible effects of the perpetrator of a traumatic event.. This allowed for interpretation of whether these symptoms are related to only the interpersonal nature of the events, or if the perpetrator of the interpersonal event is a more important component of these problematic outcomes. Additionally, the current study assessed and compared PTSD severity and diagnosis with emotion regulation and interpersonal difficulties.

Consequently, it was possible to determine whether significant problematic interpersonal behavior and emotion regulation difficulties stemming from traumatic events tend to occur only in the context of a 
PTSD diagnosis, or if these difficulties are just as likely to be exhibited without a PTSD diagnosis. This is an important empirical question. The results of this inquiry support the utilization of trauma-informed assessment, even when children and adolescents do not present with clear PTSD symptoms, and that children without PTSD but with significant emotion regulation and interpersonal difficulties may benefit from trauma-informed mental health treatment if they have experience a traumatic event.

One limitation to the methodology of this study is the lack of masked coding for $65 \%$ of the sample, which allows for a greater likelihood of investigator bias. Importantly, a random $25 \%$ of the data was double coded with adequate reliability. A second methodological limitation is the use of the History of Psychosocial Stressors as a measure of potentially traumatic life stressors of the adolescent. Although the HPS is in the process of being validated, a gold standard life stress measure that utilizes contextual information when rating the impact of life stressors, such as the Youth Life Stress Interview (Rudolph \& Flynn, 2007), would have yielded a more thorough assessment of potentially traumatic events in this study. Although the current study used a dichotomous yes/no rating of trauma and trauma type, this method yielded multiple significant results. A third limitation relates to research design. Ideally, a study examining these factors would have four groups: No Trauma Group, Non-Interpersonal Trauma Group, Interpersonal (Non-Betrayal) Trauma Group, and Betrayal Trauma Group. This would allow for cleaner comparisons between those with betrayal trauma and interpersonal non-betrayal trauma, as well as comparisons between interpersonal non-betrayal trauma and non-interpersonal trauma. Additionally, a No Trauma Group would allow for comparisons between all of these groups with a healthy comparison group. However, a small sample size prohibited this design. The small sample size in this study also raises a fourth limitation, in regards to the large number of analyses conducted without $p$ value adjustments (e.g., Bonferroni corrections). This increases the probability of a Type 1 error. Further, with the current sample size, power analyses estimated that only large effect sizes would show significant differences. Although large effect sizes have been found on the key measures in previous studies, it is possible that some true differences exist that were not found in this study. Additionally, some analyses were estimated 
to be underpowered (i.e., repeated measures MANOVA in Step 2). Therefore, these analyses could only be exploratory in nature and should be interpreted with caution, particularly the null result regarding the differences in mother's behavior. However, the medium to large effect sizes found in the majority of the analyses in this study reflect meaningful differences.

The fact that a low rate of PTSD diagnosis was found in this sample prevented the use of PTSD diagnosis as in independent variable in the $2 \times 2$ between-groups MANOVA. Using an actual diagnosis of PTSD would have allowed for a more accurate examination of the interrelations between PTSD diagnosis, trauma group status, and communication behavior, as was examined in Step 4. However, the use in this study of High vs. Low PTSD Status as a substitute variable was actually a more conservative analysis of Hypothesis 5a. High vs. Low status was calculated using a median split of the PTSD Total Score, which was 19 points (the cutoff score for "Probable PTSD" on this measure is 38). This lower score is more likely to obtain PTSD Status differences in communication behavior, with the possibility of a Betrayal Trauma Group x PTSD Status interaction. This more conservative analysis allows one to be more confident that PTSD diagnosis (and likely not even sub-threshold PTSD) is necessarily related to problematic communication behavior during a stressful interpersonal task. It is possible that, if a true PTSD group was available, or if the sample size in this study was larger, PTSD status differences would be found. Though, this is unlikely, given the lack of predictability that was found for PTSD diagnosis and severity in the multiple regression analyses.

Another challenge for this study is related to the study participants. The adolescents in the Betrayal Trauma Group, by definition, experienced an interpersonal trauma perpetrated by someone living in their home. Although none of the mothers participating in the study were engaging in abusive or neglectful behaviors toward their child at the time of the study, several adolescents reported either neglect or substance use by their mothers which resulted in them having been removed from their home in the past. One adolescent reported corporal punishment by her mother that was very distressing to her (which Child Protective Services concluded as non-reportable after consulting with the family using no 
identifiable data). Additionally, although no mothers were reported to be the direct perpetrators of sexual abuse in this sample of adolescents, it may be argued in some cases that the mothers failed to protect the adolescents from the perpetrator, or at least were perceived that way by the adolescents. This, in turn, may limit the generalization of these findings to their interpersonal communication with their mothers. To account for this confound, a study may have to use strict exclusion criteria in defining the nature of the betrayal trauma. This, however, would be very challenging as betrayal trauma and who is accountable for the perpetration is very much nuanced.

A final limitation to this study is the questionable validity found in the parent-report of their adolescent's PTSD symptoms. This may be due to problematic methodology when giving the assessment measures. However, the high rate of mothers reported I don't know on the PTSD Reaction Index may highlight the mother's lack of knowledge and insight regarding their child's symptoms. This knowledge is important for both research and clinical reasons. If parents, in general, tend to have limited awareness of their child's psychopathology, it creates questions about the validity of using parent-report measures for research purposes. In the same vain, parent's lack of awareness that their child is struggling with traumatic stress symptoms is concerning, as it decreases the likelihood that these children will have access to mental health treatment.

\section{Future Directions}

Replication of the current study, using masked coding for $100 \%$ of the data would be valuable. Additionally, if this replication utilized a larger sample size, the four "ideal" groups discussed above could be compared, which would allow for cleaner analyses and more specific aspects of trauma characteristics (e.g., non-interpersonal vs. non-betrayal interpersonal groups) could be compared. Replication with a larger sample size may also allow comparisons to be made between adolescents with and without a true PTSD diagnosis, possibly even using the Clinician-Administered PTSD Scale for Children and Adolescents, the gold-standard PTSD diagnostic interview (Newman et al., 2004). Further, this replication should utilize DSM 5 PTSD criteria. 
As with the majority of existing research examining the effects of potentially traumatic events, this study was cross-sectional and partially retrospective. Therefore, one cannot make causal interpretations about the relation between traumatic events and the "outcomes" that were examined. As in any crosssectional, quasi-experimental study, causation and directionality can only be speculated, using theory as the backbone for the interpretation. For example, in the current study, emotion regulation was examined as a mediator between betrayal trauma and negative communication behavior. As Kramer, Stice, Kazdin, Offord, and Kupfer (2001) discuss, to be a mediator, the predictor variable must temporally predict the potential mediator. However, this is not easily done in cross-sectional research. It is particularly difficult in children and adolescents because, as children develop, emotion regulation skills naturally change and mature. Establishing temporal precedence would thus be quite a challenge, especially retrospectively. Also, although $27 \%$ of the variance was accounted for with this model, there are, of course, other important variables that contribute to emotion regulation skill deficits and interpersonal difficulties not able to be measured here. Behaviors also could be modeled through aspects of the adolescent's environment, such as through peer groups or with other individual in the home. For example, ridiculing or mocking someone during an interpersonal interaction could be modeled within the adolescent's peer group. However, analyses of the behavior of the mothers showed that maternal modeling of negative interpersonal behaviors was not occurring during the problem-solving tasks. Still, the mediator model illustrated in the current study is valuable, as it accounts for $27 \%$ of the variance in the relation between betrayal trauma and negative communication, which is a meaningful proportion of the variance in social science research. This limitation could be addressed in future research by conducting a longitudinal, prospective study. This type of study would likely be an intensive process, requiring a large sample size followed over decades. Yet, cross-sectional research examining these trajectories is still quite valuable, as an understanding of potential differential trajectories and outcomes must be obtained in cross-sectional studies first, to guide future longitudinal studies on which outcomes to measure (Kramer et al., 2001). 


\section{Conclusions}

Despite limitations, this study contributes to the literature on the relation between interpersonal difficulties, emotion regulation, and PTSD in adolescents with a history of betrayal trauma. The results of this study demonstrate that adolescents with a history of betrayal trauma exhibit more interpersonal difficulties, as evidenced by problematic communication with their mothers during an interpersonally stressful problem-solving task. Further, mothers of adolescents with betrayal trauma report more conflict with their adolescent than adolescents with only other types of potentially traumatic events. These findings corroborate previous research showing that those with interpersonal trauma exhibit more emotion regulation and interpersonal difficulties, while also adding knowledge to this literature. However, these results show that it may be the betrayal aspect of the trauma, rather than only the interpersonal nature of the trauma, that contributes to more severe interpersonal difficulties. This study also provided evidence that, although PTSD severity does predict interpersonal difficulties, adolescents experience clinically significant problems with emotion regulation and problematic interpersonal functioning regardless of a PTSD diagnosis. Finally, this study presents evidence that lack of emotion regulation stills mediates the relation between experiencing a betrayal trauma and engagement of problematic interpersonal behaviors. Together, these findings add to the body of literature supporting Developmental Trauma Disorder as a useful diagnosis.

The current study provides knowledge that may guide clinical assessment and treatment planning. Given the findings of prior research and the results presented here, it is important to use trauma-informed assessments when assessing for a wide range of psychopathology in children and adolescents. It is also important to consider that children who present to therapy with emotion regulation problems and interpersonal difficulties may have experienced a traumatic event, particularly an interpersonal or a betrayal trauma. Essentially, the function of, and contingencies maintaining, these behaviors in children and adolescents exposed to a betrayal trauma are likely different from those seen in children who exhibit these same behaviors who do not have such a trauma history. For example, parent training may be an 
appropriate stand-alone intervention for a child without a trauma history whose negative externalizing behaviors are being maintained through parental reinforcement. However, a primary or important additional component of the conceptualization of the same symptoms for a child who has experienced a betrayal trauma may be that parents and loved ones are a traumatic conditioned stimulus, thus leading to emotionally dysregulated behavior in the context of interpersonal interactions. These two symptom conceptualizations would, obviously, lead to different treatment plans, the latter of which should address the child's trauma history. Therefore, appropriate treatment for these children requires trauma-informed care that addresses and targets a child's ideographic symptoms as well as how they relate to the child's trauma history. 


\section{References}

Abe, K., \& Suzuki, T. (1986). Prevalence of some symptoms in adolescence and maturity: Social phobias, anxiety symptoms, episodic illusions and ideas of reference. Psychopathology, 19, 200-205.

Ackerman, P.T., Newton, J. E., McPherson, W. B., Jones, J. G., \& Dykman, R. A. (1998). Prevalence of posttraumatic stress disorder and other psychiatric diagnoses in three groups of abused children (sexual, physical, and both). Child Abuse and Neglect, 22, 759-774.

Adler, A. B., Wright, K. M., Bliese, P. D., Eckford, R., \& Hoge, C. W. (2008). A2 diagnostic criterion for combat-related posttraumatic stress disorder. Journal of Traumatic Stress, 21, 301-308.

Adrian, M., Zeman, J., Erdley, C., Lisa, L., \& Sim, L. (2011). Emotional dysregulation and interpersonal difficulties as risk factors for non-suicidal self-injury in adolescent girls. Journal of Abnormal Child Psychology, 39, 389-400.

Ainsworth, M. D. S., Blehar, M. C., Waters, E., \& Wall, S. (1978). Patterns of attachment: A psychological study of the strange situation. Hillsdale, NJ: Erlbaum.

Allen, E. S., Rhoades, G. K., Stanley, S. M., \& Markman, H. J. (2010). Hitting home: Relationships between recent deployment, posttraumatic stress symptoms, and marital functioning for army couples. Journal of Family Psychology, 24, 280-288.

American Psychiatric Association. (1987). Diagnostic and statistical manual of mental disorders (3rd ed., revised). Washington, DC: Author.

American Psychiatric Association. (2000). Diagnostic and statistical manual of mental disorders (4th ed., text revision). Washington, DC: Author.

American Psychiatric Association. (2013). Diagnostic and statistical manual of mental disorders (5th ed.). Washington, DC: Author.

Anders, S. L., Frazier, P. A., \& Frankfurt, S. (2011). Variations in criterion A and PTSD prevalence rates and symptoms. Journal of Anxiety Disorders, 25, 176-184. 
Anders, S. L., Shallcross, S. L. \& Frazier, P. A. (2012). Beyond criterion A1: The effects of relational and non-relational traumatic events, Journal of Trauma \& Dissociation, 13, 134-151.

Bedard-Gilligan, M. \& Zoellner, L. A. (2008). The utility of the criteria A1 and A2 stressors in the diagnosis of PTSD. Behaviour Research and Therapy, 46, 1062-1069.

Beijersbergen, M. D., Bakermans-Kranenburg, M. J., van Ijzendoorn, M. H., \& Juffer, F. (2008). Stress regulation in adolescents: Physiological reactivity during the adult attachment interview and conflict interaction. Child Development, 79, 1707 - 1720.

Blos, P. (1979). The adolescent passage. Madison, WI: International University Press.

Bowlby, J. (1969). Attachment and loss, Vol. I. London: Hogarth Press.

Bowlby, J. (1973). Attachment and loss: Separation, Vol. II. New York: Basic Books.

Breslau, N., Kessler, R. C., Chilcoat, H. D., Schultz, L. R., Davis, G. C., \& Andreski, P. A. (1998). Trauma and posttraumatic stress disorder in the community. Archives of General Psychiatry, 55, $626-632$.

Brewin, C. R., Andrews, B., \& Valentine, J. D. (2000). Meta-analysis of risk factors for posttraumatic stress disorder in trauma-exposed adults. Journal of Consulting and Clinical Psychology, 68, 748766.

Briere, J. (1997). Treating adults severely abused as children: The Self-Trauma Model. In D. A. Wolfe, B. McMahon, \& R. D. Peters (Eds.), Child abuse: New directions in treatment and prevention across the lifespan. Newbury Park, CA: Sage.

Briere, J. (2002). Treating adult survivors of severe childhood abuse and neglect: Further development of an integrative model. In J. E. B. Myers, L. Berliner, J. Briere, T. Reid, \& C. Jenny (Eds.). The APSAC handbook on child maltreatment, 2nd Edition. Newbury Park, CA: Sage Publications.

Briere, J. (2004). Psychological assessment of adult posttraumatic states: Phenomenology, diagnosis, and measurement, 2nd edition. Washington, D.C.: American Psychological Association.

Briere, J. (2006). Dissociative symptoms and trauma exposure: Specificity, affect dysregulation, and 
posttraumatic stress. Journal of Nervous and Mental Disease, 194, 78-82.

Briere, J., \& Elliott, D. M. (2000). Prevalence, characteristics, and long-term sequelae of natural disaster exposure in the general population. Journal of Traumatic Stress, 13, 661-679.

Briere, J., Hodges, M., \& Godbout, N. (2010). Traumatic stress, affect dysregulation, and dysfunctional avoidance: A structural equation model. Journal of Traumatic Stress, 23, 767-774.

Briere, J., Kaltman, S., \& Green, B. L. (2008). Accumulated childhood trauma and symptom complexity. Journal of Traumatic Stress, 21, 223-226.

Calkins, S. D., Gill, K., Johnson, M. C., \& Smith, C. (1999). Emotional reactivity and emotion regulation strategies as predictors of social behavior with peers during toddlerhood. Social Development, 8 , 310-341.

Catanzaro, S. J., \& Mearns, J. (1990). Measuring generalized expectancies for negative mood regulation: Initial scale development and implications. Journal of Personality Assessment, 54, 546-563.

Charuvastra, A., \& Cloitre, M. (2008). Social bonds and posttraumatic stress disorder. Annual Review of Psychology, 59, 301-328.

Cloitre, M., Kline, N. S., Stolbach, B. C., Herman, J. L., van der Kolk, B., \& Pynoos, R. (2009). A developmental approach to complex PTSD: Childhood and adult cumulative trauma as predictors of symptom complexity. Journal of Traumatic Stress, 22, 399-408.

Cohen, J. (1988). Statistical power analysis for the behavioral sciences. Hillsdale, NJ: Erlbaum.

Collins, W. A., \& Laursen, B. (2004). Parent-adolescent relationships and influence. In R. Lerner \& L. Steinberg (Eds.). Handbook of adolescent psychology (pp. 331-362). New York: Wiley.

Compas, B. E., Orosan, P. G., \& Grant, K. E. (1993). Adolescent stress and coping: Implications for psychopathology during adolescence. Journal of Adolescence, 16, 331-349.

Cook, A., Spinazzola, J., Ford, J., Lanktree, C., Baustein, M., Cloitre, M., et al. (2005). Complex trauma in children and adolescents. Psychiatric Annals, 35, 390-398.

Copeland, W. E., Keeler, G., Angold, A., \& Costello J. (2007). Traumatic events and posttraumatic stress 
in childhood. Archives of General Psychiatry, 64, 577-584.

Costello, E. J., Erkanli, A., Fairbank, J. A., \& Angold, A. (2002). The prevalence of potentially traumatic events in childhood and adolescence. Journal of Traumatic Stress, 15, 99-112.

Crowley (2007). Memories of childhood sexual abuse: Narrative analyses of types, experiences, and processes of remembering. Journal of Interpersonal Violence, 22, 1095-113.

de Vries, G. J., \& Olff, M. (2009). The lifetime prevalence of traumatic events and posttraumatic stress disorder in the Netherlands. Journal of Traumatic Stress, 22, 259-267.

DiLillo, D., Peugh, J., Walsh, K., Panuzio, J., Trask, E., \& Evans, S. (2009). Child maltreatment history among newlywed couples: A longitudinal study of marital outcomes and mediating pathways. Journal of Consulting and Clinical Psychology 77, 680-692.

Dorrington, S., Zavos, H., Ball, H., McGuffin, P., Rijsdijk, F., Siribaddana, S., et al. (2014). Trauma, post-traumatic stress disorder and psychiatric disorders in a middle-income setting: Prevalence and comorbidity. British Journal of Psychiatry, 10, 1-7.

Eaton, L. K., Kann, L., Kinchen, S., Shanklin, S., Ross, J., Hawkins, J., et al. (2008). Youth Risk Behavior Surveillance: United States, 2007, surveillance summaries. Morbidity and Mortality Weekly Report, 57, 1-31.

Ellis, B. H., Lhewa, D., Charney, M., \& Cabral, H. (2006). Screening for PTSD among Somali adolescent refugees: Psychometric properties of the UCLA PTSD Index. Journal of Traumatic Stress, 19, $547-551$.

Finkelhor, D., Ormrod, R. K., Turner, H. A., \& Hamby, S. L. (2005). Measuring poly-victimization using the Juvenile Victimization Questionnaire. Child Abuse \& Neglect, 29, 1297-1312.

Foa, E. B., \& Kozak, M. J. (1986). Emotional processing of fear: Exposure to corrective information. Psychological Bulletin, 99, 20-35.

Fonagy, P., Target, M., Gergely, G., Allen, J., \& Bateman, A. W. (2003). The developmental roots of borderline personality disorder in early attachment relationships: A theory and some evidence. 
Psychoanalytic Inquiry, 23, 412-459.

Ford, J. D. (1999). Disorders of extreme stress following war-zone military trauma: Associated features of posttraumatic stress disorder or comorbid but distinct syndromes? Journal of Consulting and Clinical Psychology, 67, 3-12.

Freyd, J. J. (1994). Betrayal trauma: Traumatic amnesia as an adaptive response to childhood abuse. Ethics and Behavior, 4, 307-329.

Freyd, J. J. (1996). Betrayal trauma: The logic of forgetting childhood abuse. Cambridge, MA: Harvard University Press.

Freyd, J. J. (1999). Blind to betrayal: New perspectives on memory for trauma. The Harvard Mental Health Letter, 15, 4-6.

Freyd, J. J. (2001). Memory and dimensions of trauma: Terror may be 'all-too-well remembered' and betrayal buried. In J.R. Conte (Ed.) Critical issues in child sexual abuse: Historical, legal, and psychological perspectives (pp. 139-173). Sage Publications: Thousand Oaks, CA.

Freyd, J.J., DePrince, A.P., \& Zurbriggen, E.L. (2001). Self-reported memory for abuse depends upon victim-perpetrator relationship. Journal of Trauma and Dissociation 2, 5-17.

Freyd, J. J., Klest, B., \& Allard, C. B. (2005). Betrayal trauma: Relationship to physical health, psychological distress, and a written disclosure intervention. Journal of Trauma and Dissociation, 6, 83-104.

Friedman, M. J., Resick, P. A, Bryant, R. A., \& Brewin, C. R. (2011). Considering PTSD for DSM-5. Depression and Anxiety, 28, 750-769.

Frisman, L., Ford, J., Lin, H. J., Mallon, S., \& Chang, R. (2008). Outcomes of trauma treatment using the TARGET model. Journal of Groups in Addiction and Recovery, 3, 285-303.

Gratz, K. L. \& Roemer, L. (2004). Multidimensional assessment of emotion regulation and dysregulation: Development, factor structure, and initial validation of the Difficulties in Emotion Regulation Scale. Journal of Psychopathology and Behavioral Assessment, 26, 41-54. 
Green, B. L., Grace, M. C., Lindy, J. D., Gleser, G. C., \& Leonard, A. (1990). Risk factors for PTSD and other diagnoses in a general sample of Vietnam veterans. American Journal of Psychiatry, 147, 729-733.

Herman, J. L. (1992). Complex PTSD: A syndrome in survivors of prolonged and repeated trauma. Journal of Traumatic Stress, 5, 377-391.

Jacoby, V. M. (2011). Self-reported posttraumatic stress and borderline personality behaviors in relation to reports of traumatic events, attachment, parental behavior, and social support. Unpublished master's thesis, West Virginia University, Morgantown.

Jacoby, V. M. \& Scotti, J. R., (2012, November). Examination of the history of psychosocial stressors: Predictive validity. Paper presented at the annual conference of the International Society for Traumatic Stress Studies, Los Angeles, CA.

Kessler, R. C., Berglund, P., Delmer, O., Jin, R., Merikangas, K. R., \& Walters, E. E. (2005). Lifetime prevalence and age-of-onset distributions of DSM-IV disorders in the National Comorbidity Survey Replication. Archives of General Psychiatry, 62, 593-602.

Kim, H. K., Pears, K. C., Capaldi, D. M., \& Owen, L. D. (2009). Emotion dysregulation in the intergenerational transmission of romantic relationship conflict. Journal of Family Psychology, 23, $585-595$.

Kira, I., Fawzi, M., \& Fawzi, M. (2012). The dynamics of cumulative trauma and trauma types in adults patients with psychiatric disorders: Two cross-cultural studies. Traumatology, Advanced online Publication.

Kiser, L. J., Heston, J., Millsap, P. A., \& Pruitt, D. C. (1991). Physical and sexual abuse in childhood: Relationship with post-traumatic stress disorder. American Academy of Child and Adolescent Psychiatry, 30, 776-783.

Kobak, R. R., Cole, H. E., Ferenz-Gillies, R., Fleming, W. S., \& Gamble, W. (1993). Attachment and emotion regulation during mother-teen problem solving: A control theory analysis. Child 
Development, 64, 231-245.

Kramer, H. C., Stice, E. Kazdin, A., Offord, D., \& Kupfer, D. (2001). How do risk factors work together? Mediators, moderators, and independent, overlapping, and proxy risk factors. American Journal of Psychiatry, 158, 848-856.

Kupersmidt, J. D., Burchinal, M., \& Patterson, C. J. (1995). Developmental patterns of childhood peer relations as predictors of externalizing behavior problems. Development and Psychopathology, 7 , $825-843$.

Laursen, B., Coy, K. C., \& Collins, W. A. (1998). Reconsidering changes in parent-child conflict across adolescence: A meta-analysis. Child Development, 69, 817-832.

Linehan, M. (1993). Cognitive-behavioral treatment of borderline personality disorder. New York: Guilford Press.

Liotti, G., Cortina, M., \& Farina B. (2008). Attachment theory and multiple integrated treatments of borderline patients. Journal of the American Academy of Psychoanalysis and Dynamic Psychiatry, $36,295-315$.

Lopes, P. N., Nezlek, J. B., Extremera, N., Hertel, J., Fernàndez-Berrocal, P., Schütz, A., et al. (2011). Emotion regulation and the quality of social interaction: Does the ability to evaluate emotional situations and identify effective responses matter? Journal of Personality, 79, 429-467.

MacDonald, C., Chamberlain, K., Long, N., \& Flett, R. (1999). Posttraumatic stress disorder and interpersonal functioning in Vietnam War Veterans: A mediational model. Journal of Traumatic Stress, 12, 701-707.

Main, M. \& Solomon, J. (1990). Procedures for identifying insecure-disorganized/disoriented infants: Procedures, finding, and implications for the classification of behavior. In M. Greenberg, D. Cicchetti, \& M. Cummings (Eds.), Attachment in the preschool years: Theory, research, and intervention (pp. 121-160). Chicago: University of Chicago Press.

March, J. S. (1993). What constitutes a stressor? The "criterion A" issue. In J. R. T. Davidson \& E. B. Foa 
(Eds.), Posttraumatic stress disorder: DSM-IV and beyond. Washington, DC: American Psychiatric Association.

Markman, H. J., \& Notarius, C. I. (1987). Coding marital and family interaction: Current status. In T. Jacob (Ed.), Family interaction and psychopathology (pp. 329-390). New York: Plenum Press.

McDonagh-Coyle, A., McHugo, G., Ford, J., Mueser, K., Demment, C., \& Descamps, M. (1999, December). Cognitive-behavioral treatment for childhood sexual abuse survivors with PTSD. Paper presented at the 15th Annual Meeting of the International Society for Traumatic Stress Studies, Miami, FL.

McNally, R. J. (2009). Can we fix PTSD in DSM-V?. Depression and Anxiety, 26, 597-600.

Montemayor, R. (1983). Parents and adolescents in conflict: All families some of the time and some families most of the time. Journal of Early Adolescence, 3, 83-103.

Neumann, A., van Lier, P. A. C., Gratz, K. L., \& Koot, H. M. (2010). Multidimensional assessment of emotion regulation difficulties in adolescents using the Difficulties in Emotion Regulation scale. Assessment, 17, 138-149.

Newman, E., Weathers, F. W., Nader, K. O., Kaloupek, D. G., Pynoos, R., Blake, D. D., et al. (2004). Clinician-Administered PTSD Scale for Children and Adolescents for DSM-IV Manual. Los Angeles, CA: Western Psychological Services.

Offer, D., Ostrov, E., \& Howard, K. (1981). The adolescent: A psychological self-portrait. New York: Basic Books.

Ogle, C. M., Rubin, D. C., \& Siegler, I. S. (2014) Cumulative exposure to traumatic events in older adults. Aging and Mental Health, 18, 316-325.

Owen, J., Quirk, K., \& Manthos, M. (2012). I get no respect: The relationship between betrayal trauma and romantic relationship functioning. Trauma \& Dissociation, 13, 175 - 189.

Pelcovitz, D., van der Kolk, B., Roth, S., Mandel, F., Kaplan, S., \& Resick, P. (1997). Development of a criteria set and a structured interview for disorders of extreme stress (SIDES). Journal of 
Traumatic Stress, 10, 3-16.

Pereda, N., \& Forero, C. G. (2012). Contribution of criterion A2 to PTSD screening in the presence of traumatic events. Journal of Traumatic Stress, 5, 587-591.

Pinquart, M., \& Silbereisen, R. K. (2002). Changes in adolescents' and mothers' autonomy and connectedness in conflict discussions: An observation study. Journal of Adolescence, 25, 509-522

Plattner, B., Karnik, N., Jo, B., Hall, R. E., Schallauer, A., \& Carrion, V. (2007). State and trait emotions in delinquent adolescents. Child Psychiatry and Human Development, 38, 155-169.

Preacher, K. J. \& Hayes, A. F. (2008). Asymptotic and resampling strategies for assessing and comparing indirect effects in multiple mediator models. Behavior Research Methods, 40, 879-891.

Prinz, R. J. (1977). The assessment of parent-adolescent relations: Discriminating distressed and nondistressed dyads. Unpublished doctoral dissertation, State University of New York, Stony Brook.

Prinz, R. J., Foster, S. L., Kent, R. N., \& O’Leary, K. D. (1979). Multivariate assessment of conflict in distressed and nondistressed mother-adolescent dyads. Journal of Applied Behavior Analysis, 12, $691-700$.

Pynoos, R. S, Rodriguez, N., Steinberg, A. S., Stuber, M., \& Frederick, C., et al. (1998). The UCLA PTSD Reaction Index for DSM- IV (Revision 1). Los Angeles: UCLA Trauma Psychiatry Program.

Robin, A. L., \& Foster S. L. (1989). Negotiating parent-adolescent conflict. New York: Guilford.

Rodriguez, N., Steinberg, A., \& Pynoos, R. S. (1999). ULCA PTSD Index for DSM-IV instrument information: Child version, parent version, adolescent version. California: UCLA Trauma Psychiatry Service.

Rodriguez, N., Steinberg, A. M., Saltzman, W. S., \& Pynoos, R. S. (2001). PTSD Index: Psychometric analysis of the Adolescent Version. In N. Rodriguez (Chair), Youth PTSD assessment: Psychometric investigation of PTSD self-report instruments. Symposium conducted at the Annual Meeting of the International Society for Traumatic Stress Studies, New Orleans, LA.

Rosen G. M., \& Lilienfeld, S. O. (2008). Posttraumatic stress disorder: An empirical evaluation of core 
assumptions. Clinical Psychology Review, 28, 837-868.

Roth, S., Newman, E., Pelcovitz, D., van der Kolk, B., \& Mandel, F. S. (1997). Complex PTSD in victims exposed to sexual and physical abuse: Results from the DSM-IV Field Trial for Posttraumatic Stress Disorder. Journal of Traumatic Stress, 10, 539-555.

Roussos, A., Goenjian, A. K., Steinberg, A. M., Sotiropoulou, C., Kakaki, M., Kabakos, C., et al. (2005). Posttraumatic stress and depressive reactions among children and adolescents after the 1999 earthquake in Ano Liosia, Greece. American Journal of Psychiatry, 162, 530-537.

Rudolph, K. D., \& Flynn, M. (2007). Childhood adversity and youth depression: The role of gender and pubertal status. Development and Psychopathology, 19, 497-521.

Ruggiero, K. J., Del Ben, K., Scotti, J. R., \& Rabalais, A. E. (2003). Psychometric properties of the PTSD Checklist-Civilian Version. Journal of Traumatic Stress, 16, 495-502.

Scotti, J. R., Ruggiero, K. J., Rabalais, A., Parker, L., Smith, T., \& Del Ben, K. (2000, November). History of Psychosocial Stressors: Conceptualization, utilization, validity, and test-retest reliability. Paper presented at the 34th annual convention of the Association for Advancement of Behavior Therapy, New Orleans, LA.

Shields, A., \& Cicchetti, D. (1998). Reactive aggression among maltreated children: The contributions of attention and emotion regulation. Journal of Clinical Child Psychology, 27, 381-395.

Shields, A,. \& Cicchetti, D. (2001). Parental maltreatment and emotion dysregulation as risk factors for bullying and victimization in middle childhood. Journal of Clinical Child Psychology, 30, 349363.

Shin Tang, S. S., \& Freyd, J. J. (2012.) Betrayal trauma and gender differences in posttraumatic stress. Psychological Trauma: Theory, Research, Practice, and Policy, 4, 469 - 478.

Smetana, J. G. (1988). Adolescents' and parents' conceptions of parental authority. Child Development, 59, 18-29.

Spear, L. P. (2000). The adolescent brain and age-related behavioral manifestations. Neuroscience and 
Biobehavioral Reviews, 24, 417-463.

Spinazzola, J., Blaustein, M., \& van der Kolk, B. A. (2002). Full versus partial DESNOS prevalence in a PTSD research sample. Unpublished manuscript. Trauma Center, Boston.

Stacom, E. E. (2011). PTSD and its relation to trauma and offending in incarcerated juveniles.

Unpublished doctoral dissertation. West Virginia University, Morgantown.

Steinberg, A. M., Brymer, M. J., Decker, K. B., \& Pynoos, R. S. (2004). The University of California at Los Angeles Post-traumatic Stress Disorder Reaction Index. Current Psychiatry Reports, 6, 96100.

Steinberg, L. D. (1990). Autonomy, conflict, and harmony in the family relationship. In S. Feldman \& G. Elliott (Eds.), At the threshold: The developing adolescent (pp. 255-276). Cambridge, MA: Harvard University Press.

Thompson, R.A. (1994). Emotion regulation: A theme in search of definition. Monographs of the Society for Research in Child Development, 59, 25-52.

van der Kolk, B. A. (2003). The neurobiology of childhood trauma and abuse. Child and Adolescent Clinics of North America, 12, 293-317.

van der Kolk, B. A. (2005). Developmental trauma disorder: Toward a rational diagnosis for children with complex trauma histories. Psychiatric Annals, 35, 401-408.

van der Kolk, B. A. (2007). The developmental impact of childhood trauma. In L. J. Kirmayer, R.

Lemelson, \& M. Barad (Eds.), Understanding trauma: Integrating biological, clinical, and cultural perspectives (pp. 224-241). Cambridge, NY: Cambridge University Press.

van der Kolk, B. A., Pelcovitz, D., Roth, S., Mandel, F., McFarlane, A., \& Herman, J. L. (1996).

Dissociation, affect dysregulation, and somatization: The complexity of adaptation to trauma. American Journal of Psychiatry, 153, July Festschrift Supplement, 83-93.

van der Kolk, B. A., Roth, S., Pelcovitz, D., Sunday, S., \& Spinazzola, J. (2005). Disorders of extreme stress: The empirical foundation of a complex adaptation to trauma. Journal of Traumatic Stress, 
18, 389-399.

Vielhauer, M. J. (1996). Complex post-traumatic stress disorder associated with childhood sexual and physical abuse in male veterans with histories of substance abuse disorders. ProQuest Dissertations and Theses.

Vrana, S. \& Lauterbach, D. (1994). Prevalence of traumatic events and post-traumatic psychological symptoms in a nonclinical sample of college students. Journal of Traumatic Stress, 7, 289-302.

Wilson, S. Norris, A., Shi, X., \& Rack, J. (2010). Comparing physically abused, neglected, and nonmaltreated children during interactions with their parents: A meta-analysis of observational studies. Communication Monographs, 77, 540-575.

Youniss J., \& Smollar, J. (1985). Adolescent relations with mothers, fathers, and friends. Chicago: University of Chicago Press. 
Table 1

Demographics (Number and Percentage): Race/Ethnicity of Mothers and Adolescents, Marital Status of Mothers, and Annual Household Income, Overall and by Sex of Adolescent

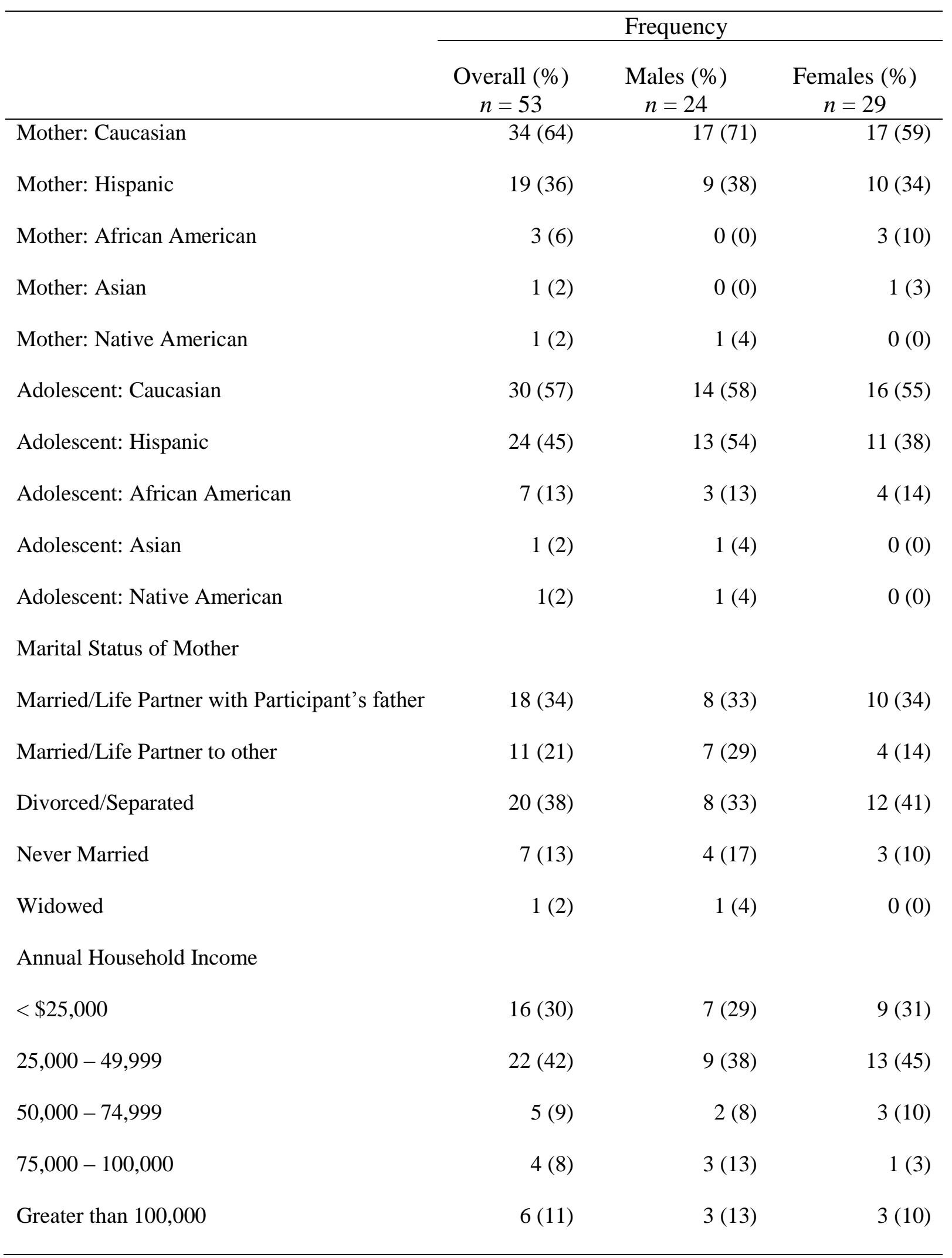


Table 2

Number (Percentage) of Participants Reporting Each Type of Non-Interpersonal Event by Sex of Adolescent and Group

\begin{tabular}{|c|c|c|c|c|}
\hline \multirow[b]{2}{*}{ Non-Interpersonal Event Type } & \multicolumn{2}{|c|}{ Sex of Adolescent } & \multicolumn{2}{|c|}{ Group } \\
\hline & $\begin{array}{c}\text { Male } \\
(n=24)\end{array}$ & $\begin{array}{l}\text { Female } \\
(n=29)\end{array}$ & $\begin{array}{c}\text { Non- } \\
\text { Betrayal } \\
\text { Trauma } \\
(n=26) \\
\end{array}$ & $\begin{array}{c}\text { Betrayal } \\
\text { Trauma } \\
(n=27)\end{array}$ \\
\hline Motor vehicle crash: Experienced & 12 & 10 & 10 & 12 \\
\hline Motor vehicle crash: Witnessed & 9 & 9 & 10 & 8 \\
\hline Natural disaster: Experienced & 2 & 3 & 4 & 1 \\
\hline Natural disaster: Witnessed & 1 & 0 & 1 & 0 \\
\hline Building evacuation: Experienced & 9 & 5 & 7 & 7 \\
\hline Building evacuation: Witnessed & 1 & 1 & 1 & 1 \\
\hline Emergency rescue: Experienced & 4 & 5 & 3 & 6 \\
\hline Emergency rescue: Witnessed & 4 & 4 & 3 & 5 \\
\hline Life threatening illness: Experienced & 1 & 5 & 2 & 4 \\
\hline Life threatening illness: Witnessed & 16 & 16 & 16 & 16 \\
\hline Accidental injury: Experienced & 9 & 4 & 5 & 8 \\
\hline Accidental injury: Witnessed & 12 & 4 & 9 & 7 \\
\hline Seeing a dead body (not at funeral) & 1 & 2 & 2 & 1 \\
\hline Homelessness & 4 & 6 & 2 & 8 \\
\hline Other events: Experienced & 2 & 0 & 1 & 1 \\
\hline Other events: Witnessed & 0 & 1 & 1 & 0 \\
\hline
\end{tabular}

Note. For full description of potentially traumatic events, see the History of Psychosocial Stressors (Appendix D) 
Table 3

Number (Percentage) of Participants Reporting Each Type of Interpersonal Event by Sex of Adolescent and Group

\begin{tabular}{|c|c|c|c|c|}
\hline \multirow[b]{2}{*}{ Type of Interpersonal Event } & \multicolumn{2}{|c|}{ Sex of Adolescent } & \multicolumn{2}{|c|}{ Group } \\
\hline & $\begin{array}{c}\text { Male } \\
(n=24)\end{array}$ & $\begin{array}{c}\text { Female } \\
(n=29)\end{array}$ & $\begin{array}{c}\text { Non- } \\
\text { Betrayal } \\
\text { Trauma } \\
(n=26)\end{array}$ & $\begin{array}{l}\text { Betrayal } \\
\text { Trauma } \\
(n=27)\end{array}$ \\
\hline Removed from home & 7 & 11 & 0 & 18 \\
\hline Neglect & 1 & 1 & 0 & 2 \\
\hline Emotional abuse: Experienced & 8 & 11 & 6 & 13 \\
\hline Emotional abuse: Witnessed & 4 & 5 & 2 & 7 \\
\hline Physical abuse (No weapon): Experienced & 7 & 6 & 4 & 9 \\
\hline Physical abuse(No weapon): Witnessed & 9 & 9 & 6 & 12 \\
\hline Physical abuse(No weapon): Experienced & 5 & 3 & 0 & 8 \\
\hline Physical abuse(No weapon): Witnessed & 4 & 3 & 2 & 5 \\
\hline Threat: Experienced & 6 & 4 & 6 & 4 \\
\hline Threat: Witnessed & 1 & 4 & 1 & 4 \\
\hline Kidnapping & 3 & 3 & 0 & 6 \\
\hline SA-Visual Exposure: Experienced & 2 & 3 & 0 & 5 \\
\hline SA-Visual Exposure: Witnessed & 1 & 2 & 0 & 3 \\
\hline SA-Fondling: Experienced & 2 & 3 & 0 & 5 \\
\hline SA-Fondling: Witnessed & 2 & 1 & 0 & 3 \\
\hline SA-Penetration: Experienced & 1 & 3 & 1 & 3 \\
\hline SA-Penetration: Witnessed & 2 & 2 & 0 & 4 \\
\hline Other events: Experienced & 1 & 1 & 1 & 1 \\
\hline Other events: Witnessed & 0 & 2 & 1 & 1 \\
\hline
\end{tabular}

Note. $\mathrm{SA}=$ Sexual Abuse. Removed from home refers to removal of the adolescent due to the behavior of the caregiver (such as due to drug use). For full description of potentially traumatic events, see the History of Psychosocial Stressors (Appendix D) 
Table 4

Number (Percentage) of Participants in the Betrayal Trauma Group Reporting Each Type of

Interpersonal Event Classifiable as Betrayal Trauma by Sex of Adolescent

\begin{tabular}{lcc}
\hline Type of Interpersonal Event & $\begin{array}{c}\text { Male } \\
(n=11)\end{array}$ & $\begin{array}{c}\text { Female } \\
(n=16)\end{array}$ \\
\hline Removed from home & $7(64)$ & $11(69)$ \\
Neglect & $1(9)$ & $1(6)$ \\
Emotional abuse: Experienced & $3(27)$ & $6(38)$ \\
Emotional abuse: Witnessed & $2(18)$ & $1(6)$ \\
Physical abuse/No weapon: Experienced & $3(27)$ & $6(38)$ \\
Physical abuse/No weapon: Witnessed & $4(36)$ & $6(38)$ \\
Physical abuse/Weapon: Experienced & $4(36)$ & $2(12)$ \\
Physical abuse/Weapon: Witnessed & $3(27)$ & $2(12)$ \\
Threat: Experienced & $1(9)$ & $0(0)$ \\
Threat: Witnessed & $1(9)$ & $3(19)$ \\
Kidnapping & $2(18)$ & $3(19)$ \\
SA-Visual Exposure: Experienced & $2(18)$ & $2(12)$ \\
SA-Visual Exposure: Witnessed & $1(9)$ & $1(6)$ \\
SA-Fondling: Experienced & $2(18)$ & $2(12)$ \\
SA-Fondling: Witnessed & $1(9)$ & $1(6)$ \\
SA-Penetration: Experienced & $1(9)$ & $2(12)$ \\
SA-Penetration: Witnessed & $2(18)$ & $1(6)$ \\
Other events: Experienced & $1(9)$ & $0(0)$ \\
Other events: Witnessed & $0(0)$ & $1(6)$ \\
\hline
\end{tabular}

Note. $\mathrm{SA}=$ Sexual Abuse. Removed from home refers to removal of the adolescent due to the behavior of the caregiver (such as due to drug use). For full description of potentially traumatic events, see the History of Psychosocial Stressors (Appendix D) 
Table 5

Means (Standard Deviations) and Ranges for Non-Interpersonal, Interpersonal, and Betrayal Traumatic Events, Overall and by Sex of Adolescent and Group

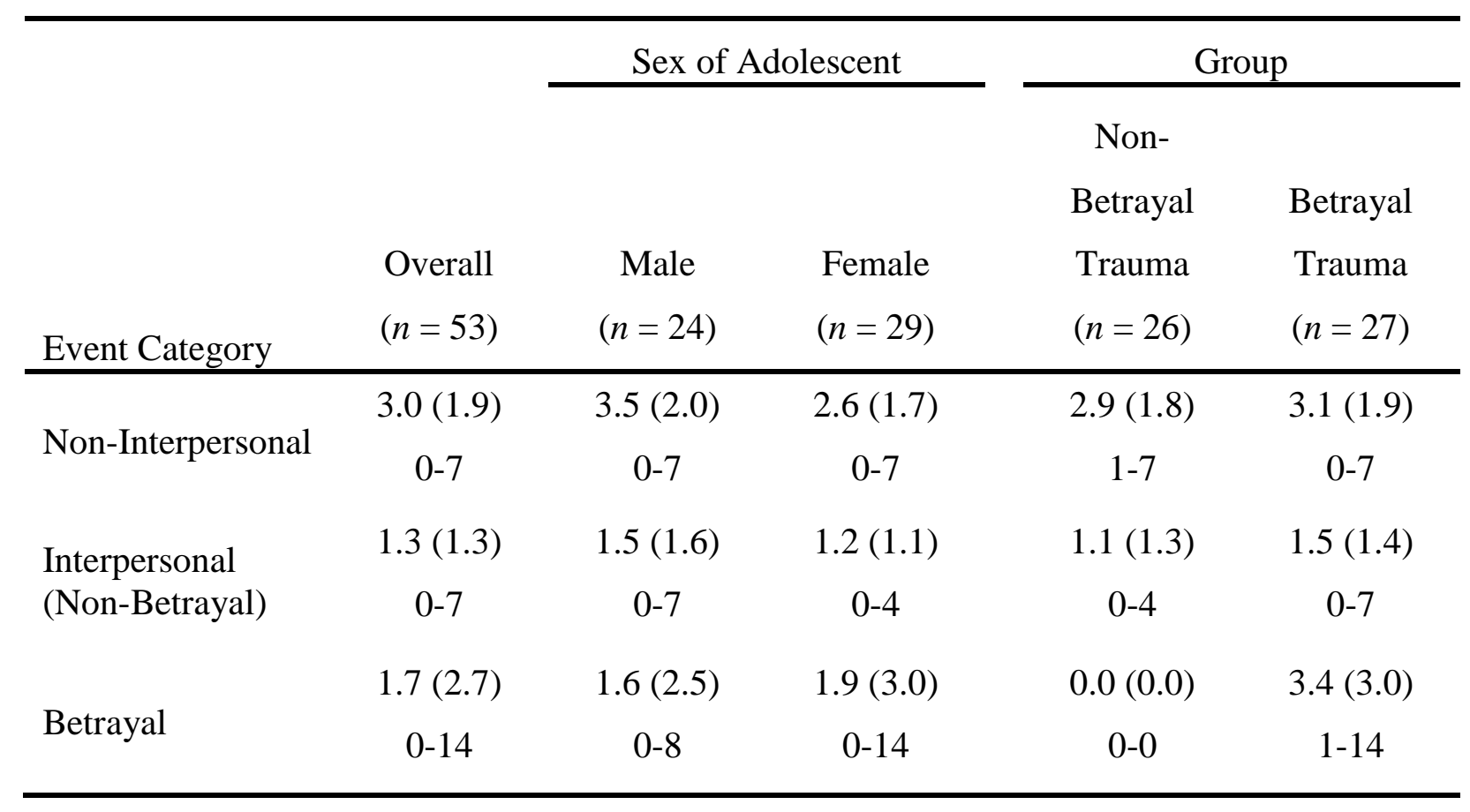

Note. Possible range of scores is 0-16 for Non-Interpersonal Events and 0-19 both Betrayal and NonBetrayal Interpersonal events. 
Table 6

Means (Standard Deviations) and Ranges for Adolescent and Parent Communication Behaviors during the Low-Stress and High-Stress Problem-Solving Tasks, Overall and by Sex of Adolescent and Group

\begin{tabular}{|c|c|c|c|c|c|}
\hline \multirow[b]{3}{*}{$\begin{array}{l}\text { Participant: Task / } \\
\text { Communication Behavior }\end{array}$} & \multirow[b]{3}{*}{$\begin{array}{l}\text { Overall } \\
(n=53)\end{array}$} & \multicolumn{2}{|c|}{ Sex of Adolescent } & \multicolumn{2}{|c|}{ Group } \\
\hline & & & & $\begin{array}{c}\text { Non- } \\
\text { Betrayal }\end{array}$ & Betrayal \\
\hline & & $\begin{array}{c}\text { Male } \\
(n=24)\end{array}$ & $\begin{array}{l}\text { Female } \\
(n=29)\end{array}$ & $\begin{array}{l}\text { Trauma } \\
(n=26)\end{array}$ & $\begin{array}{l}\text { Trauma } \\
(n=27)\end{array}$ \\
\hline \multicolumn{6}{|l|}{ Adolescent: Low Stress } \\
\hline \multirow{3}{*}{ Positive } & 23.2 & 22.8 & 23.5 & 23.6 & 22.9 \\
\hline & (13.4) & (13.4) & $(13.6)$ & $(13.0)$ & $(14.0)$ \\
\hline & $2-54$ & $4-54$ & $2-51$ & $4-54$ & $2-51$ \\
\hline \multirow{3}{*}{ Neutral } & 68.1 & 67.8 & 68.4 & 69.8 & 66.5 \\
\hline & $(13.6)$ & $(12.2)$ & $(14.9)$ & $(11.1)$ & $(15.6)$ \\
\hline & $36-90$ & $41-85$ & $36-90$ & $46-89$ & $36-90$ \\
\hline \multirow[b]{2}{*}{ Negative non-aggressive } & $7.8(13.1)$ & $8.5(13.1)$ & $7.2(13.3)$ & $5.8(10.0)$ & $9.7(15.5)$ \\
\hline & $0-54$ & $0-51$ & $0-54$ & $0-40$ & $0-54$ \\
\hline \multirow{2}{*}{ Negative aggressive } & $0.9(2.2)$ & $0.9(2.3)$ & $0.9(2.1)$ & $0.8(2.4)$ & $1.0(2.0)$ \\
\hline & $0-10$ & $0-10$ & $0-8$ & $0-10$ & $0-8$ \\
\hline \multicolumn{6}{|l|}{ Adolescent: High Stress } \\
\hline \multirow{3}{*}{ Positive } & 29.0 & 33.1 & 25.5 & 36.3 & 21.9 \\
\hline & $(21.4)$ & $(20.0)$ & $(22.2)$ & $(24.4)$ & $(15.4)$ \\
\hline & $0-86$ & $0-83$ & $4-86$ & $4-86$ & $0-59$ \\
\hline \multirow{3}{*}{ Neutral } & 48.1 & 47.1 & 48.8 & 49.7 & 46.5 \\
\hline & $(20.4)$ & $(13.6)$ & $(24.8)$ & $(19.1)$ & $(21.8)$ \\
\hline & $6-91$ & $17-68$ & $6-91$ & $12-91$ & $6-91$ \\
\hline
\end{tabular}




\begin{tabular}{|c|c|c|c|c|c|}
\hline \multirow[b]{2}{*}{$\begin{array}{l}\text { Participant: Task / } \\
\text { Communication Behavior }\end{array}$} & \multirow[b]{2}{*}{$\begin{array}{l}\text { Overall } \\
(n=53)\end{array}$} & \multicolumn{2}{|c|}{ Sex of Adolescent } & \multicolumn{2}{|c|}{ Group } \\
\hline & & $\begin{array}{c}\text { Male } \\
(n=24)\end{array}$ & $\begin{array}{l}\text { Female } \\
(n=29)\end{array}$ & $\begin{array}{c}\text { Non- } \\
\text { Betrayal } \\
\text { Trauma } \\
(n=26)\end{array}$ & $\begin{array}{l}\text { Betrayal } \\
\text { Trauma } \\
(n=27)\end{array}$ \\
\hline \multirow{3}{*}{ Negative non-aggressive } & 18.3 & 15.5 & 20.7 & 12.4 & 24.1 \\
\hline & $(18.1)$ & $(16.2)$ & $(19.5)$ & $(14.7)$ & $(19.4)$ \\
\hline & $0-73$ & $0-50$ & $0-73$ & $0-53$ & $0-73$ \\
\hline \multirow{2}{*}{ Negative aggressive } & $4.6(10.0)$ & $4.4(9.0)$ & $5.0(11.0)$ & $1.7(3.2)$ & $7.5(13.2)$ \\
\hline & $0-54$ & $0-38$ & $0-54$ & $0-12$ & $0-54$ \\
\hline \multicolumn{6}{|l|}{ Parent: Low Stress } \\
\hline \multirow{3}{*}{ Positive } & 31.7 & 31.1 & 32.1 & 30.5 & 32.7 \\
\hline & $(14.8)$ & $(14.1)$ & $(15.6)$ & $(16.0)$ & $(13.8)$ \\
\hline & $5-58$ & $7-58$ & $5-58$ & $5-58$ & $11-55$ \\
\hline \multirow{3}{*}{ Neutral } & 65.0 & 64.8 & 65.2 & 66.2 & 63.9 \\
\hline & $(13.5)$ & $(12.0)$ & $(14.8)$ & $(14.5)$ & $(12.7)$ \\
\hline & $42-93$ & $42-87$ & $42-93$ & $42-93$ & $44-87$ \\
\hline \multirow{2}{*}{ Negative non-aggressive } & $3.1(5.8)$ & $3.8(7.7)$ & $2.5(3.9)$ & $3.1(7.1)$ & $3.0(4.5)$ \\
\hline & $0-35$ & $0-35$ & $0-16$ & $0-35$ & $0-16$ \\
\hline \multirow{2}{*}{ Negative aggressive } & $0.3(1.0)$ & $0.4(1.3)$ & $0.2(0.5)$ & $0.2(0.6)$ & $0.3(1.2)$ \\
\hline & $0-6$ & $0-6$ & $0-3$ & $0-3$ & $0-6$ \\
\hline \multicolumn{6}{|l|}{ Parent: High Stress } \\
\hline \multirow{3}{*}{ Positive } & 41.4 & 41.8 & 41.1 & 46.0 & 37.0 \\
\hline & $(21.3)$ & $(18.9)$ & $(23.4)$ & $(19.0)$ & $(22.8)$ \\
\hline & $2-93$ & $6-78$ & $2-93$ & $16-93$ & $2-87$ \\
\hline
\end{tabular}




\begin{tabular}{|c|c|c|c|c|c|}
\hline \multirow[b]{3}{*}{$\begin{array}{l}\text { Participant: Task / } \\
\text { Communication Behavior }\end{array}$} & \multirow[b]{3}{*}{$\begin{array}{l}\text { Overall } \\
(n=53)\end{array}$} & \multicolumn{2}{|c|}{ Sex of Adolescent } & \multicolumn{2}{|c|}{ Group } \\
\hline & & & & $\begin{array}{l}\text { Non- } \\
\text { Betrayal }\end{array}$ & Betrayal \\
\hline & & $\begin{array}{c}\text { Male } \\
(n=24)\end{array}$ & $\begin{array}{l}\text { Female } \\
(n=29)\end{array}$ & $\begin{array}{l}\text { Trauma } \\
(n=26)\end{array}$ & $\begin{array}{l}\text { Trauma } \\
(n=27)\end{array}$ \\
\hline \multirow{3}{*}{ Neutral } & 48.9 & 46.8 & 50.6 & 46.9 & 50.8 \\
\hline & $(18.7)$ & $(16.4)$ & $(20.5)$ & $(16.3)$ & $(20.9)$ \\
\hline & $7-94$ & $22-93$ & $7-94$ & $7-76$ & $13-94$ \\
\hline \multirow[b]{2}{*}{ Negative non-aggressive } & $6.8(7.9)$ & $7.8(8.2)$ & $6.0(7.7)$ & $5.2(6.1)$ & $8.3(9.1)$ \\
\hline & $0-31$ & $0-26$ & $0-31$ & $0-21$ & $0-31$ \\
\hline \multirow{2}{*}{ Negative aggressive } & $2.9(6.3)$ & $3.6(7.8)$ & $2.3(4.8)$ & $1.9(3.4)$ & $3.9(8.1)$ \\
\hline & $0-34$ & $0-34$ & $0-24$ & $0-14$ & $0-34$ \\
\hline
\end{tabular}

Note. All values are percentages. Possible range of values for each behavior is $0-100 \%$. Within a task, the sum of all behaviors (Positive + Neutral + Negative non-aggressive + Negative aggressive $)=100 \%$ 
Table 7

Means (Standard Deviations) and Ranges for Adolescent and Parent Versions of the PTSD Reaction Index, Overall and by Sex of Adolescent and Group

\begin{tabular}{|c|c|c|c|c|c|}
\hline \multirow[b]{2}{*}{$\begin{array}{l}\text { Version / } \\
\text { Subscale (or Total) }\end{array}$} & \multirow[b]{2}{*}{$\begin{array}{l}\text { Overall } \\
(n=53)\end{array}$} & \multicolumn{2}{|c|}{ Sex of Adolescent } & \multicolumn{2}{|c|}{ Group } \\
\hline & & $\begin{array}{c}\text { Male } \\
(n=24)\end{array}$ & $\begin{array}{l}\text { Female } \\
(n=29)\end{array}$ & $\begin{array}{c}\text { Non- } \\
\text { Betrayal } \\
\text { Trauma } \\
(n=26)\end{array}$ & $\begin{array}{l}\text { Betrayal } \\
\text { Trauma } \\
(n=27)\end{array}$ \\
\hline \multicolumn{6}{|l|}{ Adolescent-Report } \\
\hline \multirow{2}{*}{ Reexperiencing } & $5.5(5.2)$ & $3.5(4.1)$ & $7.2(5.5)$ & $4.4(4.8)$ & $6.6(5.5)$ \\
\hline & $0-20$ & $0-16$ & $1-20$ & $0-18$ & $0-20$ \\
\hline \multirow{2}{*}{ Avoidance } & $7.6(6.3)$ & $6.5(7.2)$ & $8.5(5.3)$ & $5.3(3.9)$ & $9.8(7.4)$ \\
\hline & $0-27$ & $0-26$ & $1-27$ & $0-12$ & $0-27$ \\
\hline \multirow{2}{*}{ Hyperarousal } & $8.8(4.9)$ & $6.6(4.9)$ & $10.6(4.2)$ & $7.3(4.7)$ & $10.2(4.7)$ \\
\hline & $0-20$ & $0-19$ & $3-20$ & $0-18$ & $3-20$ \\
\hline \multirow{3}{*}{ Total score } & 22.9 & 17.2 & 27.7 & 17.9 & 27.8 \\
\hline & $(15.3)$ & $(15.0)$ & $(14.2)$ & (12.9) & $(16.1)$ \\
\hline & $1-71$ & $1-61$ & $10-71$ & $1-51$ & $9-71$ \\
\hline \multicolumn{6}{|l|}{ Parent-Report } \\
\hline \multirow{2}{*}{ Reexperiencing } & $4.4(4.1)$ & $4.4(3.4)$ & $4.3(4.7)$ & $3.1(2.7)$ & $5.6(4.8)$ \\
\hline & $0-18$ & $0-15$ & $0-18$ & $0-11$ & $0-18$ \\
\hline \multirow{2}{*}{ Avoidance } & $5.3(5.1)$ & $6.3(5.3)$ & $4.5(4.7)$ & $3.3(3.1)$ & $7.3(5.8)$ \\
\hline & $0-20$ & $0-20$ & $0-16$ & $0-9$ & $0-20$ \\
\hline \multirow{2}{*}{ Hyperarousal } & $7.5(4.6)$ & $8.2(4.2)$ & $7.0(4.9)$ & $6.3(4.3)$ & $8.7(4.7)$ \\
\hline & $0-18$ & $2-17$ & $0-18$ & $0-17$ & $0-18$ \\
\hline
\end{tabular}




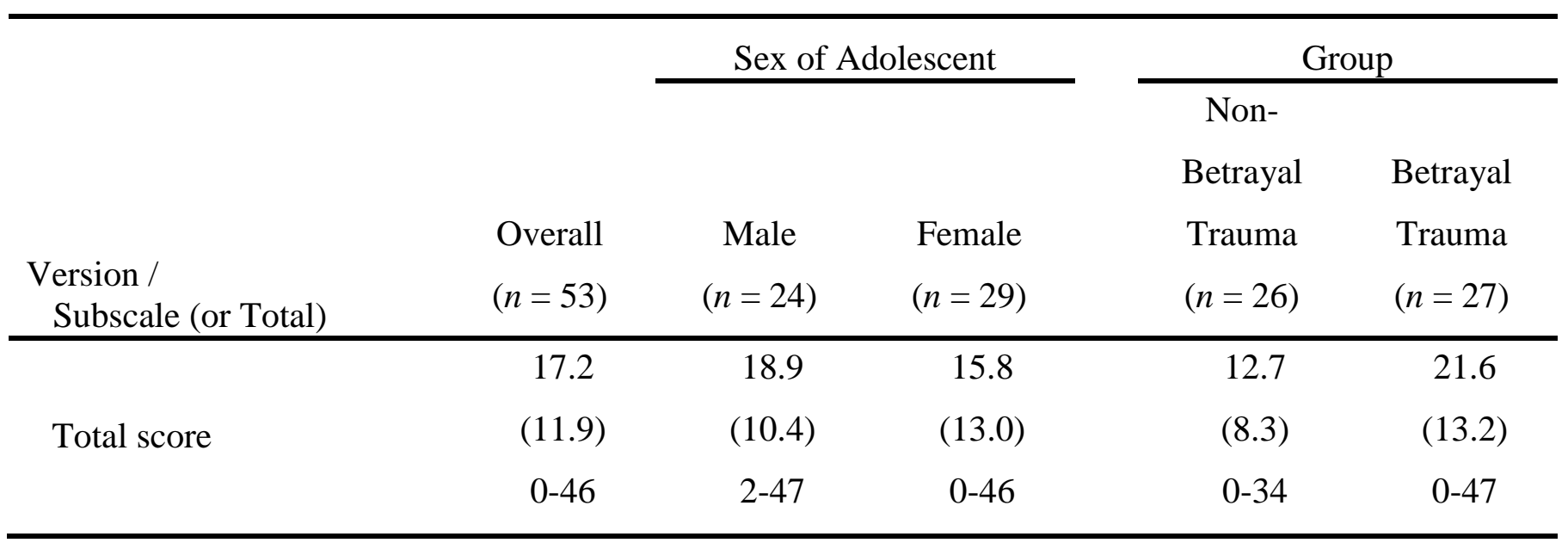

Note. Items reported as I don't know on the UCLA PTSD Index: Parent Report were considered missing data for the reporting of descriptive statistics. I don't know answers accounted for $8 \%$ of the data on this measure. Possible ranges of scores are: (a) 0-20 for Reexperiencing, (b) 0-28 for Avoidance, (c) 0-20 for Hyperarousal, and (d) 0-68 for Total. 
Table 8

Means (Standard Deviations) and Ranges for the Difficulties with Emotion Regulation Scale, Overall and by Sex of Adolescent and Group

\begin{tabular}{|c|c|c|c|c|c|}
\hline \multirow[b]{2}{*}{$\begin{array}{l}\text { Sub-scale } \\
\text { (or Total) }\end{array}$} & \multirow[b]{2}{*}{$\begin{array}{l}\text { Overall } \\
(n=53)\end{array}$} & \multicolumn{2}{|c|}{ Sex of Adolescent } & \multicolumn{2}{|c|}{ Group } \\
\hline & & $\begin{array}{c}\text { Male } \\
(n=24)\end{array}$ & $\begin{array}{l}\text { Female } \\
(n=29)\end{array}$ & $\begin{array}{c}\text { Non- } \\
\text { Betrayal } \\
\text { Trauma } \\
(n=26)\end{array}$ & $\begin{array}{l}\text { Betrayal } \\
\text { Trauma } \\
(n=27)\end{array}$ \\
\hline \multirow{2}{*}{ Non-acceptance } & $11.3(5.6)$ & $10.5(6.1)$ & $11.9(5.2)$ & $9.9(3.6)$ & $12.6(6.8)$ \\
\hline & $6-27$ & $6-26$ & $6-27$ & $6-18$ & $6-27$ \\
\hline \multirow{2}{*}{ Goals } & $16.0(5.7)$ & $13.9(5.5)$ & $17.8(5.3)$ & $14.4(5.8)$ & $17.7(5.1)$ \\
\hline & $5-25$ & $5-25$ & $8-25$ & $5-25$ & $9-25$ \\
\hline \multirow{2}{*}{ Impulse } & $12.7(6.5)$ & $11.9(5.7)$ & $13.4(7.0)$ & $9.5(2.6)$ & $15.8(7.6)$ \\
\hline & $6-30$ & $6-30$ & $6-30$ & $6-16$ & $7-30$ \\
\hline \multirow{2}{*}{ Awareness } & $17.2(6.4)$ & $19.0(6.7)$ & $15.7(5.8)$ & $15.3(5.9)$ & $19.0(6.3)$ \\
\hline & $6-30$ & $9-30$ & $6-27$ & $6-30$ & $6-30$ \\
\hline \multirow{2}{*}{ Strategies } & $17.2(8.4)$ & $15.1(8.1)$ & $18.9(8.4)$ & $15.2(7.3)$ & $19.2(9.1)$ \\
\hline & $8-40$ & $8-39$ & $9-40$ & $8-40$ & $8-39$ \\
\hline \multirow{2}{*}{ Clarity } & $13.0(3.1)$ & $12.9(2.9)$ & $13.1(3.2)$ & $12.9(2.4)$ & $13.1(3.7)$ \\
\hline & $8-23$ & $8-19$ & $9-23$ & $9-19$ & $8-23$ \\
\hline \multirow{3}{*}{ Total score } & 85.4 & 81.5 & 88.6 & 74.2 & 96.2 \\
\hline & $(25.9)$ & $(27.1)$ & $(24.9)$ & $(20.2)$ & $(26.5)$ \\
\hline & $44-150$ & $44-150$ & $44-138$ & $44-137$ & $62-150$ \\
\hline
\end{tabular}

Note. Possible ranges of scores are: (a) 0-30 for Non-acceptance, (b) 0-25 for Goals, (c) 0-30 for Impulse, (d) 0-30 for Awareness, (e) 0-40 for Strategies, (f) 0-25 for Clarity, and (g) 0-180 for Total. 
Table 9

Means (Standard Deviations) and Ranges for Adolescent and Parent Versions of the Conflict

Behavior Scale, Overall and by Sex of Adolescent and Group

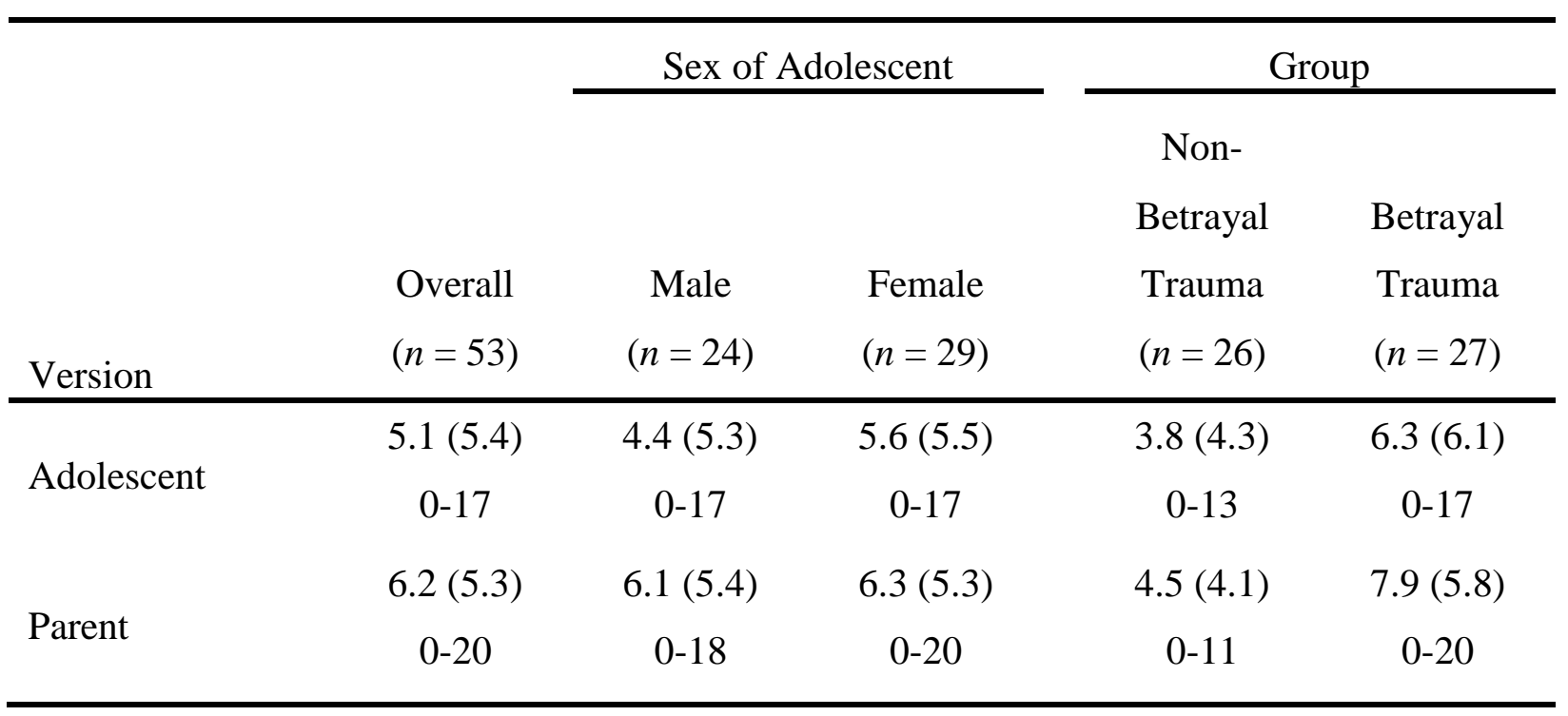

Note. Possible range of scores is $0-20$ on both versions of the scale. 
Table 10

Means (Standard Deviations) and Ranges for Adolescent and Parent Versions of the Issues Checklist, Overall and by Sex of Adolescent and Group

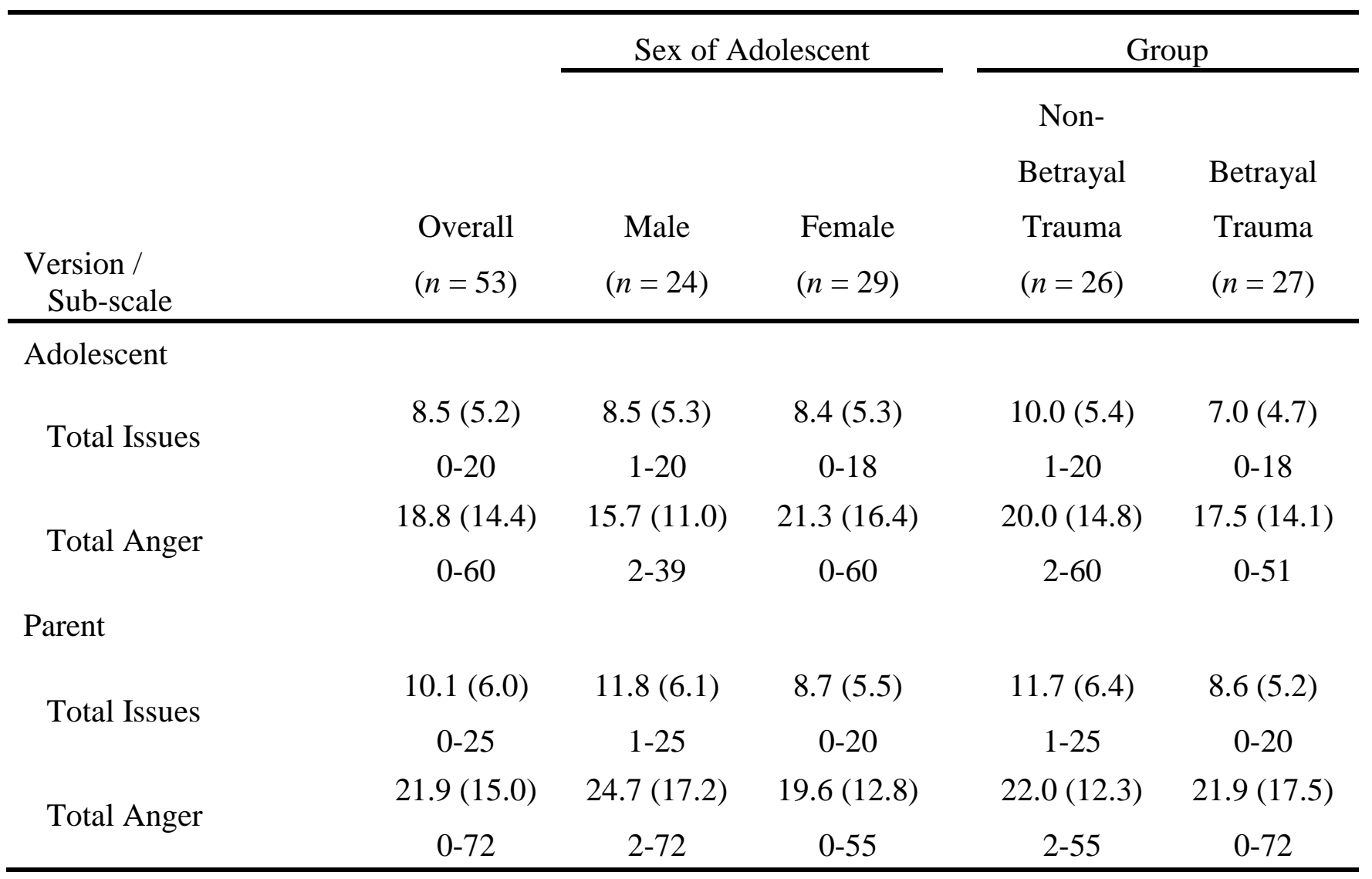

Note. Possible ranges of scores are: (a) 0-26 for Total Issues, and (b) 0-130 for Total Anger. 
Table 11

Means (Standard Deviations) and Ranges for Adolescent and Parent Versions of the Problem-Solving

Reaction Scales following the Low-Stress and High-Stress Problem-Solving Tasks, Overall and by Sex of Adolescent and Group

\begin{tabular}{|c|c|c|c|c|c|}
\hline \multirow[b]{2}{*}{$\begin{array}{l}\text { Participant: Task / } \\
\text { Scale item }\end{array}$} & \multirow[b]{2}{*}{$\begin{array}{l}\text { Overall } \\
(n=52)\end{array}$} & \multicolumn{2}{|c|}{ Sex of Adolescent } & \multicolumn{2}{|c|}{ Group } \\
\hline & & $\begin{array}{c}\text { Male } \\
(n=23)\end{array}$ & $\begin{array}{l}\text { Female } \\
(n=29)\end{array}$ & $\begin{array}{c}\text { Non- } \\
\text { Betrayal } \\
\text { Trauma } \\
(n=26)\end{array}$ & $\begin{array}{l}\text { Betrayal } \\
\text { Trauma } \\
(n=26)\end{array}$ \\
\hline \multicolumn{6}{|l|}{ Adolescent: Low Stress } \\
\hline \multirow{2}{*}{ How difficult } & $1.9(1.3)$ & $2.3(1.5)$ & $1.7(1.1)$ & $1.8(1.1)$ & $2.1(1.5)$ \\
\hline & $1-5$ & $1-5$ & $1-5$ & $1-5$ & $1-5$ \\
\hline \multirow{2}{*}{ How emotional } & $1.7(1.3)$ & $1.4(0.8)$ & $1.9(1.5)$ & $1.3(0.5)$ & $2.1(1.6)$ \\
\hline & $1-7$ & $1-4$ & $1-7$ & $1-3$ & $1-7$ \\
\hline \multirow{2}{*}{ Cooperativeness: Self } & $1.8(1.5)$ & $1.8(1.6)$ & $1.8(1.5)$ & $1.4(0.8)$ & $2.3(1.9)$ \\
\hline & $1-7$ & $1-7$ & $1-7$ & $1-4$ & $1-7$ \\
\hline \multirow{2}{*}{ Cooperativeness: Partner } & $1.4(0.8)$ & $1.3(0.6)$ & $1.5(0.9)$ & $1.2(0.4)$ & $1.5(1.1)$ \\
\hline & $1-5$ & $1-3$ & $1-5$ & $1-2$ & $1-5$ \\
\hline \multirow{2}{*}{ How successful } & $1.7(1.2)$ & $1.6(1.2)$ & $1.9(1.2)$ & $1.4(0.8)$ & $2.0(1.5)$ \\
\hline & $1-6$ & $1-6$ & $1-5$ & $1-4$ & $1-6$ \\
\hline \multirow{2}{*}{ How typical } & $2.1(1.3)$ & $1.9(1.1)$ & $2.3(1.5)$ & $2.1(1.1)$ & $2.2(1.6)$ \\
\hline & $1-7$ & $1-5$ & $1-7$ & $1-5$ & $1-7$ \\
\hline \multicolumn{6}{|l|}{ Adolescent: High Stress } \\
\hline \multirow{2}{*}{ How difficult } & $3.1(1.9)$ & $2.8(1.9)$ & $3.4(1.9)$ & $3.0(1.7)$ & $3.3(2.1)$ \\
\hline & $1-7$ & $1-7$ & $1-7$ & $1-7$ & $1-7$ \\
\hline \multirow{2}{*}{ How emotional } & $2.5(1.8)$ & $2.2(1.8)$ & $2.8(1.8)$ & $2.0(1.2)$ & $3.0(2.1)$ \\
\hline & $1-7$ & $1-7$ & $1-7$ & $1-5$ & $1-7$ \\
\hline \multirow{2}{*}{ Cooperativeness: Self } & $2.3(1.4)$ & $1.7(1.1)$ & $2.7(1.5)$ & $2.2(1.5)$ & $2.4(1.4)$ \\
\hline & $1-6$ & $1-5$ & $1-6$ & $1-6$ & $1-6$ \\
\hline \multirow{2}{*}{ Cooperativeness: Partner } & $2.2(1.6)$ & $1.9(1.5)$ & $2.4(1.6)$ & $2.0(1.5)$ & $2.4(1.7)$ \\
\hline & $1-7$ & $1-7$ & $1-7$ & $1-7$ & $1-7$ \\
\hline
\end{tabular}




\begin{tabular}{|c|c|c|c|c|c|}
\hline \multirow[b]{3}{*}{$\begin{array}{l}\text { Participant: Task / } \\
\text { Scale item }\end{array}$} & \multirow[b]{3}{*}{$\begin{array}{l}\text { Overall } \\
(n=52)\end{array}$} & \multicolumn{2}{|c|}{ Sex of Adolescent } & \multicolumn{2}{|c|}{ Group } \\
\hline & & & & $\begin{array}{l}\text { Non- } \\
\text { Betrayal }\end{array}$ & Betrayal \\
\hline & & $\begin{array}{c}\text { Male } \\
(n=23)\end{array}$ & $\begin{array}{l}\text { Female } \\
(n=29)\end{array}$ & $\begin{array}{l}\text { Trauma } \\
(n=26)\end{array}$ & $\begin{array}{l}\text { Trauma } \\
(n=26)\end{array}$ \\
\hline \multirow[b]{2}{*}{ How successful } & $2.2(1.8)$ & $2.0(1.7)$ & $2.4(1.8)$ & $2.1(1.4)$ & $2.4(2.1)$ \\
\hline & $1-7$ & $1-7$ & $1-7$ & $1-5$ & $1-7$ \\
\hline \multirow{2}{*}{ How typical } & $2.3(1.3)$ & $2.0(1.1)$ & $2.5(1.5)$ & $2.8(1.5)$ & $1.8(1.0)$ \\
\hline & $1-6$ & $1-5$ & $1-6$ & $1-6$ & $1-4$ \\
\hline \multicolumn{6}{|l|}{ Parent: Low Stress } \\
\hline \multirow{2}{*}{ How difficult } & $1.5(0.9)$ & $1.5(0.8)$ & $1.5(0.9)$ & $1.4(0.6)$ & $1.6(1.1)$ \\
\hline & $1-4$ & $1-4$ & $1-4$ & $1-3$ & $1-4$ \\
\hline \multirow{2}{*}{ How emotional } & $1.3(0.6)$ & $1.2(0.4)$ & $1.4(0.7)$ & $1.2(0.7)$ & $1.4(0.6)$ \\
\hline & $1-4$ & $1-2$ & $1-4$ & $1-4$ & $1-3$ \\
\hline \multirow{2}{*}{ Cooperativeness: Self } & $1.4(0.9)$ & $1.1(0.3)$ & $1.6(1.2)$ & $1.3(0.8)$ & $1.5(1.0)$ \\
\hline & $1-5$ & $1-2$ & $1-5$ & $1-4$ & $1-5$ \\
\hline \multirow{2}{*}{ Cooperativeness: Partner } & $1.4(0.9)$ & $1.2(0.7)$ & $1.6(1.1)$ & $1.4(1.0)$ & $1.5(0.9)$ \\
\hline & $1-4$ & $1-4$ & $1-4$ & $1-4$ & $1-4$ \\
\hline \multirow{2}{*}{ How successful } & $1.4(0.9)$ & $1.5(0.7)$ & $1.6(1.1)$ & $1.4(0.9)$ & $1.3(1.0)$ \\
\hline & $1-6$ & $1-4$ & $1-6$ & $1-4$ & $1-6$ \\
\hline \multirow{2}{*}{ How typical } & $1.7(1.2)$ & $1.5(0.7)$ & $1.5(1.5)$ & $1.7(1.4)$ & $1.7(1.0)$ \\
\hline & $1-7$ & $1-4$ & $1-7$ & $1-7$ & $1-5$ \\
\hline \multicolumn{6}{|l|}{ Parent: High Stress } \\
\hline \multirow{2}{*}{ How difficult } & $3.5(1.9)$ & $3.3(2.1)$ & $3.6(1.8)$ & $3.5(1.6)$ & $3.4(2.1)$ \\
\hline & $1-7$ & $1-7$ & $1-7$ & $1-7$ & $1-7$ \\
\hline \multirow{2}{*}{ How emotional } & $2.5(1.3)$ & $2.3(1.1)$ & $2.6(1.4)$ & $2.2(1.0)$ & $2.7(1.5)$ \\
\hline & $1-6$ & $1-5$ & $1-6$ & $1-4$ & $1-6$ \\
\hline \multirow{2}{*}{ Cooperativeness: Self } & $2.0(1.3)$ & $1.7(1.0)$ & $2.2(1.4)$ & $1.6(1.0)$ & $2.2(1.5)$ \\
\hline & $1-6$ & $1-5$ & $1-6$ & $1-5$ & $1-6$ \\
\hline \multirow{2}{*}{ Cooperativeness: Partner } & $2.5(1.7)$ & $2.4(1.7)$ & $2.7(1.7)$ & $2.2(1.3)$ & $2.9(2.0)$ \\
\hline & 1-7 & $1-7$ & $1-7$ & 1-6 & 1-7 \\
\hline \multirow{2}{*}{ How successful } & $2.6(1.8)$ & $2.4(1.9)$ & $2.7(1.8)$ & $2.4(1.5)$ & $2.8(2.1)$ \\
\hline & $1-7$ & $1-7$ & $1-6$ & $1-6$ & $1-7$ \\
\hline
\end{tabular}




\begin{tabular}{|c|c|c|c|c|c|}
\hline \multirow[b]{3}{*}{$\begin{array}{l}\text { Participant: Task / } \\
\text { Scale item }\end{array}$} & \multirow[b]{3}{*}{$\begin{array}{l}\text { Overall } \\
(n=52)\end{array}$} & \multicolumn{2}{|c|}{ Sex of Adolescent } & \multicolumn{2}{|c|}{ Group } \\
\hline & & & & $\begin{array}{l}\text { Non- } \\
\text { Betrayal }\end{array}$ & Betrayal \\
\hline & & $\begin{array}{c}\text { Male } \\
(n=23)\end{array}$ & $\begin{array}{l}\text { Female } \\
(n=29)\end{array}$ & $\begin{array}{l}\text { Trauma } \\
(n=26)\end{array}$ & $\begin{array}{l}\text { Trauma } \\
(n=26)\end{array}$ \\
\hline \multirow{2}{*}{ How typical } & $2.5(1.9)$ & $2.4(1.9)$ & $2.6(1.9)$ & $2.6(1.9)$ & $2.4(1.9)$ \\
\hline & $1-7$ & $1-7$ & $1-7$ & $1-7$ & $1-7$ \\
\hline
\end{tabular}

Note. All items rated on a 7-point scale, where higher scores are more negative. The specific items were:

(a) How difficult: This task was: Very Easy/Very Difficult, (b) How emotional: I felt: Very Happy/Very

Upset, (c) Cooperativeness: Self: I was: Very Cooperative/Very Uncooperative, (d) Cooperativeness:

Partner: My partner was: Very Cooperative/Very Uncooperative, (e) How successful: We were: Very

Successful/Very Unsuccessful at Solving these problems, and (f) How typical: This interaction was: Very typical of us/Not typical at all of us. 
Table 12

Correlations Among the Subscales of the UCLA PTSD Reaction Index for Adolescent (AR) and Parent (PR) Versions

\begin{tabular}{lccccc}
\hline Subscale: Version & 1 & 2 & 3 & 4 & 5 \\
\hline 1. Reexperiencing: AR & & & & & \\
2. Reexperiencing: PR & $.61^{* *}$ & & & & \\
3. Avoidance: AR & $.63^{* *}$ & $.57^{* *}$ & & & \\
4. Avoidance: PR & $.33^{*}$ & $.57^{* *}$ & $.61^{* *}$ & & \\
5. Hyperarousal: AR & $.72^{* *}$ & $.44^{* *}$ & $.76^{* *}$ & $.46^{* *}$ & \\
6. Hyperarousal: PR & $.35^{*}$ & $.62^{* *}$ & $.49^{* *}$ & $.66^{* *}$ & $.48^{* *}$ \\
\hline
\end{tabular}

$* p<.05, * * p<.01$

Note. $n=53$ for all correlation 
Table 13

Correlations Among the Subscales of Difficulties in Emotion Regulation Scale

\begin{tabular}{lccccc}
\hline Subscale: Version & 1 & 2 & 3 & 4 & 5 \\
\hline 1. Goals & & & & & \\
2. Impulse & $.51 * *$ & & & & \\
3. Aware & -.15 & .13 & & & \\
4. Strategies & $.65^{* *}$ & $.73^{* *}$ & .06 & & \\
5. Clarity & $.32^{*}$ & $.46^{* *}$ & $-.33^{*}$ & $.56 * *$ & \\
6. Non-Accept & $.47^{* *}$ & $.69^{* *}$ & -.17 & $.80^{* *}$ & $.65^{* *}$ \\
\hline
\end{tabular}

$* p<.05, * * p<.01$

Note. $n=53$ for all correlations 
Table 14

Correlations of Among the Primary Measures (PTSD Reaction Index, Difficulties in

Emotion Regulation Scale, Conflict Behavior Questionnaire, and Issues Checklist) for

Adolescent (AR) and Parent (PR) Versions

\begin{tabular}{lcccccccc}
\hline Scale: Version & 1 & 2 & 3 & 4 & 5 & 6 & 7 & 8 \\
\hline 1. PRI (Total): AR & & & & & & & \\
2. PRI (Total): PR & $.63^{* *}$ & & & & & & & \\
3. DERS (Total) & $.68^{* *}$ & $.51^{* *}$ & & & & & & \\
4. CBQ (Total): AR & $.39^{* *}$ & $.46^{* *}$ & $.41^{* *}$ & & & & & \\
5. CBQ (Total): PR & $.41^{* *}$ & $.58^{* *}$ & $.49^{* *}$ & $.62^{* *}$ & & & & \\
6. IC (Issues): AR & .19 & .05 & .10 & .23 & .14 & & & \\
7. IC (Issues): PR & -.13 & .05 & -.01 & .12 & .21 & $.60 * *$ & & \\
8. IC (Anger): AR & $.34 *$ & .16 & .25 & $.35^{*}$ & $.28 *$ & $.83 * *$ & $.53^{* *}$ & \\
9. IC (Anger): PR & .06 & .17 & .15 & .24 & $.49 * *$ & $.53 * *$ & $.73 * *$ & $.62 * *$ \\
\hline
\end{tabular}

Note. $n=53$ for all correlations PRI = PTSD Reaction Index, DERS = Difficulties in Emotional

Regulation Scale, $\mathrm{CBQ}=$ Conflict Behavior Questionnaire, $\mathrm{IC}=$ Issues Checklist (Total Issues and Total Anger subscales).

$* p<.05, * * p<.01$ 
Table 15

Correlations among Adolescent and Parent Communication Behaviors during the Low-Stress and High-Stress Problem-Solving Tasks

\begin{tabular}{|c|c|c|c|c|c|c|}
\hline \multirow[b]{2}{*}{ Adolescent Behavior } & \multicolumn{6}{|c|}{ Parent Behavior } \\
\hline & 1 & 2 & 3 & 4 & 5 & 6 \\
\hline \multicolumn{7}{|l|}{ Low-Stress Task } \\
\hline 1. Positive & $.54 * *$ & $-.34 *$ & -.02 & $.41 * *$ & -.24 & .02 \\
\hline 2. Negative non-aggressive & $-.41 *$ & $.53 * *$ & -.01 & -.25 & $.34 *$ & .26 \\
\hline 3. Negative aggressive & -.27 & $.56 * *$ & $.30 *$ & -.16 & .01 & .17 \\
\hline \multicolumn{7}{|l|}{ High-Stress Task } \\
\hline 4. Positive & $.32 *$ & $-.27 *$ & .06 & $.60 * *$ & $-.29 *$ & -.16 \\
\hline 5. Negative non-aggressive & -.11 & .26 & -.05 & -.17 & .04 & .16 \\
\hline 6. Negative aggressive & -.12 & .16 & .20 & -.10 & $.30 *$ & $.47 * *$ \\
\hline
\end{tabular}


Table 16

Correlation of Trauma Characteristics, PTSD Scores, and Emotion Regulation scores with Negative Communication Behavior, Conflict Behavior Questionnaire-AR, and Conflict Behavior Questionnaire-

$P R$

\begin{tabular}{lccc}
\hline & Negative & CBQ: & CBQ: \\
& Communication & Adolescent & Parent \\
Measures & Behavior & Version & Version \\
\hline
\end{tabular}

Trauma Characteristic

1. Event Type ${ }^{b}$ $.28 *$ .23

.21

2. Total Interpersonal Events $^{a}$ $.28 *$ .27 .16

3. Total Incidents ${ }^{a}$ .21

$.32 *$

.14

4. Perpetrator ${ }^{b}$ $.42 * *$ .24 $.29 *$

5. Total Betrayal

Trauma Events ${ }^{a}$ .24 $.29 *$ .15

6. Total Chronicity ${ }^{a}$ .14 .26

7. Interpersonal Chronicity $^{a}$ .16 .24 .08

PTSD

1. UCLA PTSD IndexAR: Total Score ${ }^{a}$

2. UCLA PTSD IndexAR: Diagnosis ${ }^{b}$

Emotion Regulation

\section{1. $\mathrm{DERS}^{a}$}

${ }^{*} p<.05, * * p<.01$

Note. ${ }^{a}=$ Pearson Correlations, ${ }^{b}=$ Spearman Correlations, $n=53$, $\mathrm{df}=1,51$ for all correlations, $\mathrm{CBQ}=$ Conflict Behavior Questionnaire 
Table 17

Best Predictors of Negative Communication Behavior, Conflict Behavior Questionnaire-AR, and Conflict Behavior Questionnaire -PR

\begin{tabular}{l}
\hline \multicolumn{3}{l}{ Regression Analyses } \\
\cline { 2 - 3 }
\end{tabular}

All Negative Communication

Best Trauma Characteristic: Perpetrator $\begin{array}{lll}.18 & .17 & 3.2 * *\end{array}$

Best PTSD Score: PRI-AR Total Score

$.01 \quad .19 \quad 3.5^{* *}$

DERS-AR

$.004 \quad .21 \quad 3.7 * *$

CBQ-AR

Best Trauma Characteristic: Total Incidents

$\begin{array}{rrr}.13 & .10 & 2.4^{*} \\ .14 & .15 & 3.0^{* *} \\ .08 & .17 & 3.2^{* *}\end{array}$

CBQ-PR

\begin{tabular}{lccc} 
Best Trauma Characteristic: Perpetrator & 3.3 & .10 & $2.4^{*}$ \\
Best PTSD Score: PRI-AR Total Score & .14 & .16 & $3.2^{* *}$ \\
DERS-AR & .10 & .24 & $4.1^{* *}$ \\
\hline
\end{tabular}

${ }^{*} p<.05, * * p<.01$

Note. $n=53, \mathrm{df}=1,51$ for all regressions. PRI $=$ PTSD Reaction Index, $\mathrm{CBQ}=$ Conflict Behavior Questionnaire, DERS = Difficulty in Emotion Regulation Scale 


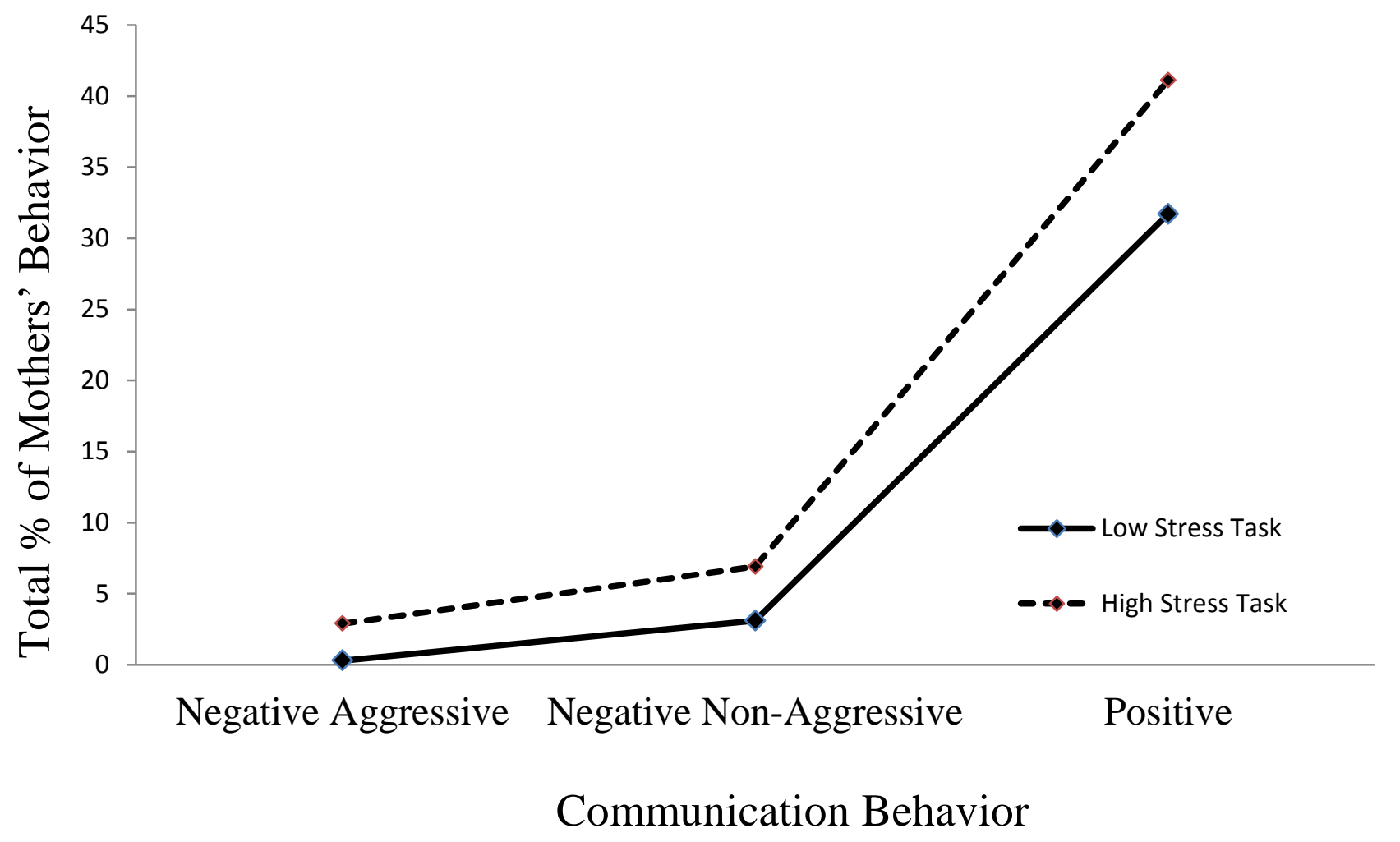

Figure 1. Graph showing total percent of mother's communication behaviors, across groups, for the Low Stress and High Stress Problem-Solving tasks. 


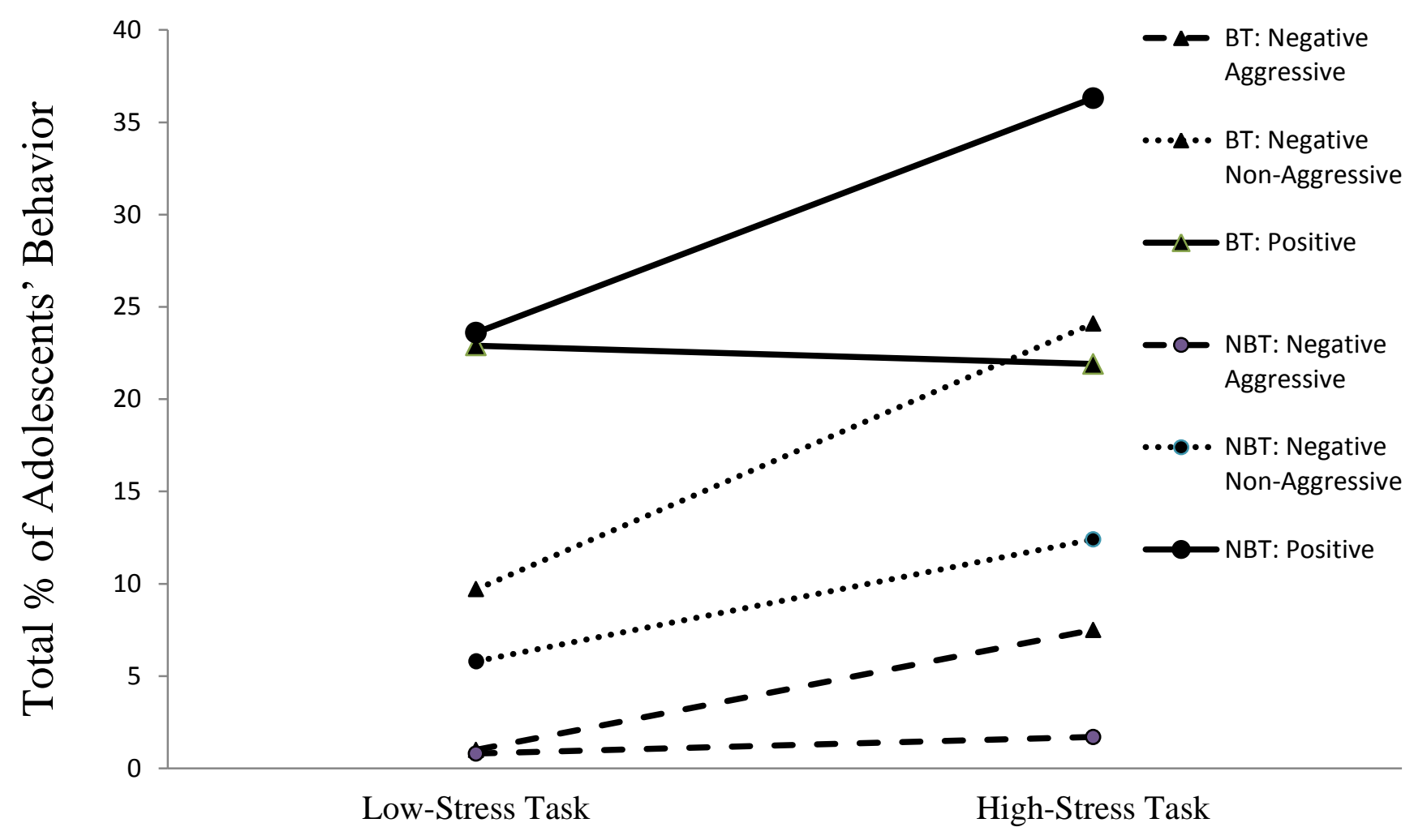

Figure 2. Percent of Negative Aggressive, Negative Non-Aggressive, and Positive Communication Behaviors during Low and High Stress Tasks for Adolescents in the Non-Betrayal Trauma (NBT) and Betrayal Trauma (BT) Groups 


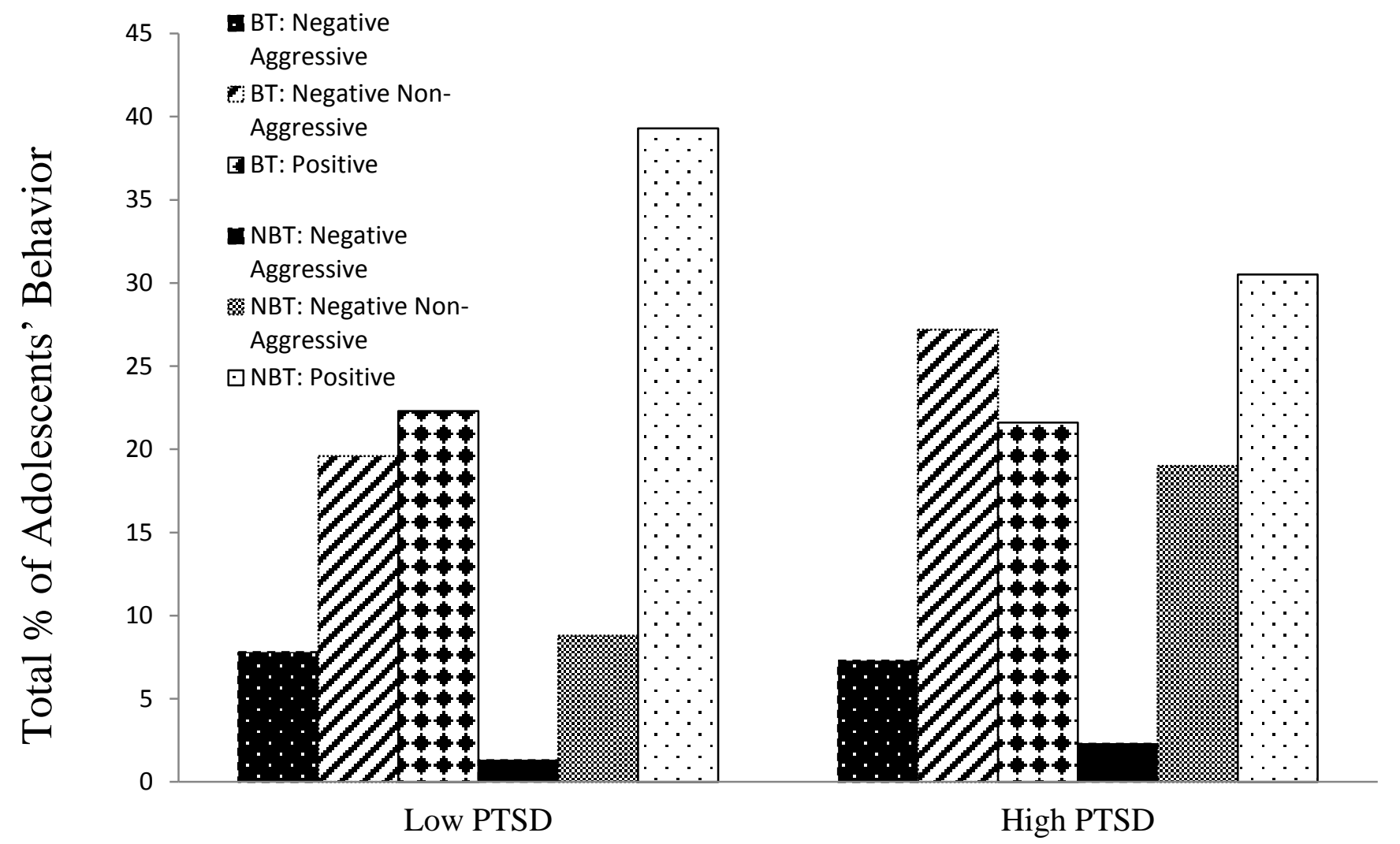

Figure 3. Percent of Negative Aggressive, Negative Non-Aggressive, and Positive Communication Behaviors for Adolescents in the Non-Betrayal Trauma (NBT) and Betrayal Trauma (BT) Groups Compared with Adolescents with Low PTSD severity status vs. High PTSD severity status 


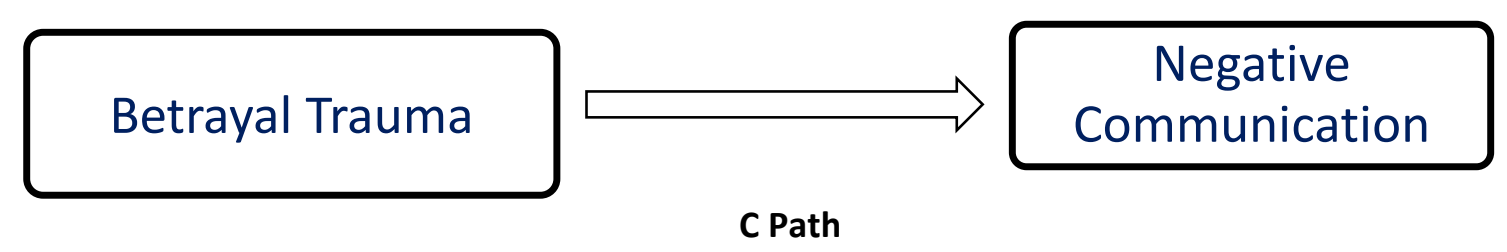

$$
B=.18(0.06), t(53)=3.23, p<.01
$$

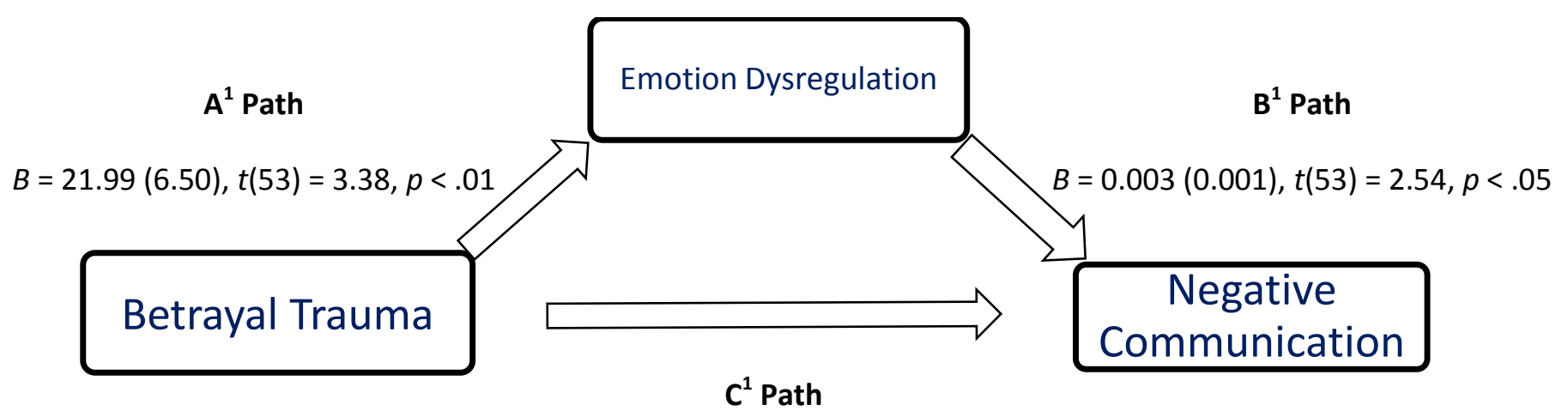

$$
B=0.11(0.06), t(53)=1.99, p=.053
$$

Figure 4. Mediation model for overall Negative Communication behavior during a stressful interpersonal task, with Betrayal Trauma History as the predictor and Emotion Dysregulation as the mediator 


\section{Appendix A}

\section{Behavior Code Descriptions, Definitions, and Examples}

\begin{tabular}{|c|c|c|}
\hline Behaviors & Definition & Examples \\
\hline \multicolumn{3}{|l|}{ Negative Aggressive: Verbal } \\
\hline Criticism/negative exaggeration & $\begin{array}{l}\text { Finding fault with partner's } \\
\text { actions, statements, beliefs. } \\
\text { Overemphasizing partner's } \\
\text { negative qualities (look for } \\
\text { "always" and "never"). }\end{array}$ & $\begin{array}{l}\text { "I can't believe you actually } \\
\text { think that!" } \\
\text { "What a stupid thing to say." } \\
\text { "You NEVER listen to me." } \\
\text { "All you ever do is say no!" }\end{array}$ \\
\hline Accuse/blame & $\begin{array}{l}\text { Telling partner the problem is } \\
\text { their fault. Asking a question } \\
\text { that implies wrongdoing. }\end{array}$ & $\begin{array}{l}\text { "This problem would be solved } \\
\text { if you weren't so difficult." } \\
\text { "You're lying, aren't you?" }\end{array}$ \\
\hline Name calling & $\begin{array}{l}\text { Applying a name to partner } \\
\text { that implies something } \\
\text { negative. }\end{array}$ & $\begin{array}{l}\text { "You're a jerk!" } \\
\text { "Why do you always have to } \\
\text { act like an ass?!" }\end{array}$ \\
\hline Threaten & $\begin{array}{l}\text { Expression of intention to do } \\
\text { harm to another person or } \\
\text { object. }\end{array}$ & $\begin{array}{l}\text { "I'll just run away if you don't } \\
\text { let me." } \\
\text { "I'm going to tear my room } \\
\text { apart just to make you mad!" }\end{array}$ \\
\hline Demand & $\begin{array}{l}\text { Forceful statement that } \\
\text { requires action from the } \\
\text { partner }\end{array}$ & $\begin{array}{l}\text { "You will let me go out } \\
\text { tonight." } \\
\text { "Stop talking about that!" }\end{array}$ \\
\hline Ridicule/make fun & $\begin{array}{l}\text { Mock, tease, or belittle } \\
\text { partner }\end{array}$ & $\begin{array}{l}\text { "Ha ha! You're so funny when } \\
\text { you get mad." } \\
\text { Repeating what partner said } \\
\text { word for word with mocking } \\
\text { tone. }\end{array}$ \\
\hline $\begin{array}{l}\text { Negative Aggressive: } \\
\text { Non-verbal }\end{array}$ & & \\
\hline
\end{tabular}




\begin{tabular}{|c|c|c|}
\hline Behaviors & Definition & Examples \\
\hline Yelling & $\begin{array}{l}\text { Raising voice louder than } \\
\text { appropriate indoor level, } \\
\text { implying aggression. }\end{array}$ & \\
\hline Negative physical contact & $\begin{array}{l}\text { Hitting, pushing (e.g., } \\
\text { partner's body, hand), } \\
\text { throwing or forcefully } \\
\text { pushing an object (e.g., pen, } \\
\text { worksheet). }\end{array}$ & \\
\hline \multicolumn{3}{|l|}{ Negative Non-Aggressive: } \\
\hline \multicolumn{3}{|l|}{ Verbal } \\
\hline Excuse/defensive statement & $\begin{array}{l}\text { Denying responsibility of } \\
\text { problem; justifying negative } \\
\text { behavior (but not accusing or } \\
\text { blaming the other person). }\end{array}$ & $\begin{array}{l}\text { "This is not my fault. Jacob is } \\
\text { the one that fights all the time. } \\
\text { Not me." }\end{array}$ \\
\hline Sarcasm/facetiousness & $\begin{array}{l}\text { Remarks that imply } \\
\text { something different than the } \\
\text { verbal message, such as } \\
\text { criticism or dislike, by the } \\
\text { tone of voice. }\end{array}$ & $\begin{array}{l}\text { Note. If sarcastic statement } \\
\text { meets criteria for aggressive } \\
\text { talk (e.g., criticism, ridicule), } \\
\text { mark as aggressive. }\end{array}$ \\
\hline Negative self-talk & $\begin{array}{l}\text { Changing the topic to give } \\
\text { self-defeating statements. }\end{array}$ & $\begin{array}{l}\text { "I'm just a stupid person, that's } \\
\text { why I did it." }\end{array}$ \\
\hline Quibble & $\begin{array}{l}\text { Disputing minute or trivial } \\
\text { aspects of the discussion. }\end{array}$ & $\begin{array}{l}\text { 'No! We weren't talking about } \\
\text { last night, we were talking } \\
\text { about two nights ago!” }\end{array}$ \\
\hline Reject/ignore solution & $\begin{array}{l}\text { Quick, negative judgment of } \\
\text { partner's suggestion without } \\
\text { consideration, or completely } \\
\text { ignoring what partner says. }\end{array}$ & $\begin{array}{l}\text { "That's dumb." } \\
\text { "That will never work!" } \\
\text { "I will NOT take my sister with } \\
\text { me. NO way!" }\end{array}$ \\
\hline \multicolumn{3}{|l|}{ Negative Non-Aggressive: } \\
\hline Non-verbal & & \\
\hline
\end{tabular}




\begin{tabular}{|c|c|c|}
\hline Behaviors & Definition & Examples \\
\hline Eye/head rolling & $\begin{array}{l}\text { Rolling eyes or tilting head } \\
\text { back to display exasperation. }\end{array}$ & \\
\hline Exaggerated sigh & $\begin{array}{l}\text { Loud sigh implying } \\
\text { frustration or anger. }\end{array}$ & \\
\hline Withdrawal & $\begin{array}{l}\text { Putting head down, turning } \\
\text { away. Avoiding conversation. } \\
\text { Short, unhelpful responses. }\end{array}$ & $\begin{array}{l}\text { "Whatever." } \\
\text { "Uh huh. Fine." }\end{array}$ \\
\hline \multicolumn{3}{|l|}{ Positive: Verbal } \\
\hline $\begin{array}{l}\text { Paraphrasing, reflecting, } \\
\text { validating, empathy statement }\end{array}$ & $\begin{array}{l}\text { Expressing partner's views or } \\
\text { feelings without losing } \\
\text { original intent. }\end{array}$ & $\begin{array}{l}\text { "It sounds like you're really } \\
\text { worried about me drinking at } \\
\text { parties, right?" } \\
\text { "I can understand how you } \\
\text { would worry about me when I } \\
\text { don't get home on time." }\end{array}$ \\
\hline Compliment/praise/thank & $\begin{array}{l}\text { Expressing approval of the } \\
\text { other person, their beliefs or } \\
\text { ideas. }\end{array}$ & $\begin{array}{l}\text { "That's a good idea!" } \\
\text { "You're a good mom." }\end{array}$ \\
\hline $\begin{array}{l}\text { Emotional disclosure, I } \\
\text { statement, disclosure with } \\
\text { explanation }\end{array}$ & $\begin{array}{l}\text { Explaining own feelings } \\
\text { without name-calling or } \\
\text { criticism of the partner (often } \\
\text { begins with "I"). }\end{array}$ & $\begin{array}{l}\text { "It makes me sad when you } \\
\text { fight with your brother so } \\
\text { much." } \\
\text { "This would be my preference } \\
\text { because I really like those } \\
\text { flowers." }\end{array}$ \\
\hline $\begin{array}{l}\text { Asking opinion or preference, } \\
\text { clarifying position }\end{array}$ & $\begin{array}{l}\text { Attempting to find out what } \\
\text { partner wants, expects, or } \\
\text { prefers (without sarcasm). }\end{array}$ & $\begin{array}{l}\text { "Do you think that would } \\
\text { work?" } \\
\text { "What grades do you think are } \\
\text { acceptable for me?" }\end{array}$ \\
\hline
\end{tabular}




\begin{tabular}{lll}
\hline \multicolumn{1}{c}{ Behaviors } & \multicolumn{1}{c}{ Definition } & \multicolumn{1}{c}{ Examples } \\
\hline Suggest compromise & Offering possible ideas for a & "I have an idea. What if, instead \\
solution (without demanding) & of going out every night, I leave \\
for doing things differently in & three nights per week for family \\
the future, while modifying & time ... and one night per week \\
& original preferences. & I can stay out 1 hour later than \\
Agree/compliance with partner- & Approving of partner's idea & "That would probably work." \\
posed solution & (without withdrawal). & Note: "Whatever" could be \\
& & Agree/compliance if the tone is \\
Positive: Non-Verbal & & not dismissive. \\
Positive physical contact & Hug, touch hand, touch & \\
& shoulder. & \\
Active listening & Nodding head, showing & \\
& approval or understanding of & \\
& &
\end{tabular}




\section{Appendix B}

\section{Low-Stress Problem-Solving Task Worksheets}

Planning a Party for a Loved One

Loved one:

Parent money contribution? \$_ Adolescent money contribution? \$

Please plan out the details of the party: (Keep your budget in mind and write out who will do each task needed to plan the party)

Guests: (e.g., how many? Who?)

Tasks adolescent will complete?

Tasks parent will complete?

Place: (Where? Outside or in? Reservations? Budget for venue?)

Tasks adolescent will complete?

Tasks parent will complete?

Food and drinks: (What kind? How much? Budget for food?)

Tasks adolescent will complete?

Tasks parent will complete?

Music: (What kind? Band? DJ? Budget?)

Tasks adolescent will complete?

Tasks parent will complete?

Other: (What other details need to be carried out for the party and who will do it?)

Parent Signature:

Adolescent Signature: 


\section{Planning the Next Family Vacation}

Parent money contribution? Adolescent money contribution? \$ Other?

Who is going?

Please plan out the details of the vacation: (Keep your budget in mind and write out who will do each task needed to plan a successful trip)

Location/Length of vacation: (Beach? Abroad? Theme Park? Keep budget in mind)

Tasks adolescent will complete?

Tasks parent will complete?

Sleeping: (Hotel? Camping? How many rooms/tents? Reservations? Budget?)

Tasks adolescent will complete?

Tasks parent will complete?

Food: (Packing food? Eating out? Cooking? Budget?)

Tasks adolescent will complete?

Tasks parent will complete?

Activities: (What will you do on vacation? Snorkeling? Museums? Rides? Budget?)

Tasks adolescent will complete?

Tasks parent will complete?

Other: (What other details need to be carried out for a successful vacation?)

Parent Signature:

Adolescent Signature: 


\section{Planning a Garden}

Parent money contribution? \$

Adolescent money contribution? \$

Please plan out the details of the garden: (Keep your budget in mind and write out who will do each task needed to create and maintain a successful garden)

Location/Size of garden: (Do you need to buy land?)

Tasks adolescent will complete?

Tasks parent will complete?

Contents: (What's in the garden? Flowers? Food? Does research need to be done?)

Tasks adolescent will complete?

Tasks parent will complete?

Preparation: (Who will till the ground? Equipment needed? Planting the seeds?)

Tasks adolescent will complete?

Tasks parent will complete?

Maintaining: (Watering? Pruning? Picking veggies? Weeding?)

Tasks adolescent will complete?

Tasks parent will complete?

Other: (What other details need to be carried out a successful garden?)

Parent Signature:

Adolescent Signature: 


\section{Appendix C \\ High-Stress Problem-Solving Task Worksheet}

Issue:

Adolescent: I agree to

Parent: I agree to

Parent Signature:

Adolescent Signature: 


\section{Appendix D \\ History of Psychosocial Stressors}

Below are a number of difficult or stressful things that sometimes happen to people.

For each item, in part (A), please mark if you directly experienced the event, if you witnessed it happening to someone else, or if you did NOT experience or witness it. If you both experienced AND witnessed the event, please mark both options. IF YOU DID NOT WITNESS OR EXPERIENCE THE EVENT, GO TO THE NEXT EVENT LISTED.

In part (B), please indicate the number of times you experienced or witnessed the event. To differentiate between experiencing and witnessing an event, mark a capital $\underline{E}$ next to the number of times you experienced the event, and mark a capital $\underline{\mathrm{W}}$ next to the number of times you witnessed the event. If you both witnessed AND experienced an event, please be sure to mark both an E AND a W next to the number of times that each occurred. If you did not experience an event, do not mark an E in part $(B)$, and if you did not witness an event, do not mark a $\underline{W}$ in part (B).

In part (C), please indicate all of the age ranges in which this event occurred in your life (check all that apply). To differentiate between experiencing and witnessing an event, mark a capital $\underline{E}$ next to ALL the ages you were when you experienced the event, and mark a capital $\underline{\mathrm{W}}$ next to ALL the ages you were when you witnessed the event. If you both witnessed AND experienced an event, please be sure to mark both an E AND a W next to all the ages you were when that event occurred. If you did not experience an event, do not mark an $\underline{E}$ in part $(C)$, and if you did not witness an event, do not mark a $\underline{W}$ in part $(C)$.

Finally, in part (D), indicate how much the event still bothers or distresses you TODAY. If you experienced or witnessed this event multiple times, please indicate how much the MOST DISTRESSING event bothers you today. Remember, if you are referring to an event you experienced, use an E to indicate how much the event bothers you today. If you are referring to an event you witnessed, please use a $\underline{\mathrm{W}}$. If you did not experience an event, do not mark an $\underline{E}$ in part $(D)$, and if you did not witness an event, do not mark a $\underline{W}$ in part (D).

1. Motor Vehicle Accident (Crash, run over, or hit by; Car, Truck, Motorcycle, ATV, Bus, Train wreck, plane crash, or boat/ship)

a. __ This event happened to me __ I witnessed this event___ This event did not happen to me

b. 1 time $2-3$ times 3-5 times Greater than 5 times

c. _ $0-4$ years $\quad 5-8$ years 9-12 years 13-16 years 17-18 years

d. ___ Not at all Distressing TODAY___ A little Distressing TODAY __ Moderately Distressing TODAY __ Quite a bit Distressing TODAY___Extremely Distressing TODAY

\section{Natural Disaster (e.g., flood, tidal wave, earthquake, mud or rock slide, forest fire, tornado,} hurricane)

a. __ This event happened to me

b. __ 1 time 2-3 times I witnessed this event

c. $0-4$ years 5-8 years

d. Not at all Distressing TODAY TODAY __ Quite a bit Distressing TODAY
This event did not happen to me 3-5 times 9-12 years A little Distressing TODAY Greater than 5 times 13-16 years 17-18 years Moderately Distressing 
3. Fire, bombing, or collapse of building while you were inside

a. _ This event happened to me __ I witnessed this event __ This event did not happen to me

b. __ 1 time 2-3 times 3-5 times Greater than 5 times

c. _ $0-4$ years 5-8 years

9-12 years 13-16 years $17-18$ years

d. __ Not at all Distressing TODAY A little Distressing TODAY Moderately Distressing TODAY __ Quite a bit Distressing TODAY_Extremely Distressing TODAY

4. Performing an emergency rescue (at the scene of an accident, fire, shooting)

a. _ This event happened to me __ I witnessed this event _ _ This event did not happen to me

b. _ 1 time 2-3 times 3-5 times Greater than 5 times

c. _ $0-4$ years 5-8 years

9-12 years 13-16 years 17-18 years

d. __ Not at all Distressing TODAY A little Distressing TODAY Moderately Distressing TODAY _ Quite a bit Distressing TODAY Extremely Distressing TODAY

5. Finding or seeing a dead body (other than at a funeral)

a. _ This event happened to me __ I witnessed this event __ This event did not happen to me

b. _ 1 time 2-3 times 3-5 times Greater than 5 times

c. _ $0-4$ years $5-8$ years 9-12 years 13-16 years $17-18$ years

d. __ Not at all Distressing TODAY A little Distressing TODAY Moderately Distressing TODAY _ Q Quite a bit Distressing TODAY Extremely Distressing TODAY

\section{Life-threatening illness (being diagnosed and/or treated for cancer, brain tumor, etc.)}

a. _ This event happened to me

b. 1 time 2-3 times

c. $0-4$ years 5-8 years

d. __ Not at all Distressing TODAY TODAY _ Quite a bit Distressing TODAY I witnessed this event 3-5 times 9-12 years A little Distressing TODAY
This event did not happen to me Greater than 5 times 13-16 years 17-18 years Moderately Distressing

7. Serious physical injury (e.g., severe sports injury, loss of limb, etc.)

a. _ This event happened to me

b. 1 time 2-3 times

c. _ $0-4$ years 5-8 years

d. __ Not at all Distressing TODAY
I witnessed this event 3-5 times 9-12 years
This event did not happen to me Greater than 5 times 13-16 years 17-18 years A little Distressing TODAY __ Moderately Distressing Quite a bit Distressing TODAY Extremely Distressing TODAY

\section{Homelessness}

a. This event happened to me

b. __ 1 time 2-3 times

c. $0-4$ years 5-8 years

d. ___ Not at all Distressing TODAY TODAY Quite
I witnessed this event 3-5 times 9-12 years
This event did not happen to me Greater than 5 times

13-16 years 17-18 years

9. Being separated from parents (e.g., as a result of placement in foster care, being adopted, loss of custody)
a. _ This event happened to me I witnessed this event

b. _ 1 time 2-3 times

3-5 times This event did not happen to me Greater than 5 times 
c. $0-4$ years

5-8 years

d. ___ Not at all Distressing TODAY TODAY __ Quite a bit Distressing TODAY___Extremely Distressing TODAY

9-12 years

A little Distressing TODAY
13-16 years

17-18 years

Moderately Distressing

For the next set of questions, please follow the same directions you followed for the first part of this questionnaire. However, in this set of questions, in part (C), please indicate the person who did this by placing an $\underline{\mathrm{E}}$ or a $\underline{\mathrm{W}}$ in the appropriate box. Remember, if you did not experience an event, do not mark an $\underline{E}$, and if you did not witness an event, do not mark $a \underline{W}$.

1. Neglect: The REPEATED failure to have basic needs (e.g., food, water, clothing, shelter, physical health, basic education) met by family members/caretakers

a. __ This event happened to me __ I witnessed this event__ This event did not happen to me

b. _ 1 time 2-3 times_ $\quad 3-5$ times

Greater than 5 times

\begin{tabular}{|l|l|l|l|l|l|}
\hline c. & $\begin{array}{l}0-4 \\
\text { years }\end{array}$ & $\begin{array}{l}5-8 \\
\text { years }\end{array}$ & $\begin{array}{l}9-12 \\
\text { years }\end{array}$ & $\begin{array}{l}13-16 \\
\text { years }\end{array}$ & $\begin{array}{l}17-18 \\
\text { years }\end{array}$ \\
\hline Parent/Guardian & & & & & \\
\hline $\begin{array}{l}\text { Other family } \\
\text { member/ friend of } \\
\text { family }\end{array}$ & & & & & \\
\hline $\begin{array}{l}\text { Professional (e.g., } \\
\text { teacher, babysitter) }\end{array}$ & & & & & \\
\hline
\end{tabular}

d. ___ Not at all Distressing TODAY

A little Distressing TODAY

Moderately Distressing TODAY __ Quite a bit Distressing TODAY Extremely Distressing TODAY

\section{Emotional Abuse (being REPEATEDLY embarrassed, ignored, yelled at, humiliated, verbally} harassed, etc.)

a. __ This event happened to me __ I witnessed this event__ This event did not happen to me

b. _ 1 time 2-3 times_ 3-5 times

\begin{tabular}{|c|c|c|c|c|c|}
\hline c. & $\begin{array}{l}0-4 \\
\text { years }\end{array}$ & $\begin{array}{l}5-8 \\
\text { years }\end{array}$ & $\begin{array}{l}9-12 \\
\text { years }\end{array}$ & $\begin{array}{l}13-16 \\
\text { years }\end{array}$ & $\begin{array}{l}17-18 \\
\text { years }\end{array}$ \\
\hline Parent/Guardian & & & & & \\
\hline Other family member & & & & & \\
\hline Significant Other & & & & & \\
\hline Friend/Acquaintance & & & & & \\
\hline Stranger & & & & & \\
\hline
\end{tabular}

d. N__ Not at all Distressing TODAY

A little Distressing TODAY TODAY ___ Quite a bit Distressing TODAY___Extremely Distressing TODAY Moderately Distressing

\section{Physical assault without a weapon (being hit, kicked, bitten, beaten, etc.)}

a. __ This event happened to me __ I witnessed this event__ This event did not happen to me

b. _ 1 time _ 2-3 times

3-5 times

Greater than 5 times 


\begin{tabular}{|l|l|l|l|l|l|}
\hline c. & $\begin{array}{l}0-4 \\
\text { years }\end{array}$ & $\begin{array}{l}5-8 \\
\text { years }\end{array}$ & $\begin{array}{l}9-12 \\
\text { years }\end{array}$ & $\begin{array}{l}13-16 \\
\text { years }\end{array}$ & $\begin{array}{l}17-18 \\
\text { years }\end{array}$ \\
\hline Parent/Guardian & & & & & \\
\hline Other family member & & & & & \\
\hline Significant Other & & & & & \\
\hline Friend/Acquaintance & & & & & \\
\hline Stranger & & & & & \\
\hline
\end{tabular}

d. ___ Not at all Distressing TODAY___ A little Distressing TODAY Moderately Distressing TODAY __ Quite a bit Distressing TODAY___Extremely Distressing TODAY

4. Physical assault with a weapon (Being attacked with a belt, bottle, gun knife, club, etc.) a. ___ This event happened to me __ I witnessed this event___ This event did not happen to me b. __ 1 time 2-3 times_ _ _ 3-5 times

\begin{tabular}{|l|l|l|l|l|l|}
\hline c. & $\begin{array}{l}0-4 \\
\text { years }\end{array}$ & $\begin{array}{l}5-8 \\
\text { years }\end{array}$ & $\begin{array}{l}9-12 \\
\text { years }\end{array}$ & $\begin{array}{l}13-16 \\
\text { years }\end{array}$ & $\begin{array}{l}17-18 \\
\text { years }\end{array}$ \\
\hline Parent/Guardian & & & & & \\
\hline Other family member & & & & & \\
\hline Significant Other & & & & & \\
\hline Friend/Acquaintance & & & & & \\
\hline Stranger & & & & & \\
\hline
\end{tabular}

d. ___ Not at all Distressing TODAY__ _ A little Distressing TODAY TODAY ___ Quite a bit Distressing TODAY___Extremely Distressing TODAY

Moderately Distressing

\section{Threat of physical assault (i.e., someone threatened to SERSIOUSLY harm you and you believed them, but they did not follow through with the threat)}

a.___ This event happened to me __ I witnessed this event__ This event did not happen to me

b. _ 1 time 2-3 times_ 3-5 times___ Greater than 5 times

\begin{tabular}{|l|l|l|l|l|l|}
\hline c. & $\begin{array}{l}0-4 \\
\text { years }\end{array}$ & $\begin{array}{l}5-8 \\
\text { years }\end{array}$ & $\begin{array}{l}9-12 \\
\text { years }\end{array}$ & $\begin{array}{l}13-16 \\
\text { years }\end{array}$ & $\begin{array}{l}17-18 \\
\text { years }\end{array}$ \\
\hline Parent/Guardian & & & & & \\
\hline Other family member & & & & & \\
\hline Significant Other & & & & & \\
\hline Friend/Acquaintance & & & & & \\
\hline Stranger & & & & & \\
\hline
\end{tabular}

d. ___ Not at all Distressing TODAY___ A little Distressing TODAY Moderately Distressing TODAY __ Quite a bit Distressing TODAY __ Extremely Distressing TODAY 
6. Kidnapping (Forced to stay somewhere against your desire to leave)

a. __ This event happened to me __ I witnessed this event __ This event did not happen to me

b.

\begin{tabular}{|c|c|c|c|c|c|}
\hline time & mes & & nes & _Greate & 5 times \\
\hline c. & $\begin{array}{l}0-4 \\
\text { years }\end{array}$ & $\begin{array}{l}5-8 \\
\text { years }\end{array}$ & $\begin{array}{l}9-12 \\
\text { years }\end{array}$ & $\begin{array}{l}13-16 \\
\text { years }\end{array}$ & $\begin{array}{l}17-18 \\
\text { years }\end{array}$ \\
\hline Parent/G & & & & & \\
\hline Other far & & & & & \\
\hline Significa & & & & & \\
\hline Friend/A & & & & & \\
\hline Stranger & & & & & \\
\hline
\end{tabular}

d. ___ Not at all Distressing TODAY__ _ A little Distressing TODAY TODAY __ Quite a bit Distressing TODAY___Extremely Distressing TODAY

7. Someone exposing the sexual parts of their body or showing sexual pictures to you when, (A) they were much older than you or (B) you did not want that to occur

a. __ This event happened to me __ I witnessed this event__ This event did not happen to me

b. __ 1 time 2-3 times 3-5 times

Moderately Distressing

\begin{tabular}{|l|l|l|l|l|l|}
\hline c. & $\begin{array}{l}0-4 \\
\text { years }\end{array}$ & $\begin{array}{l}5-8 \\
\text { years }\end{array}$ & $\begin{array}{l}9-12 \\
\text { years }\end{array}$ & $\begin{array}{l}13-16 \\
\text { years }\end{array}$ & $\begin{array}{l}17-18 \\
\text { years }\end{array}$ \\
\hline Parent/Guardian & & & & & \\
\hline Other family member & & & & & \\
\hline Significant Other & & & & & \\
\hline Friend/Acquaintance & & & & & \\
\hline Stranger & & & & & \\
\hline
\end{tabular}

d. ___ Not at all Distressing TODAY A little Distressing TODAY Moderately Distressing TODAY __ Quite a bit Distressing TODAY Extremely Distressing TODAY

8. Someone touching the sexual parts of your body or forcing you to touch the sexual parts of their body when, (A) they were much older than you or (B) you did not want that to occur a. __ This event happened to me __ I witnessed this event__ This event did not happen to me

b. __ 1 time 2-3 times_ $\quad$ _-5 times

\begin{tabular}{|l|l|l|l|l|l|}
\hline c. & $\begin{array}{l}0-4 \\
\text { years }\end{array}$ & $\begin{array}{l}5-8 \\
\text { years }\end{array}$ & $\begin{array}{l}9-12 \\
\text { years }\end{array}$ & $\begin{array}{l}13-16 \\
\text { years }\end{array}$ & $\begin{array}{l}17-18 \\
\text { years }\end{array}$ \\
\hline Parent/Guardian & & & & & \\
\hline Other family member & & & & & \\
\hline Significant Other & & & & & \\
\hline Friend/Acquaintance & & & & & \\
\hline Stranger & & & & & \\
\hline
\end{tabular}


d. ___ Not at all Distressing TODAY__ _ A little Distressing TODAY TODAY __ Quite a bit Distressing TODAY Extremely Distressing TODAY Moderately Distressing

9. Someone having or attempting to have sex with you when, (A) they were much older than you or (B) you did not want that to occur

a. __ This event happened to me __ I witnessed this event__ This event did not happen to me

b. __ 1 time 2-3 times 3-5 times Greater than 5 times

\begin{tabular}{|l|l|l|l|l|l|}
\hline c. & $\begin{array}{l}0-4 \\
\text { years }\end{array}$ & $\begin{array}{l}5-8 \\
\text { years }\end{array}$ & $\begin{array}{l}9-12 \\
\text { years }\end{array}$ & $\begin{array}{l}13-16 \\
\text { years }\end{array}$ & $\begin{array}{l}17-18 \\
\text { years }\end{array}$ \\
\hline Parent/Guardian & & & & & \\
\hline Other family member & & & & & \\
\hline Significant Other & & & & & \\
\hline Friend/Acquaintance & & & & & \\
\hline Stranger & & & & & \\
\hline
\end{tabular}

d. ___ Not at all Distressing TODAY___ little Distressing TODAY TODAY __ Quite a bit Distressing TODAY___Extremely Distressing TODAY

Moderately Distressing

10. Any other very bad, scary, fearful, or extreme experience or time in which you though your life was in danger, you might be hurt, or you were extremely distressed by something that someone did or threatened to do to you.

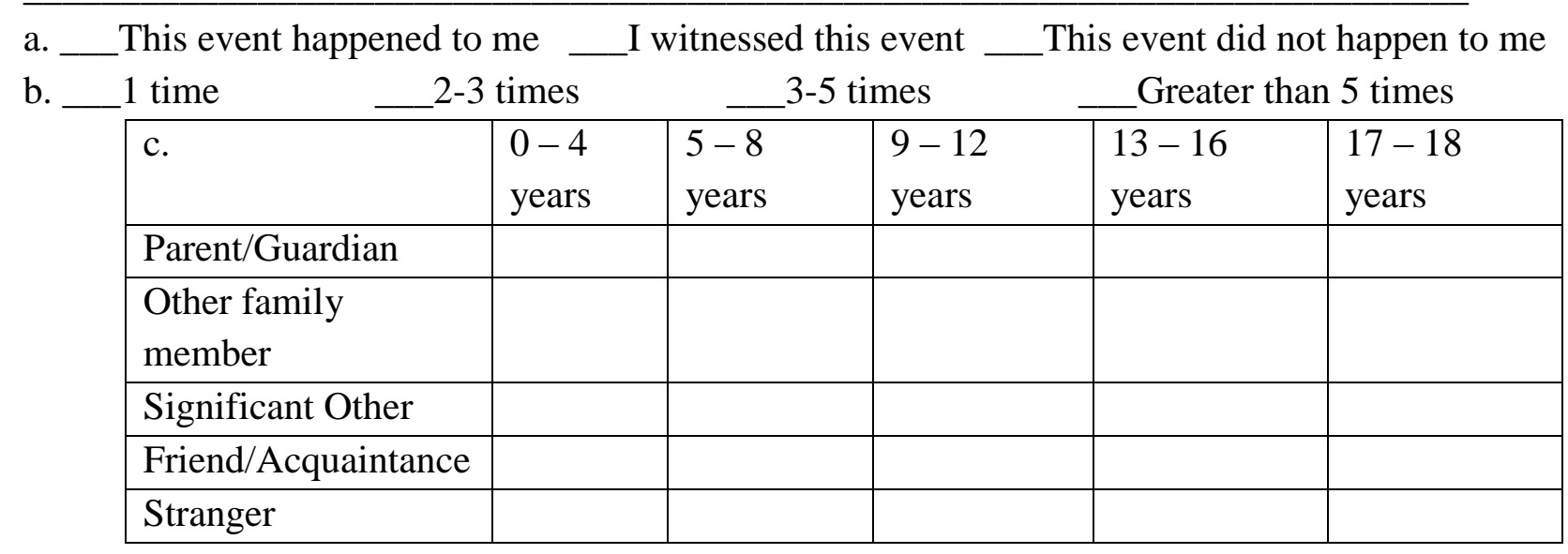

d. ___ Not at all Distressing TODAY A little Distressing TODAY Moderately Distressing TODAY __ Quite a bit Distressing TODAY Extremely Distressing TODAY 


\section{Appendix E}

\section{Problem-Solving Rating Scale: Mom}

1. How difficult was this problem-solving task for you?
1
2
3
4
5
6
7

Very Easy

Very Difficult

2. How upset did you feel during the problem-solving task?

1

$$
2
$$

3

4

5

6

7

Very Happy

Very Upset

3. How cooperative do you feel $\underline{Y O U}$ were during the task?

1

2

3

4

5

6

7

Very Cooperative

Very Uncooperative

4. How cooperative do you feel YOUR PARTNER was during the task?

1

2

3

4

5

6

7

Very Cooperative

Very Uncooperative

5. How successful you feel you and your partner were at solving the problem?
1
2
3
4
5
6
7

Very Successful

Very Unsuccessful

6. How typical was this interaction with most interactions you have about these issues?
1
2
3
4
5
6
7 
1. How difficult was this problem-solving task for you?

$1 \quad 2 \quad 3 \quad 4$

5

6

7

Very Easy

Very Difficult

2. How upset did you feel during the problem-solving task?

$\begin{array}{lllllll}1 & 2 & 3 & 4 & 5 & 6 & 7\end{array}$

Very Happy

3. How cooperative do you feel $\underline{Y O U}$ were during the task?

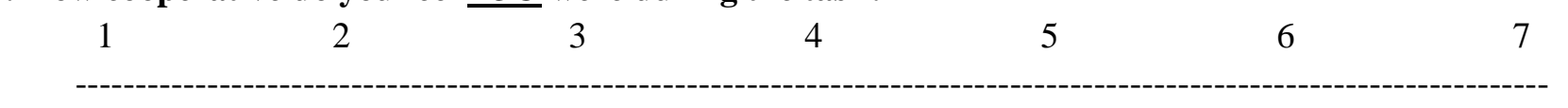

Very Cooperative

Very Uncooperative

4. How cooperative do you feel YOUR PARTNER was during the task?

$\begin{array}{cccccc}1 & 2 & 3 & 5 & 6 & 7 \\ \text { Very Cooperative } & & 3 & 5 & \text { Very Uncooperative }\end{array}$

5. How successful you feel you and your partner were at solving the problem?

$\begin{array}{llllllll}1 & 2 & 3 & 4 & 5 & 6 & 7\end{array}$

Very Successful

Very Unsuccessful

6. How typical was this interaction with most interactions you have about these issues?

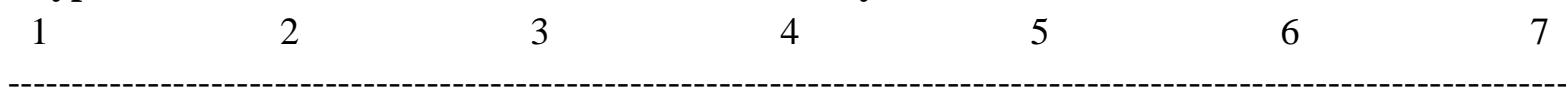

